University of San Diego

Digital USD

2015-12

\title{
Exploring Strategies for Effective Advocacy: The Lived Experience of Leaders of Pakistani Non-Governmental Organizations
}

Rubina F. Bhatti
University of San Diego

Follow this and additional works at: https://digital.sandiego.edu/dissertations

Part of the Peace and Conflict Studies Commons

\section{Digital USD Citation}

Bhatti, Rubina F., "Exploring Strategies for Effective Advocacy: The Lived Experience of Leaders of Pakistani Non-Governmental Organizations" (2015). Dissertations. 27.

https://digital.sandiego.edu/dissertations/27

This Dissertation: Open Access is brought to you for free and open access by the Theses and Dissertations at Digital USD. It has been accepted for inclusion in Dissertations by an authorized administrator of Digital USD. For more information, please contact digital@sandiego.edu. 
EXPLORING STRATEGIES FOR EFFECTIVE ADVOCACY:

THE LIVED EXPERIENCE OF LEADERS OF PAKISTANI NON-GOVERNMENTAL ORGANIZATIONS

\author{
by \\ Rubina F. Bhatti \\ A dissertation submitted in partial fulfillment \\ of the requirements for the degree of \\ Doctor of Philosophy
}

December 2015

Dissertation Committee

Robert Donmoyer, Ph.D., Chair

Lea Hubbard, Ph.D., Member

William O. Lowrey, Ph.D., Member

University of San Diego 
(C) Rubina Feroze Bhatti, 2015

All Rights Reserved 


\begin{abstract}
Non-governmental Organizations (NGOs) have increasingly been recognized as influential players in world politics and international development. Despite limited financial resources and having to rely on volunteers who often lack formal training, NGOs' advocacy work has often been highly effective. Since the beginning of the 1990s, it has resulted in both the formulation of new policies and the cancellation or modification of existing ones.
\end{abstract}

Advocacy work by NGOs is especially important in countries like Pakistan because deep-rooted injustices and discrimination are unlikely to change without pressure from NGOs. This study investigated the strategies used by five NGO leaders for effective advocacy work in the Pakistani context. The study specifically examined (a) how NGO leaders attempted to influence the external environment and the impact of their attempts, (b) leaders' efforts internally to create effective advocacy organizations, and (c) strategies NGO leaders used to nurture their personal capacity for effective leadership both within their own organizations and in the external advocacy arena.

This exploratory qualitative study focused on five Pakistani NGO leaders. A combination of convenience, maximum variation and snowball sampling was employed to identify the five leaders. Using qualitative methodologies, this study relied upon document analysis and two extended interviews with each research participant. The findings of this study are presented in two forms: (a) a narrative for each of the NGO leaders developed from the transcribed data through a process Polkinghorne calls narrative analysis and (b) a cross-case analysis that employed what Polkinghorne characterizes as an analysis of narrative approach. The analysis of narrative was built 
around five categories derived inductively from the data about the advocacy process in Pakistan and its impact on both the society and individuals.

The study documented, among other things, how the leaders determined their effectiveness and the various strategies they employed to manage their own lives so their advocacy work can be effectively sustained in a challenging environment. The results further demonstrated the importance of leaders nurturing NGO staff members and demonstrated how the five leaders approached this task. Finally, implications for practice, policy and future research were discussed. 


\section{DEDICATION}

To my beloved brother Kamran, without whom I would not be a leader.

You made me who I am. 


\section{ACKNOWLEDGEMENTS}

My doctorate work and the completion of this dissertation have been one of the toughest journeys of my life, one that would not have been possible without the support of the following:

Dr. Robert Donmoyer, my advisor and advocate, who did not cower at obstacles and believed in me against all odds.

Dr. William O. Lowery, my mentor and fellow peacebuilder, who served on my committee and made a way for me where there was none in sight, and Dr. Lea Hubbard, who helped me shape this study with her unique insights and probing questions as my committee member.

Kaitlin Barker Davis and Peggy Burns, loyal friends who are always there when I am most in need.

My classmates, fellow travelers on the journey of leadership.

Father Sohail Patrick, who has supported me in my work since the beginning, keeping our organization running when I could not be in Pakistan and most especially after the death of my brother Kamran Bhatti.

My family and particularly my brother, who have stood steadfastly beside me over the years, despite the challenges and risks of my work. Though Kamran is no longer here to see me complete this journey, he has never ceased to be my inspiration and encouragement. He is with me always, and I have finished this journey for him.

Finally, I wish to express my deep appreciation to the five study participants for sharing their time, their insights, and their trust. 


\section{TABLE OF CONTENTS}

ACKNOWLEDGEMENTS... vii

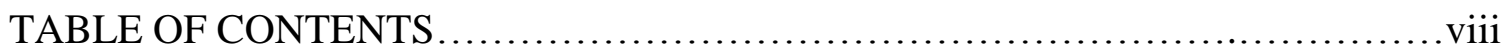

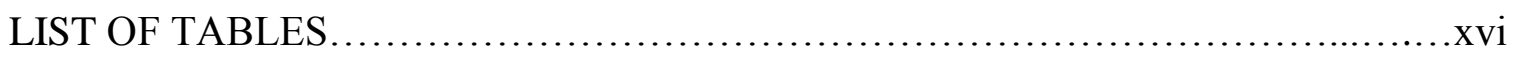

LIST OF FIGURES .......................................................

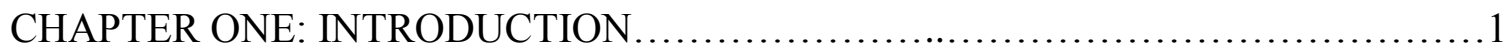

Background of the Study.............................................2

Statement of the Problem.................................................5

NGO leaders and theory of change................................5

NGO leaders and contextual influences............................6

NGO leaders and dearth of research...............................

Purpose of this Study and Research Questions..............................9

CHAPTER TWO: LITERATURE REVIEW .................................11

Defining the Sector: Civil Society, Nonprofit Organizations or NGOs.......... 12

An Overview of Pakistani NGOs: Challenges vs. Opportunities................16

First generation NGOs $(1947-1977)$............................... 17

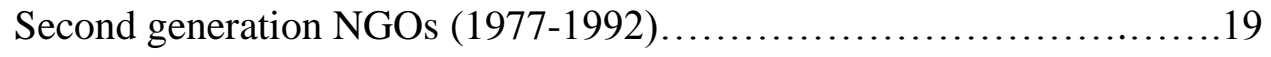

Third generation NGOs (1992 Onward)........................21

NGO Leaders in Developing Countries: Influences and Strategies..............23

Key external factors impacting NGO leaders strategies ...................24

Key internal factors impacting NGO leaders strategies ................32

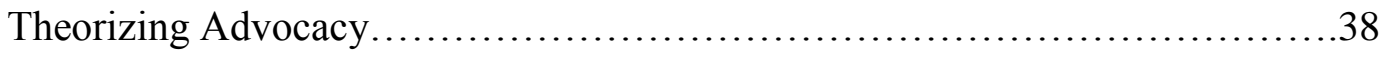


Definitions and concepts of advocacy.

Activities and types of advocacy.................................44

Strategies and tactics of advocacy ................................48

Assessing Advocacy.................................................50

Theories of change........................................... 51

Logic model...............................................54

Perspectives on Social Capital..........................................55

Positive utility of social capital....................................57

Negative utility of social capital ...............................58

Perspectives on Resilience...............................................58

Conclusion.......................................................60

CHAPTER THREE: METHODOLOGY ......................................62

Research Questions...............................................6 62

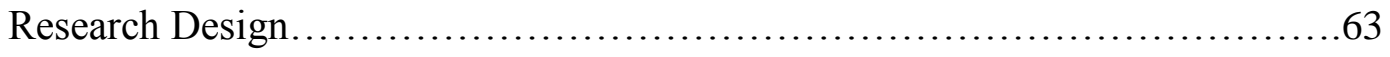

Participants......................................................65

Criterion sampling ........................................67

Maximum variation sampling .................................68

Convenience and snowball sampling .............................68

Data Collection Methods...............................................6 69

Document collection...........................................69

Interviews.................................................... 70 
Data Analysis Procedures............................................... 72

Narrative analysis procedures: The first phase.........................72

Analysis of narrative procedures: The second phase....................75

Ethical Considerations................................................... 76

Credibility and Dependability Issues.................................... 77

CHAPTER FOUR: NARRATIVE ANALYSIS—STORIES OF FIVE NGO

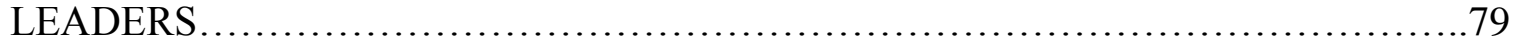

Rehana: A Frontline Human Rights Defender...................................80

Embracing advocacy work ......................................... 80

The first job: A saga of accomplishment in the face of resistance............81

A new environment, new organizations, and new challenges.............82

Working within the government and as a conduit between the government and the NGO Community ........................................... 83

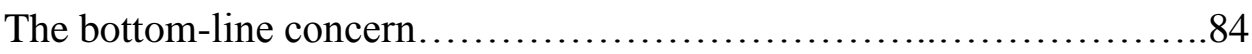

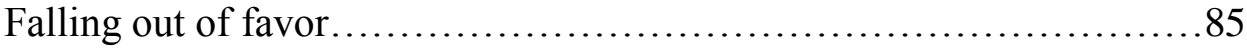

Resilience has been her ornament since childhood.........................86

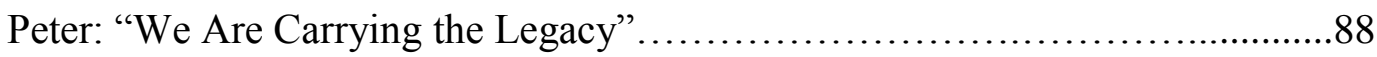

Little feet marching for a big cause .................................... 88

Making a conscious move towards advocacy ..........................89

Broadening the horizon, bridging the divide ....................... 90

A difficult balance..............................................91

Paying the price of advocacy work ................................92 
The legacy of passion and compassion.

Morning walks and a circle of friends.............................94

Conscious adaptation: A resilient pathway..........................95

Tahseen: A Fearless NGO Leader.........................................97

Yearning to speak out........................................98

Meeting the gurus and finding a path............................ 98

Good days are gone..............................................99

We have lost many activists........................................100

Feeling no fear.................................................. 100

Working with the government: A strategic engagement................101

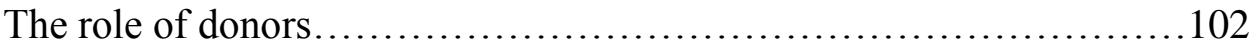

Taking care of 241 employees.................................... 103

Friends in triumph and turbulence.................................. 104

You cannot stop breathing..................................... 105

Shad: Inspired by Her Father's Social Work.................................106

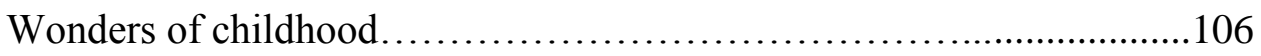

Self versus community.......................................107

First ever registered NGO in Malakand division...........................108

Starting from scratch, then moving toward success.....................110

Practicing what she preached...........................................111 
Advocacy, awards and alarms..................................111

Between highs and lows.........................................112

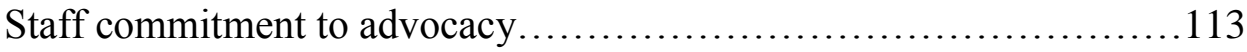

Community engagement, networking and litigation.................113

Resilience is her motivation............................................114

Tanveer: Evolving from a Challenger to a Leader..........................115

Understanding and supporting the marginalized.......................116

Walking through contextual challenges..........................117

First my mother, a clear decision................................118

Managing risk: surviving in the sector.............................119

Juggling with police/mapping the way forward....................119

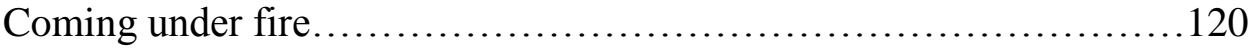

Commitment, clarity and celebrations.............................121

The universe supports her..................................122

From street protests to the negotiation tables: A resilient move...........123

CHAPTER FIVE: CROSS-CASE ANALYSIS-FIVE CASES IN SEARCH OF A

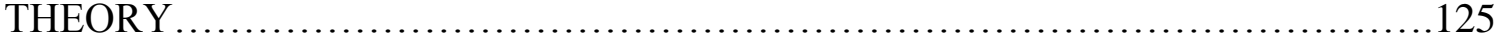

Getting Involved in Advocacy........................................127

Childhood incidents.............................................127

Political environment.......................................... 128

Vision........................................................... 131 
Legacy of martyrs.

Summary of Findings on the Theme of Getting Involved in Advocacy..134

Overcoming External Barriers.

Collaborating with government. 136

Negotiating with intelligence agencies.

Embracing culture.

Maintaining a low profile. ...

Harmonizing with media.

Partnering with donors.

Summary of findings on the theme of overcoming external challenges.. 147

Meeting Internal Challenges.

Decentralizing power

Motivating communities

Developing security policies

Strengthening networks

Summary of findings for the theme of meeting internal challenges ......156

Becoming Resilient 157

Reflective practices 157

Self-care 158

Gaining family support. .159 
Cultivating a circle of friends.

Summary of findings for the theme of becoming resilient..............162

Assessing Impacts............................................... 163

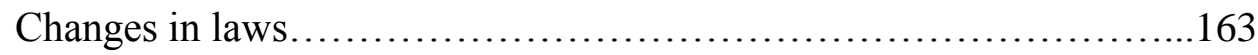

Increased awareness among masses.............................165

Recognition and respect...................................... 165

Women in leadership........................................166

Summary of findings for the theme of assessing impacts...............168

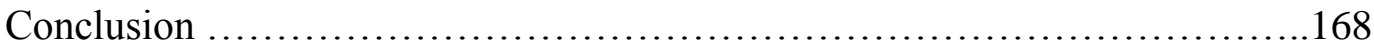

CHAPTER SIX: DISCUSSION ......................................... 170

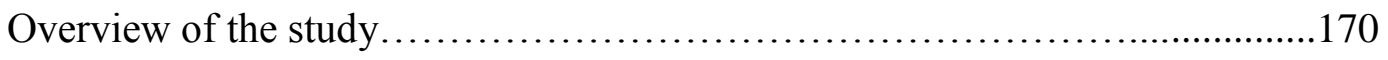

Discussion........................................................ 175

Contributions of this study..................................175

Bidirectional influence of external factors and countering strategies.....178

Bidirectional influence of internal factors and countering strategies.....186

Data in Search of a Theoretical Framework ..............................189

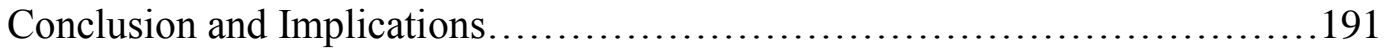

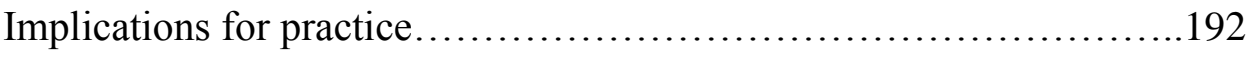

Implications for policy........................................193

Implication for future research..................................193 
A. Pakistan Map and Participants' First Location of Advocacy...............220

B. Participant Interview Protocol..........................................221

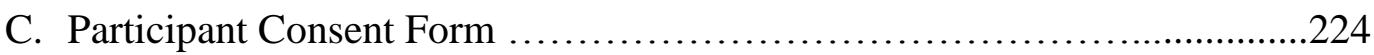

D. Sample Posters Depicting Advocacy Messages.........................226

E. Assessment Questionnaire for NGO Leaders....................................228 


\section{LIST OF TABLES}

Table 1. Participants Descriptions............................................67

Table 2. Themes and Categories............................................. 126

Table 3. Vision in Documents and Advocacy Messages on Posters......................133 


\section{LIST OF FIGURES}

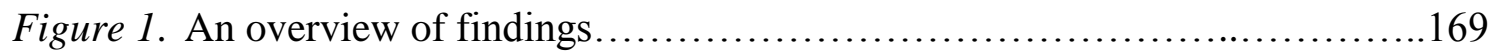

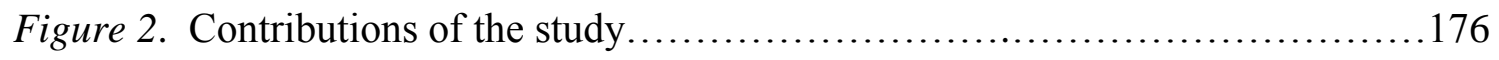

Figure 3. Systems-framework for effective advocacy......................... 190 


\section{CHAPTER ONE}

\section{INTRODUCTION}

Life on the lam wasn't easy for anyone. Whenever a serious threat arrived, dayto-day essentials would be quickly stuffed into suitcases. Rides to the homes of trusted friends took circuitous routes, usually under cover of darkness, and the driver wasn't the only one watching the rearview mirrors. Regular employment became impossible. No one wanted to share an office or a cubicle with a colleague who was on a hit-list. School work suffered. Classmates wondered why and where their friend or lab partner had disappeared. In the houses where the family came to reside, there were long discussions about trying to get visas for the kids so they could live with relatives outside of Pakistan, should it come to that. (Diaz, 2013, p. 74).

The above account is an excerpt from the personal narrative of Rehana Hashmi, the executive director of Sisters' Trust Pakistan, a non-governmental organization (NGO). The account reflects the tyranny that was so much a part of Hashmi's life, including the impact on her family, during her long-time involvement in advocacy work in Pakistan. Hashmi has worked tirelessly for the promotion and protection of women's rights, establishing two of the largest national networks of NGOs in Pakistan and wielding broad influence in a variety of domains - from grassroots organizing to advocacy and campaigning for advancing women's rights.

However, Hashmi has paid a high price for her advocacy work. She has become a regular target of threats, intimidation, and attacks and has seen her nephew murdered because of his association with her. Despite frequently needing to change locations and occasionally going into hiding, Hashmi is determined to continue her work on issues pertaining to human rights in Pakistan. She reinforced this determination even as her daughter pleaded with her to stop advocacy work. Hashmi argued clearly and convincingly: "I am so sorry for putting you and Sonu [Hashmi's son] through this. But 
this work for women is life to me. Like air. Like oxygen. It might be hard for you to understand, but I'm doing this for you, too. I can't stop.” (Diaz, 2013, p. 75).

Hashmi's story is only one story that exemplifies the challenges NGO leaders face when striving to sustain effective advocacy work in Pakistan. There are many others. This dissertation focused on some of these stories and on the strategies that NGO leaders use in the course of engaging in advocacy work with their organizations.

\section{Background of the Study}

Non-governmental organizations (NGOs) have increasingly been recognized as influential players in world politics and international development (CODE-NGO, 1998; Martens, 2002, Reimann, 2006; Lewis \& Kanji, 2009). Despite often relying upon committed, but unskilled, volunteers and limited financial resources, NGOs' advocacy work has, in many cases, been judged to be highly effective (J. Clark, 1991; Edwards \& Hulme, 1992b; UNDP, 1993; Smillie, 1995; Keck \& Sikkink, 1998; I. Anderson, 2000; Rugendyke, 2007).

Since the beginning of the 1990s, the advocacy work of NGOs has become more significant due to their growing participation in negotiation processes at national and international levels, their influence on governmental representatives through informal lobbying, and their representation as experts in official drafting committees at the United Nations (Shelton, 1994; Schoener, 1997; Arts, 1998; Martens, 2002; Betsill \& Corell, 2008).

The participation of experts from Amnesty International in drafting the Convention on the Abolition of Torture (Cook, 1996; Martens, 2004) and the Convention on the Rights of the Child (C.P. Cohen, 1990; Breen, 2003) are noteworthy examples of 
the importance of advocacy work by NGOs. Another substantial example involves the efforts of advocacy-oriented NGOs to influence World Bank policies in relation to gender, poverty, and the environment. This effort resulted in both the formulation of new policies and the cancellation or modification of others (Edwards, 1993; Smillie, 1995).

The sheer number of NGOs involved in advocacy work in some countries, at least, is also notable. For instance, in contemporary Pakistan, the total number of registered NGOs is estimated to be 45,000 (AKDN, 2000), of which about 18 percent are believed to be engaged in advocacy. Historically, political upheavals, socio-economic conditions and cultural factors played significant roles in the evolution of a diverse NGO sector in Pakistan (Davenport, 2012). Based on an NGO’s function, Iqbal, Khan and Javed (2004) categorized the NGO sector in Pakistan into three types: service delivery, service delivery/advocacy, and advocacy organizations.

Though the number of NGOs in Pakistan is large and the functions they serve are multi-faceted, the NGO sector in Pakistan faces a number of internal and external challenges. Perhaps the most significant challenge is the deep-rooted ideological conflict between the leaders of service delivery NGOs, on the one hand, and advocacy NGOs, on the other. For instance, advocacy NGOs have been effectively raising their voices against discriminatory laws and practices involving women. They support a woman's right to freedom of expression, freedom of mobility, and economic empowerment. Service delivery NGOs, however, often undervalue the importance of advocacy and sometimes often want to limit the rights that advocacy-oriented NGOs support. This ideological divide has not only split the sector; it is also a significant barrier to resolving conflict (Ghaus-Pasha, Jamal \& Iqbal, 2002; Iqbal, 2006). 
Despite the threat of widening the divide between service-delivery and advocacy types of NGOs, Edwards and Hulme (1992b) emphasize the importance of advocacy work in challenging environments, and they examine some of the reasons for engaging in such work. They argue, "It is impossible fully to address the causes of underdevelopment imbedded in unjust political and economic structures, simply through 'development projects'. Action is also needed to lobby for change at the national and international levels" (p. 82).

In addition to recognizing the importance of NGO advocacy work and articulating the reasons for engaging in advocacy in places like Pakistan, the academic literature also suggests the need for a more in-depth understanding of advocacy by "developing a better knowledge of the key institutions that advocates try to influence and their real world constraints and priorities" (Bryer \& Magrath, 1999, p.175). The impetus for this call for deeper understanding comes from a variety of sources-from concern over NGO leaders' preferences for protecting their material interests rather than organizational objectives and people's rights (Bano, 2008b) to the recognition of the influence of hostile political environments in which NGO leaders are often imprisoned or even killed (Hailey \& James, 2004). A common subtext in most of this literature, however, is that NGOs play a key role in advocacy work. Consequently, there is a need to reexamine various approaches to advocacy with an eye toward generating evidence about the effectiveness of the different advocacy strategies. There is also a need to focus more attention on NGO leaders in addition to the organizations through which they do their work. 


\section{Statement of the Problem}

The voluminous amount of literature that exists on the subject of advocacy, primarily in the developing world, mostly explicates the causes and impetus for advocacy work (Nicholson-Crotty, 2007; Nelson \& Vucetich, 2009; LeRoux \& Goerdel, 2009; Mosley \& Ros, 2011; Johansen \& LeRoux, 2013). However, research examining the effectiveness of advocacy is somewhat lacking. Morariu and Brennan (2009) argue, "Few have had experience evaluating advocacy, and many foundations consider advocacy to be 'hard to measure' - that is, beyond the scope of what can be effectively evaluated" (p.101). Nevertheless, the effectiveness of NGO advocacy is a major concern for donors, and, consequently, some of them have conducted evaluations on the advocacy work and provided some guidelines to improve that work (Davies, 2001; Laney, 2003; Hudson 2000; Reisman, Gienapp \& Stachowiak, 2007). However, at this point, there has been little empirical research and theory development about how NGO leaders navigate advocacy strategies in various contexts.

\section{NGO Leaders and Theory of Change}

Because advocacy is defined as "purposive efforts to change specific existing or proposed polices or practices on behalf of or with a specific client or a group of clients" (Ezell, 2001, p. 23), there is a general consensus among scholars and practitioners that the effectiveness of advocacy cannot be measured and evaluated without a theory of change (Christie \& Alkin, 2003; Reisman et al., 2007; Klugman, 2011; Stachowiak, 2013). The theory of change not only provides a conceptual framework based on program goals, strategies and outcomes for assessing the effectiveness of advocacy efforts, but it also helps the leaders in modifying their strategies for sustaining effective advocacy activity. 
Although researchers from various disciplines such as political science (Baumgartner \& Jones, 1993; Kingdon, 2002; Sabatier, 1999), sociology (Domhoff, 1990; Mills, 2000) and social psychology (Turner, Hogg, Oakes, Reicher, \& Wetherell, 1987; Alinsky, 2010) extensively use the theory of change from an organizational perspective for policy analysis, they usually overlook the possibility that the way NGO leaders nurture themselves could also be a factor for effective advocacy work. In the Pakistani context, where the ideological divide not only escalates conflict within the NGO sector but also creates difficulties for NGO leaders at the societal level, organizationally focused theories of change may not fully analyze the advocacy work. There may be a need to focus more directly on the leaders of advocacy organizations.

\section{NGO Leaders and Contextual Influences}

The minimal literature that exists about NGO leaders discusses the influence of both internal and external factors on NGO leaders who work in a challenging environment in developing countries (James, 2008; Smillie \& Hailey, 2001; Hailey \& James, 2004). Hailey and James draw attention to the adversities of NGO leaders in such contexts: "The leadership of advocacy NGOs face[s] extraordinary challenges as they work with very limited resources in uncertain and volatile political and economic circumstances to help the most marginalized and disadvantaged members of their communities" (p.344). Given the challenges Hailey and James point to, it makes sense to study NGO leaders in relation to the contexts in which they work.

Generally, context has had an impact on NGO leaders, and every society has had its own distinct attitudes about NGO leaders. In Pakistani society, there exists a strong polarization between service delivery and advocacy NGOs, resulting in distinct attitudes 
of society towards NGO leaders. Consequently, the recognition of the role of NGO leaders for effective advocacy and the impact of context on leaders and their work is indistinct. In addition, general leadership scholars also caution that organizations operating in a challenging environment require leaders who can respond to and lead change by creating new systems and strategies crucial for the growth and sustainability of the organization (Heifetz, 1994; Williams, 2005; Bass \& Bass, 2009). Therefore, to understand the role of NGO leaders, there is a need for a more appropriate framework for exploring the effectiveness of advocacy work because the theories of change investigate the application of different approaches to effective advocacy vis-à-vis organizations in lieu of focusing on the lived experiences of leaders in challenging contexts.

\section{NGO Leaders and Dearth of Research}

Although there has been a plethora of studies on the role and character of leaders in for-profit organizations, especially in the West (Adair, 2002; Bennis \& Nanus, 2004; Kotter, 1996), there is a dearth of research on NGO leaders involved in advocacy work in parts of the world where environments can present significant challenges, including the actual survival of NGOs and their leaders (Hailey \& James, 2004;). In addition, while there has been a significant amount of research conducted on the subject of advocacy, at this point, there has been little empirical research and theory development about how NGO leaders influence advocacy work in developing, but politically unstable, countries. Furthermore, to date, no research has been conducted focusing on the influence of NGO leaders on advocacy work in different socio-economic, cultural and political settings across Pakistan. The limited body of work that has been produced about NGOs in nonWestern countries has almost exclusively used quantitative research designs. These 
studies, consequently, do not provide anything resembling a thick description of NGO leaders' strategies in a challenging environment.

For instance, quantitative researchers, such as Salamon, Sokolowski, and List (2003), use quantitative data to assert that, because of the histories of authoritarian politics in places like Pakistan and Morocco, the NGOs in these developing countries are smaller and less developed than those found in transitional countries such as Romania, Hungary and Slovakia. According to these researchers' analysis, "Pakistan data suggesting an unusually high involvement of civil society organizations in service activities, and relatively limited involvement in expressive functions, supports this interpretation" (P.50). They reviewed survey reports by NGOs and official statistics and documented the size, scope, internal structure, finance and legal position of the nonprofit sector in each country to assess how the growth of NGOs varies from country to country. However, they overlooked the role of leaders both in the growth of the sector and in the effectiveness of advocacy work. Unless we can probe the narratives that accompany the lives of NGO leaders, we may not be able to fully understand the NGO sector in Pakistan or anywhere else, for that matter.

The few qualitative studies that focus on NGOs in developing countries also have certain limitations in terms of understanding NGO leaders. Pakistan-focused studies, for example, either tend to focus on the historical evolution of the NGO sector (Iqbal et al., 2004; Bano, 2007) or the ideological divide of NGOs in Pakistan (Iqbal, 2006; Pasha, Iqbal \& Mumtaz, 2002); they do not explore the role of leaders in depth, nor do they seek to explicate the strategies that NGO leaders employ to tackle the difficult task of sustaining their advocacy work in a challenging environment. Clearly there is a need for 
understanding the impact of Pakistani NGO leaders' experiences related to advocacy work in an often challenging environment.

\section{Purpose of this Study and Research Questions}

This study sought to address the need for increased understanding of Pakistani NGO leaders involved in advocacy work by exploring the strategies a limited number of leaders use in Pakistan. I examined the advocacy approaches and practices of NGO leaders in various socio-cultural settings. Through document analysis and in-depth interviews with a sample of five NGO leaders from various provinces of Pakistan, I intended to better understand how these leaders navigate their advocacy activities and how they nurture their personal capacity for effective advocacy work. In addition, I investigated whether NGO leaders demonstrate similar or different advocacy approaches across various political, socio-economic and cultural contexts across Pakistan.

The overarching research question was: What strategies do NGO leaders use for effective advocacy work in a Pakistani context? The following research sub-questions were used, initially, at least, to guide the study.

- How do external factors influence NGO leaders in developing their strategies for effective advocacy? How do the leaders attempt to influence the external environment?

- How do internal factors influence NGO leaders in developing their strategies for effective advocacy? What do the leaders do internally to create what is hopefully an effective organization?

- What strategies do NGO leaders use to nurture their personal capacity for effective advocacy? 
In the next chapter, I further explored the literature that has influenced my framing of this study. The methods that I used to conduct the study are described in detail in the third chapter. 


\section{CHAPTER TWO}

\section{LITERATURE REVIEW}

Chapter One of this dissertation has demonstrated the need to investigate the strategies used by NGO leaders and to document how they nurture themselves in order to sustain their advocacy work amidst the many challenges of their environment. The purpose of this chapter is to highlight and explicate the importance of existing scholarly research on the NGO sector and advocacy before setting the stage to explore the strategies of NGO leaders involved in advocacy work.

This chapter begins with a discussion on the existing definitions of NGOs aiming at a theoretical understanding of NGOs as influential players in world politics and international development. While this study is designed to explore the strategies that NGO leaders use for effective advocacy work in Pakistan, the appraisal of definitions will help in differentiating NGOs involved in advocacy work from other kinds of voluntary networks and INGOs (International Nongovernmental Organizations) and to avoid any confusion related to concepts reviewed in this literature.

After defining the NGO sector, the chapter will focus on four main bodies of literature. First, I will offer an overview of the NGO sector in Pakistan. Since NGO work takes place in both country and organizational contexts, I will then review literature on the challenges of external and internal factors which NGOs face in developing countries. I will further explore the strategies used by NGO leaders when responding to organizational or societal pressures. Third, I will review the literature on various approaches to advocacy that NGOs use to influence the policy arena. I will end with 
some literature on social capital and resilience that may reveal how NGO leaders nurture themselves in their challenging environment in order to sustain their advocacy work.

\section{Defining the Sector: Civil Society, Nonprofit Organizations or NGOs}

The term NGO was initially coined by the United Nations (UN) and is defined as follows: “a not-for profit, voluntary citizen's group that is organized on a local, national or international level to address issues in support of the public good" (UNROL, 2014). Since its inception in 1945 , the UN guaranteed space for the civil society within the UN system by citing in its Article 71 of Chapter 10 that NGOs could be accredited to the UN for consulting purposes. As a result, 41 NGOs received consultative status through the Economic and Social Council (ECOSOC) in 1946. Currently, more than 3,400 organizations are playing a significant role in policy making and implementation at the international level. Introduced by the UN, the term NGO is widely used in conjunction with civil society all over the world, especially in developing countries. Gray, Bebbington, and Collison (2006) suggest that NGOs are part of civil society, and, therefore, the term NGO is to be understood through its location within civil society.

The classical theorists like Hegel, Tocqueville and Marx had a different concept of civil society. They saw it as "a domain parallel to but separate from the state - a realm where citizens associate according to their own interests and wishes" (Carothers \& Barndt, 1999, p.18). Nevertheless, civil society theorist, Antonio Gramsci, describes civil society as a sphere of independent activities. He argues instead that "between the economic structure and the state with its legislation and coercion stands civil society" (Gramsci, 1971, p. 209). In the same vein, Edwards (1993) discusses the autonomous nature of civil society and explains that NGOs and all other organizations between family 
and state, excluding market, are categorized as civil society because they independently advance the common interests. His Highness, Prince Aga Khan (2014) offers a practical definition of civil society related to its persuasion of public goods by private means. He writes:

By Civil Society I mean an array of institutions which operate on a private, voluntary basis, but are motivated by high public purposes. They include institutions devoted to education, culture, science and research; to commercial, labor, ethnic and religious concerns; as well as professional societies in law, accounting, banking, engineering and medicine. Civil Society encompasses groups that work on health and safety and environmental matters, organizations that are engaged in humanitarian service, or in the arts or the media. (para. 57)

Civil society is often referred to as the nonprofit or third sector (Powell \& Steinberg, 2006) because of its location outside the first (state) and second (market) sectors. Added to that point, Corry (2010) provides two sets of definitions for the nonprofit sector in relation to state and market: The ontological definitions describe it as an object with certain qualities (such as civility) that is fully separated from state and market, while epistemological definitions view the sector as a societal process of communication across the sectors seeking inter-sectorial interactions. Boris and Steurerle (2006) conclude this discussion by stating that despite the autonomy of the nonprofit sector, it could be linked with both market and state due to its collaborative initiatives with them.

Anheier and Salamon (1998) identify five common characteristics: organized, private, non-profit-distributing, self-governing and voluntary of nonprofit organizations. They further point out that the term nonprofit sector (comprised of voluntary groups, NGOs, associations and networks) is not limited to the USA; it is widely used by the researchers from all over the world. Nevertheless, Powell and Steinberg (2006) present a different concept of the nonprofit sector which is most common in developing countries. 
This concept emerges from a conflict model of society and suggests that social change results from conflict among competing groups. For that reason, the term NGO, broadly used in developing countries, illustrates the entities on which it focuses, and, subsequently, NGOs are an “organized vehicle of citizens' protest against dominant elites" (p.91). This rights-based perspective of the sector focuses more on the role of NGOs as experts and watchdogs who monitor human rights situations in their respective countries, push for state reforms, and campaign against human rights violations. Nongovernmental organizations, then, play a critical role in providing a 'check' on governments, especially in regions where governments have been historically abusive or corrupt. In this view, the NGO sector is predominantly a set of institutions designed to empower the disadvantaged and, thereby, alter the balance of social power (Korten, 1990; Fisher, 1993). On the other hand, Morris-Suzuki (2000) argues that "NGOs may pursue change, but they can equally work to maintain existing social and political systems"' (p. 68). Lewis (2005), therefore, perceives NGOs as tabula rasa (blank slate) for reinventing various ideologies of change.

Considering the breadth of the NGOs vis-à-vis their size, structures, legal registration, nature of activities, funding sources and even the names (Clark, 1991; Korten, 1990; Fowler,1997; Andrews \& Edwards, 2004; Donaldson, 2007; Schmid, Bar, \& Nirel, 2008; Kimberlin, 2010), Martens (2002) cautions that "defining NGOs is a mission impossible" (p.271). She point outs that the term NGO, introduced by the UN, has a negative implication which concentrates on what it is not (i.e., nongovernment, nonprofit), rather than emphasizing the positive characteristics of NGOs for creating inter-sectorial trust relations. 
In the same article, Martens extensively reviews the literature about NGOs and concludes that NGOs are either interpreted with a juridical approach focusing on the legal status of NGOs or with a sociological approach which examines the composition and functions of NGOs. Acknowledging both approaches, Martens defines NGOs as "formal independent organizations aiming to promote common goals at the national or international levels" (p.282). Although terms such as advocacy group or advocacy organization are often used for organizations having advocacy as their core activity, Almog-Bar and Schmid (2014) caution us that, "Advocacy should be studied as an activity, and not as an organizational classification" (p.15).

Therefore, Martens' definition of NGO will be used as a working definition for this study because it includes NGOs working exclusively for advocacy as well as those working for advocacy and service delivery.

Regardless of the various definitions for NGOs, the rapid growth of NGOs as influential players in world politics and international development is increasingly being recognized (Clark, 1991; Edwards \& Hulme, 1992a; Hailey, 1999; Brown \& Kalegaonkar, 2002; CODE-NGO, 1998; Riddell, 2007). The NGO sector has become the world's seventh largest economy, a major employer with a total workforce of 39.5 million full-time workers, and a trillion U.S. dollar industry (Salmon et al., 2003). Consequently, researchers of various academic disciplines began to study why NGOs rapidly proliferated and how they influence world politics and international development (Karns \& Mingst, 2010).

Researchers from various disciplines have studied the field differently to explore the growth of NGOs. Political scientists explicate that NGOs have emerged in response 
to the unjust power relations between the state and its citizens (Berger \& Neuhaus, 1977; Bratton, 1989; Nye \& Keohane 1972; Skjelsbaek, 1972). Social movement theorists argue that the failure of government in service delivery and in protecting the human rights of its citizens has scaled up the NGO sector (Mumtaz \& Shaheed, 1987; Fowler, 1991). Thus, NGOs influence governments through social movements in order to achieve their goal of improving human lives (Clark, 1998; Duffield, 1997). As a result, governments in some developing countries have established Government Organized NGOs (GONGOs) in order to crush these movements and to grab the resources from the international community allocated for NGOs (Naim 2007, Lu 2009).

Sociological institutionalists (Boli, Thomas, \& Francisco, 1987; Boli \&Thomas, 1999) and constructivists (Katzenstein, 1996; Price, 1997; Finnemore \& Sikkink, 1998) approach the field in another way and argue that norms and world culture strongly influence state behaviors and, subsequently, the growth and effectiveness of NGOs. Alternatively, economists believe the NGO sector was developed to provide services and goods when market failure occurs (Hansmann, 1987; Weisbrod, 1988).

Therefore, the growth and effectiveness of NGOs depends on how the NGOs are shaped and what they deliver to influence the imbalance of power in society. The next section will present an overview of the NGO sector in Pakistan in relation to the growth and effectiveness of NGOs.

\section{An Overview of Pakistani NGOs: Challenges vs. Opportunities}

Numerous studies indicate that the evolution of civil society in Pakistan spans over a period of centuries (Seal, 1968; Nizami, 1983; Sherani, 1991; L. Anderson, 1998; Baig, 2001; Khan \& Khan, 2004; Bano, 2008a; Baqir, 2012). According to Khan and 
Khan (2004), civil society is an umbrella term used for non-state and non-market actors. They categorize civil society organizations into two major groups. One, which includes charity organizations (madrasas), trade unions, bar associations, teachers associations, peasant organizations and student movements, has its roots in the Mughal era (1526 1707). The other group, which encompasses NGOs, emerged in the 1800s and 1900s, and plays a key role in areas of human rights protection, sustainable development and service provision.

The perceptions about the interests and effectiveness of civil society organizations related to state and market remain conflicting throughout the history of Pakistan, regardless of whether the country was ruled by dictators or democratic leaders. However, for this study, I will concentrate on the NGO sector. Historically, political upheavals, socio-economic conditions and cultural factors played a significant role in the evolution of a diverse NGO sector in Pakistan (Davenport, 2012). According to Baqir (2013) there are three major stages in the evolution of the NGO sector in Pakistan. Borrowing from Baqir for this review, I use the typology: First Generation NGOs, Second Generation NGOs and Third Generation NGOs.

\section{First Generation NGOs (1947-1977)}

Pakistan became a separate country in 1947 for religious reasons. According to Human Rights Watch (1995), “[T]he partition of British India into India and Pakistan [is] often cited as an example of the inevitability of conflict between religious groups in South Asia" (p.19). The Partition of India in 1947 into India and Pakistan triggered a two-pronged migration. Almost 17.9 million people drifted to India, while 14.5 million moved to Pakistan (Bharadwaj, Khwaja \& Mian, 2008). Consequently, the civil society 
organizations who actively struggle for freedom against colonialism shifted their priorities to serve the needs of the arriving refugees. Later on, they expanded their area of work to include basic education and health care as well as advocacy around women's issues and population control (Iqbal, 2006).

The first setback in the history of NGOs occurred when military rule was imposed, and General Ayub Khan became the president of Pakistan in 1958. General Ayub not only barred the advocacy groups (Bano, 2007), but he also deepened the economic and political marginalization of East Pakistan by suppressing the public voices. This resulted in a further division of Pakistan and created the independent state of Bangladesh in 1971 (Ali, 1983; Noman, 1990). In addition, General Ayub strengthened service delivery organizations by allocating state funds for them through his Grants-inAid program. He also introduced the Voluntary Social Welfare Agencies Ordinance 1961 (Ghaus-Pasha \& Iqbal, 2002) which bolsters the reliance of NGOs on the state for financial resources. Despite a significant rise in aid from the West (particularly from the USA) under Ayub's rule, the funds were directed through the state with minimal direct interaction between international donors and NGOs (Zaidi, 1999).

This resulted in an expansion in service delivery NGOs and a decrease in advocacy organizations (Iqbal, 2006). Additionally, Ayub's public perception changed from that of a military dictator into a social reformer (Bano, 2008a). Likewise, the military regime indoctrinated a bifurcated perception about NGOs among the people by establishing the hegemony of service delivery organizations over advocacy NGOs. This also reveals how external factors, such as financial aid, may shape the third sector in any country. 
After the Ayub regime, the era of democratic leader Zulfikar Ali Bhutto was also very grim for NGOs. As Prime Minister from 1973 to 1977 and chairman of Pakistan People's Party (PPP), Bhutto came into power with a philosophy of socialism infused with Islamic values. He not only nationalized private schools, banks and major industries, but he also redistributed the feudal land wealth and introduced housing schemes for lower class masses.

The nationalization process crushed the NGOs as the government nationalized 19,432 educational institutions previously run by NGOs and family trusts (Ghaus-Pasha et al., 2002). Another setback for NGOs was the reduction in foreign funding because of unfriendly relations between Bhutto and the West (specifically the USA) due to Bhutto's bold decisions. These include the formation of a close relationship with China, formation of the Organization of Islamic Countries, initiation of a nuclear program and implementation of an independent foreign policy (Bano, 2007).

With all these ups and downs in relations between the state and NGOs, the stage of first generation NGOs is recognized as the charities and philanthropists era.

\section{Second Generation NGOs (1977-1992)}

Bhutto was deposed in a coup led by General Zia ul Haq in 1977, and once again Pakistan came under military rule. Islam was placed at the crux of state ideology and power. General Zia imposed Sharia (Islamic) laws, and the Soviet Union's invasion of Afghanistan gave him even greater freedom to establish Islamic rule for the promotion of Jihad (Holy War) culture without any restrictions from the West (i.e., the United States). Responding to the imposition of Sharia law during the Zia regime, Khawer and Shaheed (2004) describe it as a period of unprecedented reversals for women and minorities. 
Pakistan's new position as a valuable ally in the U.S. front against the Soviets gave General Zia further freedom to abuse human rights, resulting in a new breed of NGOs that focused on development and advocacy work. In addition, during the Cold War era, the growth of international NGOs in Pakistan predominantly engaged in relief and emergency services for Afghan refugees (by NGORC, 1999) was a significant opening for an international environment for NGOs.

This period was a complex stage in the history of NGOs. On one hand, the charity organizations (madrasas), often pampered by the government, became the dwellings to promote hate teachings and Jihad culture. The government also offered them a power-sharing arrangement that changed the balance of power within the society, and, subsequently, these organizations frequently used coercive means against what they perceived as un-Islamic (Rais, 1997; Rizvi, 2000). On the other hand, other organizations raised their voices against discriminatory laws against women and religious minorities through their advocacy work. This era included prominent organizations involved in rights-based development and advocacy work (such as Aurat Foundation, South Asia Partnership, Aga Khan Rural Support Program, Human Rights Commission of Pakistan, Shorkat Gah and Orangi Pilot Project) as well as welfare organizations like the Eddhi Foundation.

Iqbal, Khan and Javed (2004) conclude that during this stage, "some organizations grew due to state patronage while others emerged in response to state coercion" (p.4). Ironically, the term NGO is widely used for the latter with a negative connotation. Extremists groups often describe 'non-governmental' (from the term NGO) as against the government. They believe that NGOs have an anti-Islamic agenda and are 
supported by foreign forces who want to make Pakistan a secular state rather than an Islamic country (HRCP, 2000; Iqbal, 2006; Milam, 2009; Naviwala, 2010).

\section{Third Generation NGOs (1992 Onward)}

Democracy was restored at the end of Zia's regime. Benazir Bhutto and Nawaz Sharif each served as prime minister in two non-consecutive terms respectively until the military again came into power under General Musharraf, who illegally took over Pakistan in 1999. Consequently, since 1992 till now, the NGO sector in Pakistan has been in flux, "with new organizations forming, some growing, others declining, and many dying" (Galaskiewicz \& Bielefeld, 1998, p.68). Currently, the total number of registered NGOs in Pakistan is estimated to be 45,000 (AKDN, 2000). According to their area of work and operation, these organizations are registered under one of the following four laws: the Voluntary Social Welfare Agencies (Registration and Control Ordinance), 1961; the Societies Registration Act, 1860; the Companies Ordinance, 1984; or The Trust Act II, 1882. Drawing upon their functions, Iqbal, Khan and Javed (2004) categorize the NGO sector in contemporary Pakistan into three types: service delivery, service delivery/advocacy and advocacy organizations. Ghaus-Pasha, et al., (2002) further present a sector wise breakdown of NGOs with the largest concentration in education (46\%), followed by the second largest concentration in the advocacy sector (18\%). All other services including health, social services, housing, recreation, and religious, business, and professional associations comprise the remaining $36 \%$.

The increase in the number of advocacy organizations resulted in the formation of an advocacy network for influencing policies both at the national and international levels. The formation of noteworthy national advocacy networks such as, the Joint Action 
Committee, Insani Haqooq Ithad, Aman Ithad and Insaf Network made some remarkable achievements.

These advocacy networks raised a voice against every military dictator and remained at the frontline of every struggle for democracy. For instance, NGOs along with other civil society organizations launched an advocacy campaign for the restoration of democracy, and, as a result, General Musharraf left office in 2008. Their strong advocacy work influenced the government to take historical initiatives, such as increasing the number of women represented in parliament, restoring a joint electorate system that allows political participation of religious minorities, approving a women's protection bill, and signing and ratifying various international human rights covenants.

Despite these achievements, the NGOs involved in advocacy work have been facing financial challenges. According to Baqir (2013), donors need 'contractor NGOs' with a project-oriented approach for spending money rather than a result-oriented approach to bring a social change. Consequently, community perceptions about NGOs have changed, and community members label the NGO leaders as 'Social Wadera (feudal lord)' and 'robots' who depend upon the donors' coins for their mobility and action (Baqir, 2012). However, contrary to this perception, NGOs have been receiving only $6 \%$ foreign aid (Ghaus-Pasha et al., 2003). Therefore, such perceptions not only undermine the voluntary efforts of NGOs, but also demonstrate the need for additional research to better understand the diverse, but multifaceted, NGO sector in Pakistan by exploring the strategies NGO leaders employ to respond to the ideological conflict within the sector as well as the complexities of socio-political and economic factors. 
The following section will elaborate on various internal and external factors which influence NGO leaders in developing countries like Pakistan and examine how the leaders develop strategies in response to these factors and sustain their work.

\section{NGO Leaders in Developing Countries: Influences and Strategies}

There is limited research on NGO leaders in general and Pakistani NGO leaders in particular. Besides an extensive research on the role and character of leaders in forprofit organizations, especially in the West (Allison, 2002; Adair, 2002; Bennis \& Nanus, 2004; Kotter, 1996), research by Hailey and James (2004) on developing countries also reveals that there is a large body of literature on macro development issues such as civil society, the political and policy context, human rights, and the role of aid. There is also another body of research that focuses on micro issues such as project activities, fieldwork and community participation. Surprisingly, there is little research on the central issues of NGO leadership, which basically bridge the macro and the micro issues, as both macro and micro issues are interlinked with NGO leadership issues. Therefore, without understanding NGO leadership, it is impossible to assess the impacts of macro and micro issues in relation to the growth and effectiveness of the NGO sector. Hailey and James (2004) termed leadership issues as "meso" (middle) issues and emphasized that the meso issues are important to understand because they elucidate how people and NGOs are managed, motivated, or led in order to sustain the NGO sector.

Despite that there is little knowledge about how NGO leaders shape the NGO sector and design their strategies to face the contexts that they operate within, a small number of existing studies explain the impact of NGO leadership. These studies show that not only do individual leaders play a central role in shaping the destiny of many 
NGOs in developing countries, but their role and effectiveness is in part determined by the environment in which they work (Fowler, 1997; Smillie \& Hailey, 2001; Hailey \& James, 2004; James, Oladipo, Isooba, Mboizi, and Kusima, 2005). Therefore, any understanding of the role and performance of NGO leaders in shaping the NGO sector necessitates a discussion about the environment in which they work. This section will elaborate on how different external and internal factors influence NGO leaders' strategies in the evolving contexts of developing countries.

\section{Key External Factors Impacting NGO Leaders Strategies}

Unavoidably, the strategies of NGO leaders in developing countries are mainly influenced by three key external factors-political, economic and cultural.

Political factors and strategies. There is a two-pronged political influence on NGO leaders in developing countries. In some cases, governments suppress the voices of NGO leaders. However, governments have also been known to support certain NGOs, referred to as GONGOs (Government Organized NGOs), in order to control the work of other NGOs by accessing information and resources in the international community (Fowler, 1991; Bayart, 1993; Van de Walle, 2001; Pasha et al., 2002; Hailey \& James, 2004; Naim, 2007; Lu, 2009).

In their study on NGO leadership in three developing countries (Pakistan, Bangladesh and India) Smillie and Hailey (2001) found that NGO leaders work under extreme political threats. To describe the severity of political factors, the researchers argue that the killing of NGO leader Omar Asgher Khan from Pakistan and the imprisonment of Qazi Faruque Ahmed of Bangladesh show that NGO leaders commonly face political threats that need to be challenged. 
These political threats clearly shape the actions the leaders would take to sustain their work in developing countries. During their interviews with NGO leaders, Hailey \& James, (2004) discovered that a challenging environment influenced how these leaders defined their strategies for sustainable work. The research reveals five key findings about NGO leaders in these countries. They have: (1) a clear vision, a firm value set, and a strong commitment to helping the poor; (2) a willingness to learn and experiment with professional knowledge; (3) the ability to analyze the external environment and respond to changing circumstances; (4) communication and interpersonal skills that enable them to motivate staff and communities; and 5) the ability to play different roles (Hailey \& James, 2004). Smillie and Hailey (2001) claim that the growth and effectiveness of NGOs is substantial in these countries because the NGO leaders have the ability and capacity to employ their leadership strategies of adaptation and resilience that enable them to cope with the volatile political environment.

However, Goodhand and Chamberlain (1996) describe "dancing with the prince" as a survival strategy of NGO leaders in hostile environments. Referring to NGOs in Afghanistan, the researchers use the metaphors prince, merchant and citizen for state, market and civil society. They further maintain that NGOs mushroomed in Afghanistan after the Cold War, but, to remain operational in a turbulent environment, NGO leaders had to assume the strategy of "dancing to the tune of the prince, whether the prince is a government, an insurgency movement, or a local war lord” (p. 91). Referring to the quote of an NGO director who "spent 80 per cent of his time on political issues, 15 per cent on tribal matters, and only 5 per cent on the projects because survival depends on 
understanding the local power structures" (p.98), Goodhand and Chamberlain argue that such strategies diminish the effectiveness of NGOs.

Besides direct threats to NGO leaders, government policies also influence NGO leadership strategies and limit their choices and opportunities for developing the NGOs. Pasha Iqbal and Mumtaz (2002) examined the role of government policies in shaping the NGO sector in Pakistan and found that because of their policies, the NGO sector remains under crises in Pakistan. Pasha, Iqbal and Mumtaz (2002) reviewed the available literature and government policy documents and interviewed NGO leaders. They found that the government's posture towards NGOs has fluctuated and lacked consistency. The researchers argue that the government is openly hostile to NGOs that are engaged in social and political advocacy and have taken up issues like women's and human rights, nuclear disarmament, and peasants and minorities issues.

Alternatively, there is some evidence that the Pakistani government has been generally supportive of the welfare and service delivery of NGOs. They explain that the revival of the NGO Bill in 1999 by the civilian government, pending in the Senate since 1996, highlighted the motivation of the government for greater "control" of NGOs (Pasha et al, 2002). The research shows that governments allow advocacy work to the extent that suits them (Pasha et al., 2002). For instance, the military regimes allow advocacy around human rights issues to keep their liberal face among the global community, but when NGOs start advocacy campaigns for the restoration of democracy, the military regimes become hostile to NGOs.

The NGO leaders, interviewed by Pasha, Iqbal and Mumtaz unanimously suggested that for the sustainability of the NGO sector in Pakistan, the government 
should formulate a consistent policy about the advocacy role of NGOs. The interviewees also identified the need to demonstrate greater unity and solidarity by establishing stronger coalitions as a strategy to resist the attacks on individual NGOs as well as for enhancing the impact of their work (Pasha et al., 2002). However, the researchers seemed to overlook the NGO leaders' strategy to shift their priorities from advocacy work to service delivery in response to inconsistent government policies for NGOs. This strategy may affect and limit the dynamic role of NGO leaders in the policy arena in Pakistan. In addition, research on NGOs in Iran by Moghimi (2007) points out that government policies are major obstacles for the NGO sector. Nevertheless, despite that non-governmental is a key feature for NGOs, Moghimi suggests that NGO leaders should adopt a strategy of collaboration with government and market. By dealing with them as interactive parties, NGO leaders could improve their effectiveness and the sustainability of the NGOs.

Conversely, a body of literature explicates the negative aspects of NGO and government collaboration, specifically in an African context (Fowler, 1991; Bayart, 1993; Van de Walle, 2001). The researchers describe that organizations initiated and supported by politicians work in the constituencies of powerful politicians rather than in poor communities and, subsequently, received national resources. These NGOs allowed politicians to distribute state goods in a sanitized manner, thereby improving politicians' images among communities as well as demonstrating the NGOs' loyalties to the government.

Using Kenya as a case study, Brass (2011) points to another constructive reason for NGO-government relations besides attaining resources. Brass used a range of models 
evaluating 4,210 NGOs quantitatively and then interviewed NGO leaders and workers, politicians, and government officials. The findings revealed that NGOs worked in the areas where the need was great in order to support the government. Consequently, NGOs were most prevalent in areas where the state is weak, such as Kenya's Northeastern province. A respondent observed that if NGOs are there, then people do not care about the government. In fact, it will actually become problematic for the government if NGOs are not there to provide collective goods. Brass argues that countries that are scared of NGO presence in their territories (such as Ethiopia, China and Nepal) should learn a lesson from the Kenyan experience, where the government actually benefits from having NGOs provide public goods in the localities where the government has failed to do so. Therefore, rather than working in confrontation with NGOs, the government is benefitting from their presence in the area for the development of its people. Likewise, NGO leaders are bolstering their NGOs by satisfying the needs of Kenyan people in these underdeveloped areas.

Therefore, the question of how political factors might affect NGO leaders and their impact on the NGOs in developing countries is not settled. Two major forces seem to be in play: First, as Smillie and Hailey (2001) argue, the NGO sector in developing countries is growing because NGO leaders have had the ability to develop coping strategies to encounter the influence of a volatile environment. Second, according to other researchers (Pasha, Iqbal, \& Mumtaz, 2002; Goodhand \&Chamberlain, 1996; Moghimi, 2007; Fowler, 1991; Bayart, 1993; Van de Walle, 2001), the NGO leaders' strategies in the challenging environments of developing countries need to be revisited in order to manage the pressure of religio-political forces in these countries. 
Goodhand \& Chamberlain (1996) also point out some strategic foci for donors related to political factors: "in Afghanistan, donors must make difficult choices about which princes or which citizens to support” (p.105). Therefore, the next section will examine several economic factors, particularly the role of donors, which promote and constrain change in the leadership strategies of NGO leaders and shape the NGO sector in developing countries.

Economic factors and strategies. Economic factors affecting NGOs in general and NGO leaders' strategies in particular are linked with political factors in some cases. For instance, after 9/11, U.S. donors made a strategic decision to fund NGOs in Afghanistan (Brass, 2011). Similarly, explosive growth of NGOs took place in Pakistan during the 1980s, as Pakistan received generous aid from the United States and other allies because of its role in the Cold War. This opened a vast field of activity for international donors in Pakistan (NGORC, 1999). Such strategic decisions of donors throughout the world (Koch \& Ruben, 2008) may influence NGO leaders' strategies for securing the financial sustainability of their organizations. On the other hand, Parks (2008) conducts a study in three Asian countries: Cambodia, the Philippines, and Thailand. He concludes that despite donors' substantial efforts for building the capacity of advocacy NGOs, their shifting priorities in funding trends typically destabilize the effectiveness of advocacy work.

Riemann (2006) presents another analysis of economic factors that influence the NGOs genesis and growth. She traces the rise of a pro-NGO norm in the 1980s and 1990s among donor states and intergovernmental organizations (IGOs), which has actively promoted the spread of NGOs to non-Western countries. Cohen et al. (2008) 
refer to NGOs as 'new colonialists', while Tembo (2003) argues that NGOs function as a new 'imperialistic method' of disseminating developed countries' values to developing countries. Reimann, Kupcu, and Khanna (2006) conclude that the broader influence of economic factors trickles down to the organizational level, specifically motivating NGO leaders to follow Western norms for safeguarding resources for their NGOs.

Cultural factors and strategies. Apart from the impact of political and economic factors, leadership strategies are also influenced by societal and organizational cultures. The Global Leadership and Organizational Behavior Effectiveness Research Project (GLOBE) study, as well as a substantial amount of other empirical research (Hofstede, 1991; House \& Aditya, 1997; Jaffar, 2007; James, 2008; Al-Suwaihel, 2009), has demonstrated the influence of cultural forces in countries or regions in which the NGO leaders function.

A study by James (2008) highlights some powerful cultural realities that have a profound influence on African NGO leadership behavior and strategies. The research used purposive sampling to select a diverse range of 41 NGO leaders in Kenya, Uganda and Malawi. Semi-structured interviews encouraged respondents to freely describe the cultural influence on their leadership strategies and behaviors. The findings revealed that NGO leaders construct an uncomfortable hybrid of perceptions about leadership based on the concepts coming from cultural perspectives about leadership and imported Western theories. The influence of Western theories allowed respondents to identify the need for "servant leadership" (Greenleaf, 1998), while the cultural impact encouraged leaders to favor a "big man" model of social and political leadership, which offers all powers to the leader and, subsequently, creates a power imbalance in the organization and society as 
well. Such confusing understanding of leadership concepts further constrains change in leadership behavior and strategies.

A body of literature focuses specifically on the interactions of leadership, gender and culture. Atiyyah (1992) reviewed the results of research related to Arabic cultures in countries such as Egypt, Kuwait, Saudi Arabia, Lebanon and Jordan. She claimed that Arab cultural norms and values are consistent with the leadership practices of leaders. Nevertheless, the influence of gender roles on female NGO leaders is intensified when culture is influenced by religion. Research by Jaffar (2007) suggests Islamic fundamentalism as a crucial aspect of the cultural environment and a very important 'ground reality' that NGOs advocating for women's rights in Pakistan have been facing. Many of the interviewees remarked that fundamentalists' accusations that NGOs are Westernized or Western agents is one of the biggest challenges that NGO leaders face (Jaffar, 2007). According to fundamentalists, NGOs and donors are enemies of Islamic society and through secular education they are bringing obscenity and pollution to the "pure land" of Pakistan. They see female NGO leaders as disloyal to Pakistan and stress that women must stay at home. As Jaffar wrote:

According to Dawn (2002), during the last couple of years the tension between the religious circles and the NGOs continued in this province [KPK] and various cases of hostilities were reported ... [I]n some of the areas the clerics had issued religious edicts, asking their followers to forcefully marry the girls from NGOs... In southern districts hand-grenades were hurled at the offices of different NGOs ... (as cited in Jaffar, 2007).

Jaffar went on to say that women's NGOs face more antagonism from traditional religious elements in Pakistani society than other types of NGOs. To counter this fundamentalism, the NGOs employed modified leadership strategies such as 
reinterpreting the Quran, networking and establishing ties with the religious community, using religion strategically, becoming isolated and self-censoring, joining fundamentalist organizations, and using and advancing secular thoughts and arguments.

Conversely, research by Al-Suwaihel (2009) revealed the positive interactions between culture influenced by religion, gender and leadership from the perspective of Kuwaiti female leaders. Using a qualitative design approach and narrative inquiry methodology, the researcher interviewed five Kuwaiti women and examined how the Islamic culture of Kuwait facilitated women in becoming leaders. The findings revealed that religion influenced female NGO leaders positively in developing their leadership style, behavior and strategies. Nevertheless, researchers mention that some conservative groups limit the ability of women to develop their leadership skills (Al-Mughni, 1993; Al-Suwaihel, 2009). Therefore, to respond to the difficulties created by conservatives groups, the Kuwaiti female leaders created their own leadership styles and strategies that respected the culture, fit with their own leaders' and subordinates' personalities, met the expectations of their organizations, and enhanced their accomplishments. Consequently, besides their individual achievements, these female leaders influenced some aspects of the culture, including people's perspectives about the role of women as leaders.

\section{Key Internal Factors Impacting NGO Leaders Strategies}

A body of literature suggests that internal factors (such as rapid funding, turnover of staff, capacity building of leaders and staff, negative feedback from staff, and organizational culture) also influence NGO leaders' strategies (ICBF, 1998; ICBF, 2001; James, 2008). Since NGOs rely upon two major resources, human resources and 
financial resources, the various internal factors can be categorized into two major sets: factors related to financial resources and factors related to human resources.

Factors and strategies related to financial resource. To safeguard the financial resources of their NGOs, leaders must contend with the donors' influences, which are often contradictory in nature. A body of literature suggests that donors directly influence NGO leaders' strategies in shaping the NGO sector. Others suggest that donors do not directly influence NGO leaders, but the materialistic interests of NGO leaders influence them to follow donors' policies to sustain their organizations.

Direct influences. Researchers examined donors' direct influences on NGO leaders related to organizational ecology (Aldrich \& Ruef, 2006), which often determines an organization's ability to attain resources through competition and linkages with various institutions (Garrow, 2011). Consequently, NGO leaders use the strategy of engagement with key players by demonstrating adherence to their institutions' rules and policies. This strategy directly affects a leader's choice for a target community as well as the NGO's location when considering the possibility of enhancing collaboration or ensuring resources.

A burgeoning body of literature indicates that NGO leaders prefer to locate NGOs in areas where access to donor resources and material quality of life is ensured (Pfeffer, 1982; Chambers, 1997). For example, Brass (2011) explains that Kenyan NGOs prefer to locate their offices in Nairobi because all donors are based in Nairobi, the capital of Kenya. An NGO leader in Machakos (70 km from Nairobi) described the convenience of location during his interview: "The organization chose to work in Machakos not only 
because of poverty levels, HIV/AIDS incidences and unemployment rates are high, but also because Machakos is not too far. It's easy to coordinate with Nairobi” (p.32).

A study looking at channeling funds to NGOs in Uganda further confirms that donors influence NGO leaders' strategies. Fafchamps and Owens (2009) surveyed a random sample of NGOs (100 from Kampala and 200 from the 14 other districts of Uganda) to examine the donors' motivations to channel financial assistance to NGOs in Uganda. Results revealed that donors regard Ugandan NGOs as sub-contractors of their developmental effort, not as charitable organizations in their own right. Since most NGO funding in Uganda comes from international donors (Barr, Fafchamps, \& Owens, 2005), success in securing grant funding depends primarily on linkages with different institutions such as membership in an NGO network or a subsidiary of a foreign NGO. Considering that this criteria does not seem to value competence and leadership experience, it not only reduces the likelihood of grants for competent leaders but also centers their strategies on developing linkages rather than gaining knowledge and experience.

Fruttero and Ghuri (2005) further examine the impact of donors' funding policies on the effectiveness of NGO work. In their quantitative study, they point out that the strong presence of NGOs in Bangladesh contributes an increasingly important role in the delivery of public services, but the analysis does not find strong support for the claim that NGOs were targeting poverty. Since NGO leaders prefer to increase their size and outreach, they implement their programs in areas where they do not currently have programs. The researchers analyzed the data from the 1995 and 2000 rounds of the Bangladesh Household and Income and Expenditure Survey and found that the location 
choice of NGO programs was based on their need for area expansion to meet funding requirements rather than on the needs of the community. Therefore, this agrees with Mercer's (2003) argument that NGOs are more accountable to their donors than to their recipient communities.

Kaplan (2002) summarizes this debate by arguing that the unlikely demands from donors have a detrimental effect on the ability of NGO leaders to pursue long-term goals and financial stability for shaping an effective organization. Consequently, some leaders even become de facto tour guides just to entertain their donors as James (2008) learned in an interview with one NGO leader, who commented that he spent 50 percent of his time dealing with donor visits alone. Nevertheless, some researchers argue that NGO leaders prefer to locate their projects in places where the need is greatest (Stirrat, 2008; Brass, 2011).

Indirect Influence. A study by Bano (2008a) demonstrates a strong connection between donor funding and a rise in the material aspirations of NGO leaders, which, in turn, results in a lower performance by the leaders. Bano (2008a) surveyed 40 NGOs in Pakistan and examined how donors indirectly influenced the leaders' behavior. She argues that rather than taking the community's needs into account, NGO leaders shaped the NGO sector and implemented the donors' adaptation strategies in a way that protected the leaders' material interests. For instance, they modified their activities according to donors' preferences: for women's rights in the 1980s, for micro-credit in the 1990s, and for community empowerment since then.

Bano (2008a) further examined the clear material incentives for leaders working in NGOs. For instance, by comparing the salaries of NGO leaders to a government wage 
scale, Bano showed that 95 percent of the NGO leaders she interviewed drew a larger salary than the government scale. Therefore, some leaders may be motivated by material aspirations rather than ideological incentives.

Human resource management: influences and strategies. Leaders and staff are the major players in fostering an organizational culture that impacts the sustainability of NGOs and the effectiveness of their work. Influenced by their societal traditions, leaders develop different leadership styles and, subsequently, employ various strategies related to human resources (House \& Aditya, 1997). For instance, leaders with a more participative leadership style (Hailey \& James, 2004) employ strategies based on shared responsibilities. On the other hand, leaders who have a paternalistic leadership style in developing countries may attain a high level of commitment and, subsequently, take charge of their staff, families and communities as well (Fowler, 1997; James et al., 2005). Hailey (1999) further explains that the sector is full of anecdotal stories about the detrimental impacts of paternalistic leaders, known as "charismatic autocrats" or "the guru syndrome." Talking about paternalistic leaders, Chambers (1997) maintains that such NGO leaders can achieve many things through their "guts, vision and commitment but they are equally vulnerable to acquiescence, deference, flattery and placation" (p. 76). In addition, a paternalistic leadership style is at the extreme end of power distance and uncertainty avoidance (House et al., 2004).

On one hand, the paternalistic leadership style makes many leaders, specifically the founding leaders, nervous about anything bad happening to them. Concerned about his illness, one Bangladeshi NGO leader said, "what will happen to my organization if I will die tomorrow" (Sidiqqi, 2001, p.3). On other hand, this leadership style also 
increases the dependency of staff on the NGO leaders. A staff member of a national NGO in Bangladesh describes that, "Like religious leaders start their speech with 'as God said in holy book', each meeting in [the NGO] starts with 'as [the founder Chief Executive] has said'..." (Siddiqi, 2001, p.3).

James (2008) describes another dimension of the paternalistic leadership style. He argues that NGO leaders in African developing countries live congested lives under the pressure of donors, staff and families. On one hand, staff expect their leaders to ensure job security and provide direction for their work and personal development. On the other hand, their families, extended families and communities place high demands on them from paying the school fees for children to bearing the financial burden of needy extended families. In addition, African female NGO leaders suffered more as staff expect them to be 'motherly' in the office, but if they behave professionally to complete the task, they may be criticized for being 'manly' (James, 2008).

Because of such diverse demands, NGO leaders' lives are extremely congested, and they have very little time to think about their own strategies. According to Dotlich \& Noel (1998), one reason people do not change is that they do not take time to reflect. Therefore, it is imperative for a leader to create a learning environment for his/her own nurturing as well as for employees. This will not only enhance the leader's job satisfaction, but it may also reduce staff turnover.

Referring to her research on Kenyan NGOs, Brass (2008) points out that people work with nonprofits not for the sake of money but for their professional growth and experience. In addition, Bakuwa, Chasimpha, and Masamba (2013), in their study in Malawi, also accentuate the importance of human resources for sustained NGO work. 
Using survey data collected from 299 employees, findings suggest that if NGO leaders want to reduce the staff turnover, they need to design retention strategies beyond the tangible monetary interests because intangible rewards (such as learning and development opportunities) provide a deeper and lasting psychological satisfaction. This motivates staff to stay with the organization.

\section{Theorizing Advocacy}

\section{Definitions and Concepts of Advocacy}

The word advocacy originates from the Latin noun advocatia, or "call to one's aid" and is defined in the Oxford Dictionary of English as "a public support for or recommendation of a particular cause or policy." The term advocacy has its roots in various disciplines. For instance, in social work, advocacy is considered to be a process with or on behalf of clients to change policies and practices, attain resources, and promote new legislation for people who have been denied access to equal rights and resources (Hepworth \& Larsen, 1986; Schneider \& Lester, 2001; Henderson \& Pochin, 2001). According to Brandon and Brandon (2001), advocacy is a process of empowerment that both psychologically and structurally impacts individuals by enhancing their confidence, power, assertiveness and choices. Particularly in citizen advocacy, this empowering relationship between advocates and those who risk marginalization and oppression is central in amplifying the self-esteem of the disadvantaged (Atkinson, 1999). In addition, social scientists also see advocacy as 'radical potential' (Boylan \& Dalrymple, 2009, p.2), which engages people in individual and social transformation (Wilks, 2012). Nevertheless, the nursing discipline narrowly 
defines advocacy as an abstract concept of need-based responsiveness to advocate for the protection of the health, safety and rights of patients (ANA, 2010; Tomajan, 2012).

When used in relation to the NGO sector, advocacy can be defined in many ways, and it is often influenced by the political histories and socio-cultural contexts of different countries as well as the changing global context which affects the relationship between NGOs and the government. According to Andrews and Edwards (2004), nonprofit advocacy remains an important subject of interest for researchers from various disciplines including political science, sociology, and the nonprofit sector. In the 1950s, the early nonprofit organizations in the United States, such as Scope and the National Association for Parents of Backward Children, defined advocacy in compliance with the principle of normalization and concentrated on the promotion and protection of rights of marginalized people, particularly the persons with disabilities (Almog-Bar \& Schmid, 2014).

In the 1960s, the concept of bifurcation of rights within the United Nations system deepened, and finally the UN introduced two separate legally binding treaties in 1966 : One for civil and political rights and the other for economic, cultural and social rights (Donnelly, 1981; Keller, 2001; Nelson \& Dorsey, 2008). During this era, the onset of citizens' advocacy movements shifted from humanitarian grounds to the political arena in the Western world particularly. This resulted in prominent advocacy endeavors such as the establishment Amnesty International in the United Kingdom (Larsen, 1978; Buchanan, 2002; A.M. Clark, 2010) and the apex of the inspiring civil rights movement in the United States (Brooks, 1974; Weisbrot \& Cathcart, 1990). The definition of advocacy during these years expanded from protection and care to influence and change. 
More to the point, the literature presents an array of definitions which expound on advocacy as a political activity and a deliberate attempt by individuals or organizations to influence existing or proposed laws, policies and practices (Jenkins, 1987; Ezell, 2001; Salamon, 2002; Jenkins, 2006; Casey \& Dalton, 2006). The attempt to influence is made either by establishing a link between people and institutions, without any clash with the government, to ensure civic participation to strengthen the institutions administering justice (Boris \& Mosher-Williams, 1998; Baqir, 2002; Berry, 2005; Wijkström \& Zimmer, 2011; Almog-Bar \& Schmid, 2014) or by influencing government for a change in legislation for policies and practices to safeguard the rights of excluded groups (Andrews \& Edwards, 2004; Kimberlin, 2010; Casey, 2011). Another set of definitions point to the potential inherent conflict in advocacy as well as skewing the understanding of advocacy further to civil and political rights.

For that reason, in the 1980s with the ascendency of globalization and neoliberalism we see the emergence of prominent community based organizations, grassroots campaigns and environmental initiatives on social and economic issues. These include the Narmada Dam Movement in India (Gadgil \& Guha, 1994; Baviskar, 1999; Randeria, 2003) and the Orangi Pilot Project in Pakistan (Khan, 1996; Hasan, 2006). In the same vein, the end of the Cold War not only encouraged civil society to embrace economic, social and cultural rights but also reshaped the relations among NGOs in the Global North and Global South. The formation of the Jubilee Debt Coalition 2000, calling for the unpayable debts of the poorest countries to be cancelled, is a noteworthy example of this new thinking. 
Consequently, new definitions of advocacy accentuating on power balance, social justice and North-South relations emerged. Nelson and Dorsey (2008) use the term, new rights advocacy, to refer to "advocacy on social, economic or development policy, at local, national, or international levels, which makes explicit reference to internationally recognized human rights standards" (p.19). Other researchers suggest that advocacy is about balancing relationships of power between citizens and institutions of government within an overarching framework of political, economic and social rights (Nyamugasira, 1998; Cohen, de la Vega \& Watson, 2001; VeneKlasen \& Miller; 2002; CESI, 2003; Klugman, 2011).

Despite that the construct of advocacy has various traditions and foci, most of the definitions are based around two key concepts: influence and change. Although most researchers concur that influence is essential for advocacy, however, the concept of influence has been a subject of debate among scholars. Wijkström \& Zimmer (2011) suggest influencing policies by ensuring civic participation in policy reforms. Berry (2005) lamented that, "nonprofits in the United States are regulated by the federal government in such a way that discourages the involvement of their followers in the public policymaking process. These regulatory standards sharply skew public participation" (p.568).

In addition, the influence on government for changing policies to protect the rights of the disadvantaged differs in various contexts. In strong democracies like the United States, advocacy is constitutionally protected as documented in the Filer Commission (1973) that featured a wide range of advocacy undertakings. However, for some kinds of nonprofits advocacy has been restricted to lobbying to influence legislation 
due to funding restrictions and taxation issues under Federal law and Internal Revenue Service (IRS) regulations (Fogel, 1975; Boris \& Mosher-Williams, 1998). The regulations only permit these nonprofits to engage in direct lobbying with legislators or to mobilize the public to contact their legislators and present their recommendations (Vernick, 1999).

Conversely, in growing democracies like Pakistan, where the concept of advocacy is completely absent within all the laws related to the registration of the NGOs, the influence on governments for policy change faces challenges like conceptual clarity for the terms advocacy and lobbying, lack of financial support from government, and sometimes confrontational attitudes of the parliamentarians on certain issues such as educational reforms (Iqbal, 2006; Davenport, 2012).

Turning to the concept of "change", it is important to differentiate between the long-term change for balancing power relations and short-term change related to reforming laws and policies (Casey, 2011). In addition, Almog-Bar \& Schmid (2014) also differentiate between effectiveness and impact by arguing that effectiveness is a narrower concept that seeks short-term results, while impact evaluates the long-term change where policy becomes a norm of the society. In this paper, I will consider the effectiveness of advocacy related to changing laws and policies rather than the balancing of power relations in Pakistani society.

Despite this distinction, the advocacy literature points to difficulties in measuring short-term change or the effectiveness of advocacy, moreover, it is hard to evaluate the process of how change occurs rather than what actually is materialized as tangible results (McNutt, 2010; Mosely, 2010). Nevertheless, various logical models and assessment 
methodologies have been developed and used by different stakeholders to measure change (Davies, 2001; Laney, 2003; Hudson 2000; Reisman et al., 2007). According to Casey (2011), change can be measured through six steps-access, agenda, policy, output, impact and structural-because each step provides a specific result. For instance, output may bring a change in policies, while impact may succeed in shaping the voices of marginalized groups into societal norms resulting in a balance of power. In the same vein, Andrews \& Edwards (2004) suggest the following six dimensions of the advocacy process: agenda setting, access to policy makers, policy formulation, monitoring, implementation and resources. They emphasize that each stage of advocacy is separately influenced by different factors resulting in a different influence at each stage related to outcomes.

The influence of external factors on advocacy outcomes (Giugni, 1998; Bergan, 2009) increases the improbability in results because the external environment is not in control of organizations. Political scientists explain that the availability of right conditions and support from policy makers is a pre-requisite for making a change (Kingdon, 2002, Baumgartner \& Jones, 1993, Sabatier, 1999). Advocacy researchers also point out that the ineffectiveness of advocacy is often related to internal factors such as limited resources, capacity, or the organization's lack of motivation for evaluation (Almog-Bar \& Schmid, 2014; Morariu \& Brennan, 2009; Donaldson, 2007). In sum, the key point from the literature is that most definitions of advocacy are based around two key concepts: influence and change. However, the understanding of these concepts varies across the contexts. 


\section{Activities and Types of Advocacy}

Almog-Bar and Schmid (2014) caution us that, "Advocacy should be studied as an activity, and not as an organizational classification" (p.15). Nevertheless, advocacy group and advocacy organization are the terms often used for organizations having advocacy as their core activity (E. Reid, 2006; Kimberlin, 2010). This distinction not only undermines the advocacy efforts of service provider organizations who undertake advocacy as a secondary activity (Donaldson, 2007; Schmid, Bar, \& Nirel, 2008; Onyx et al., 2010), but it also demonstrates the need for a better understanding of advocacy. Academic literature focuses more on direct advocacy, such as campaigning, lobbying and media activism, but Reid (2000) prefers a broader concept of advocacy and lists a wide range of advocacy activities:

Advocacy activities can include public education and influencing public opinion; research for interpreting problems and suggesting preferred solutions; constituent action and public mobilizations; agenda setting and policy design; lobbying; policy implementation, monitoring, and feedback; and election-related activity. However, there is no agreement on which activities constitute advocacy, and no one source gives a full account of the many kinds of activities and strategies groups use to leverage influence in the policy process. Each research project must define the activities important to the question under study (pp. 1-2).

Consequently, the typology of organizations and the kinds of activities they engage in determine the purposes of advocacy for the organizations. There are two strands of theory related to the purpose of advocacy. One focuses on the normative objectives of public commitment (i.e., shared interests and consensus building between the state and its citizens) recognizing them as greater norms of democratic societies (deLeon, 1992; Denhardt \& Denhardt, 2000; Bryson \& Anderson, 2000). The other 
focuses on the descriptive drive for advocacy work that permits states to engage its citizens in the decision making process related to policy formation. The descriptive purpose of achieving better policy outcomes not only improves the government's performance but also impacts the power balance in society (Koenig, 2005; Gallagher \& Jackson, 2008; Kastens \& Newig, 2008).

While considering both normative and descriptive purposes of advocacy, advocacy activities can be initiated by either the government or the citizens. According to the top down approach of advocacy, governments initiate activities, such as consultations and public hearings, to solicit input from people on policy issues (McLaverty, 2011). Nevertheless, most advocacy activities are initiated by NGOs to give a voice to the marginalized section of society. NGOs are not only in a unique position of making connections between policy makers and constituents, but they also have access to human and financial resources (Berry, 2005; Donaldson, 2007; Kimberlin, 2010).

To meet these overall purposes of advocacy engagement, NGOs face a number of challenges which limit their choices for advocacy work. Garrow and Hasenfeld (2012) point out that NGOs sustain the pressure of having to choose between incremental changes of solving individual problems for their clients or focusing on larger societal problems. Accordingly, depending upon their overall mission, NGOs get involved in case advocacy (focusing on individuals), system advocacy (influencing organization or community context), or policy advocacy (targeting policies and legislations). Although there are various descriptions concerning the means of advocacy (such as, self-advocacy, peer advocacy, citizens' advocacy, media advocacy and group advocacy), there is minimal existing literature on the different forms of advocacy related to the NGOs' 
philosophy and organizational priorities. Kimberlin (2010) reviewed literature on US advocacy organizations and argues that many forms of advocacy cannot be tracked in available data. However, Donaldson (2008) offers two kinds of advocacy: self-interested advocacy which permits organizations to serve their own interests (such as safeguarding their funding resources) and progressive advocacy that seeks to address deep-rooted systematic inequalities and injustices by involving constituents in the advocacy process.

Scott (2012) offers an interesting threefold typology of advocacy related to government control in policy formulation. He divides the policy work into three types: "policies where the underlying conditions do not permit complete control over policythose which require technocratic expertise that the government does not possess and those that are, more or less, under the control of the government" (p.5).

When drawing types of advocacy, another distinction is suggested by practitioners who are influenced by feminist scholars' worldviews of advocacy. They see advocacy as issue-based struggles that try to change a specific issue or struggle-based issues, which provide a roadmap for strategic planning to achieve long-terms goals of social justice by addressing a specific issue (Action Aid et al., 2002). Since advocacy is not a phenomenon to just influence government for social change, researchers suggest some other forms of advocacy referring to organizational activities. They contend that through state-centered advocacy, organizations directly influence governments by organizing activities such as lobbying with legislators, while society related advocacy targets nonstate actors such as administrators, judges, businessmen, media persons and the general masses to engage them in advocacy processes (Reid, 2000; Kimberlin, 2010). 
Besides their engagement in particular types of advocacy, several studies describe the organizational choices for greater or lesser involvement in advocacy work within that category. The resource dependence theory points to the rationalities behind the participation in advocacy work, specifically in Western countries. For instance, USA advocacy organizations may be concerned about losing their state funding if they take controversial positions that may be in opposition to government policies. In addition, the government demands additional accounting systems and procedures for fulfilling taxation requirements if an organization participates in advocacy activities (Chaves, Stephens, \& Galaskiewicz, 2004; Child \& Gronberg, 2007).

Added to that point, the theory of conflict posits that governments, specifically in developing countries where NGOs have no legal protection for advocacy work, perceive them as competitors and suppress their voices to maintain societal control. Accordingly, such regimes only fund charity organizations because of their nonparticipation in advocacy activities (Salamon, 2002). Nevertheless, the theory of partnership suggests that by developing collaborative initiatives with governments, gradually the government will become dependent on them for service provision. Subsequently, this practice not only helps organizations secure their funding, but it also can make governments respect advocacy work (Chaves et al., 2004; Salamon, 2002).

In terms of organizational size, the resource mobilization theory suggests that large organizations with more staff and larger budgets are more involved in advocacy activities, while the theory of bureaucratization of NGOs offers that large organizations favor self-interested advocacy in lieu of progressive advocacy (Salamon, 2002; Child \& Gronberg, 2007). However, several studies indicate that regardless of organizational 
size, the organizations whose core mission is advocacy conduct effective advocacy and impact the policy arena (Rees, 2001; Boris \& Krehely, 2002).

\section{Strategies and Tactics of Advocacy}

Generally, practitioners use advocacy as an organizational strategy to influence policy makers for a policy change. According to Knowlton \& Phillips (2012), "Strategy is the overall plan that gives coherence and purpose to the specific actions that organizations undertake” (p.18). Fox, Helweg and Hansen (1997) reviewed literature and conducted a number of discussions with advocacy organizations to discover that, "a comprehensive advocacy strategy consists of three different components transformational, developmental and instrumental" (p. 8). They further contend that advocacy strategy is a set of various stages which begins with citizen empowerment (transformational), moves to civil society strengthening (developmental), and ends with policy influence (instrumental). Therefore, the advocacy process requires a progression of various strategies for different stages to support an idea which influences the policy makers.

In addition, advocacy strategies vary from country to country depending upon four key factors: the political environment; the right timing (elections, high visible tragedy) for coalition building on the advocacy issue; the organizational capacity; and the risk analysis of potential opposing forces related to the advocacy issue (Miller, 1994). Considering these factors, therefore, NGOs employ a combination of inside strategies related to state actors and outside strategies related to non-state actors with a concentration on one or the other for policy change (Reid, 2000; Berry, 2005; Mosley, 2011; Kimberlin, 2010, Hoefer, 2012; IS, 2012). 
In this regard, Holloway (1998) suggests two fundamental advocacy strategies: “mass movement to raise people's awareness about an issue and [a] powerful lobby to convince the people in position" (p.11). These are called outside and inside strategies respectively. Furthermore, VeneKlasen and Miller (2007) offer a range of advocacy strategies including collaboration, research, litigation, protest, persuasion (lobbying and negotiations), public education, empowerment, constituency-building and media engagement which NGOs employ in various cultural contexts for policy change.

Nevertheless, researchers suggest that different strategies are needed for different types of advocacy. According to Berry and Arons (2003), government-centered advocacy needs inside strategies to influence decision makers. They further identify two separate sets of advocacy tactics for legislators and administrators. The legislative tactics are strategies and devises used by NGOs to defeat or to stop a law. Researchers consider these tactics aggressive and confrontational as they include presenting testimony, writing a letter, visiting a legislator or releasing research reports. Therefore, organizations in the USA mostly prefer to use administrative tactics based on a cooperative form of interaction with policy makers by responding to requests for information or working with advisory groups and socializing with government officials (Schmid et al., 2008).

Although society-centered advocacy is based on outside strategies such as working with media, signature campaigns, protests and campaigns (Mosley, 2011), the NGOs in developing countries, where governments are not supportive of advocacy work, frequently use outside strategies to build pressure and then gradually move towards inside strategies or employ a combination of strategies for effectively influencing the policy agenda. This involves a lengthy process. Sabatier \& Jenkins-Smith (1999) caution that 
policy change related to certain issues may take decades, but donors want immediate results of advocacy activities and effectiveness of strategies vis-à-vis these activities. In the next section, I will review both professional and academic literature and discuss the linkages between activities, strategies and results for assessing the effectiveness of advocacy work.

\section{Assessing Advocacy}

According to Beck (2000), the effectiveness of advocacy depends upon advocacy activities which engage people in the policy process by changing their worldviews. Therefore, if activities are designed with clear desired outcomes arising from policy implementation, combined with a high probability of success, the mobilization of people inescapably increases. It also indicates that effectiveness is potently linked with clear vision, strategic designing, and effective implementation and monitoring mechanisms. Consequently, both academic and professional literature mostly focuses on outcomes for assessing the effectiveness of advocacy work related to activities and strategies (DeVita, Montilla, Reid, \& Fatiregun, 2004; Fagen, Reed, Kaye, \& Jack, 2009; Knowlton \& Phillips, 2009).

There are two strands of literature regarding the effectiveness of advocacy in general and advocacy outcomes in particular. The academic literature largely centers around the theory of change (Kingdon, 2011 Baumgartner \& Jones; 1993, Sabatier and Jenkins-Smith, 1999; Domhoff, 1990; Mills, 1999; Biklen, 1983; Turner, et al., 1987; Alinsky, 1989), whereas professional literature relies upon the logic model (Chapman \& Wameyo, 2001; Kellogg, 2004; Reisman et al., 2007). Although these two models are often interchangeably used by NGOs due to lack of conceptual clarity, they are 
significantly different in appearance and utility. The logic model (based on inputs, activities and outputs) is operational in nature and illustrates a tactical explanation of the process of producing a desired outcome. However, the theory of change is conceptual for testing the underlying assumptions. It focuses on a causal link between strategies and outcomes to explain from here to there and how and why the desired change is expected to come about. In addition, the logic model is a time bound visual display of detailed information, while the theory of change is a time free simple explanation of 'do and get' (Knowlton \& Phillips, 2012).

\section{Theories of Change}

Christie \& Alkin (2003) point out that there is a general consensus that the effectiveness of advocacy cannot be measured and evaluated without a theory of change which tests the hypothesis. Consequently, despite the innovative nature of a hypothesisbased advocacy program, the effectiveness of the program heavily depends on the right selection of strategies to achieve the desired outcomes. Since theory of change is rooted in literature and evidence-based experience, to promote the plausibility of the model, the researchers from various disciplines devised strategies by exploring what works best for each condition.

The political scientists' theory of change focuses on the availability of the right conditions and support from policy makers for making a change (Kingdon, 2002, Baumgartner \& Jones, 1993, Sabatier \& Jenkins-Smith 1999), while sociologists argue that change is possible by working directly with the power elites (Domhoff, 1990; Mills, 2000). Social psychologists argue for the active engagement and the leading role of beneficiaries in advocacy efforts for change (Biklen, 1983; Turner et al., 1987; Alinsky, 
1989). These theories focus on the outcomes of the advocacy projects, activities or campaigns launched by the organizations (Reisman et al., 2007; Korwin, 2009) and identify four major outcomes-strengthening organizational capacity, base of support, alliances and data analysis-which could provide a basis for advocacy work. Furthermore, each theory suggests a specific set of strategies for achieving the desired outcomes.

Stachowiak (2013) extensively reviewed literature on policy advocacy and categorized the ten seminal theories of change relevant to advocacy into two major groups of theories. Global theories evaluate the policy change in larger perspective strategies, and tactical theories apply to common advocacy strategies used by the masses. The first group includes Large Leaps, Policy Windows, Advocacy Coalition Framework, Power Elites theory and Regime theory, whereas the second group consists of Messaging and Frameworks, Media Influence, Community Organizing theory, Group Formation and Diffusion theories. These theories form the conceptual underpinning for assessment and evaluation of advocacy work differently and help the evaluators understand the complex policy processes.

For instance, Kingdon's (2002) policy window theory of change proposes a multiple stream framework based on three streams of processes-problem stream, proposal stream and politics stream-which largely operate independently. In Kingdon's view, a 'policy window' opens when at least two of these elements come together. He cautions that each stream requires specific strategies. If a research strategy helps in developing a proposal, the constituency building strategy develops community leadership 
for framing the problem. When problem and proposal streams come together, by employing the strategy of lobbying, the political support reaches a tipping point.

Although a number of evaluators use Kingdon's (2002) ground-breaking policy window theory for policy analysis and recognize it as the foundation of a theory of change for describing the complexities of policy processes and Sabatier's (1999) influential Advocacy Coalition Framework (ACF) is widely used in the countries of the Organization for Economic Cooperation and Development. The Advocacy Coalition Framework (Sabatier \& Jenkins-Smith, 1999) investigates how policy change happens through coordinated activities among individuals and organizations, outside of government, that have the same core policy beliefs (Schlager, 1995; Weible, 2007; Weible et al., 2011). Since ACF often requires a decade or more to analyze beliefs by focusing on sub-systems for ossifying common beliefs into policy, ACF may not be very appropriate to apply in rapidly evolving political contexts of Asian countries that are either authoritarian or have recently emerged as new democracies (Hsu, 2005; Kwon, 2007; Sato, 1999). Applying a case study approach, Scott (2012) examines the application of ACF in two authoritarian systems, China and Singapore, and two democracies, the Philippines and South Korea. The findings revealed that despite the utility of ACF in Asia, the contextual factors demonstrate the need for identifying "modes of policy change in non-Western settings and seek to compare it with what we already know about the process in the West" (p.7).

In this regard, the evolving context of Asian countries may necessitate the grass roots theory of Alinsky (1989) for understanding the policy process which explicates that groups of people can create power by taking mutual action to achieve social change. 
However, considering the intricacies of policy processes, it is essential to utilize one or a combination of theories of change for designing a conceptual framework and a set of effective advocacy strategies in various contexts. Roche (1999) recognizes the need for the use of various approaches and concludes:

NGOs need to know under what conditions they should advocate on behalf of others and when they should be strengthening others to speak for themselves. They have to demonstrate that they are going about this work in a professional and competent manner, and use the monitoring of this work to learn and to improve future performance (p. 193).

\section{Logic Model}

Theory of change provides a foundation for the logic model which displays several important elements-input, activities, outputs and outcomes-by outlining the connections among them for assessing the effectiveness of advocacy work. Logic models are widely used by NGOs and donors for evaluation of advocacy work, however the literature reveals that distinct models have been introduced for developing and developed countries taking into account the contextual specifications of these countries (Chapman \& Wameyo, 2001; Kellogg, 2004; Reisman et al., 2007). According to Gen \& Wright (2012), despite that logic models need to be grounded in evidence-based research, most logic models seem to lack this component. In their research, they reviewed the logic models of different practitioners and examined the input, activities and outcomes related to policy advocacy for six models.

The findings revealed that NGOs need two kinds of resources or inputs for an effective advocacy program. Human resources aim at the empowerment, competency and social relations of various stakeholders involved in the policy process (Rappaport, 
1981; Putnam, 2000), while financial resources include "land, labor and capital" (Tilly, 1978, p.6). By employing various theories of empowerment, social capital and resource mobilization (Hoffmann, 1999; Cress \& Snow, 1996), they found some connections between activities and inputs of logic models. Besides the key activities of coalition building, information dissemination, and engagement of various stake holders, the study revealed that the influence of these activities on the views of decision makers is neither known nor hypothesized.

Nevertheless, another study conducted by Gardner and Geierstanger (2007) about the Clinic Consortia Policy and Advocacy Program offers different findings. By using both macro-level and grantee logic models, the researchers discovered that advocacy activities increase awareness among policymakers and the public, resulting in good working relations between them and, subsequently, a successful policy change.

Since both models, theory of change and logic model, have their significance and limitations in assessing the effectiveness of advocacy work, better outcomes could be achieved by taking them together because the plausibility of theory of change and the feasibility of the logic model both are indispensable for the effectiveness of advocacy efforts.

\section{Perspectives on Social Capital}

The word Social Capital means different things to different people. There is no consensus on its source of origin or process of formation. However, there is growing recognition on the role of social capital in the development of NGOs. Though all forms of capital are pertinent for organizational and societal development (Ostrom, 1990), given certain conditions social capital can be considered as an enabling resource that improves 
the effectiveness of other inputs in development (Dhesi, 2000). King (2004) posits that, "Non-profits and their leaders must foster social capital in order to recruit board members, raise philanthropic support, develop strategic partnerships, engage in advocacy, enhance community relations, and create a shared strategic vision within the organization" (p.471). However, Field (2003) simply states that "the concept of social capital can be summed up in two words: "relationships matter" (p.1).

Opinions differ on the subject of social capital. Coleman (1988) has argued that it is a public good and, therefore, would be under produced by private agents relating to the markets. On the other hand, Putnam (2000) perceives that social capital is not just 'a public good' but 'for the public good'. He contends that social capital is the foundation of a rich society as it connects people, and, therefore, a fiscally strong society could be poor in social capital.

However, to contrast Putnam's work, recent analysis has recognized that social capital can be exclusive or inclusive in nature. Therefore, it is not necessary that it is beneficial for all because of the human tendency for splitting people into allies and opponents (Fukuyama, 1999). Building on this argument, Rubio (1997) categorizes social capital as productive social capital and pervasive social capital. He defines productive capital as that which may generate institutional change and favor growth, while pervasive social capital is based on the use of force, violence and illegal activities.

In a similar vein, the World Bank (2000) identifies three main types of social capital as bonding social capital (strong ties among relatives, neighbours and close friends), bridging social capital (horizontal ties between individuals of various identities and beliefs), and linking social capital (based on vertical ties among the poor and elites). 
The World Bank's perception of social capital is that linking capital has the potential to cause discord. Conversely, it ignores the potential of bonding capital, which connects people of similar identities and values, to also cause discord particularly in ethnically or religiously divided societies.

Uphoff (2000) proposes another typology of social capital: Structural capital encompasses the types of interpersonal relationships related to formal or informal networks. Cognitive social capital relates to the realm of ideas. Nahapiet and Ghoshal (1998) concurred with this typology and added a third type, relational capital, which builds trust in relationships within a network.

Since there is no consensus among researchers about the definitions and typology of social capital, the opinions also differ concerning the utility of it. Numerous studies show that social capital is an effective tool for development, while others argue that it causes underdevelopment.

\section{Positive Utility of Social Capital}

Researchers recognize that social capital favors economic growth and, therefore, is essential for building up economic capital (Putnam, 2000; Keefer \&Knack, 1997). It enhances trust relationships and establishes political stability, which are essential for long-term investments in any society (Wilson, 1997; Coleman, 1990).

Social capital also improves the efficacy of society by harnessing trust relations among the networks of civic engagement for facilitating coordinated action (Widner \& Mundt, 1998; Petro, 2001). This shapes new possibilities on the level of democratic growth and a strong democracy. In addition, Boix and Posner (1998) posit that social 
capital can increase the effectiveness of government by fostering a culture of dialogue among communities of conflicting opinions as well as between communities and government for strengthening democratic institutions.

\section{Negative Utility of Social Capital}

Most debates have focused on the potential of social capital for solving a wide range of problems; however, an increasing amount of literature also identifies some negative dimensions of social capital. Although the involvement of all actors is essential for building a healthy society and economy, social capital excludes some groups of society (Frazer, 2005). Therefore, bonding social capital, grounded in particularized trust, can generate negative social capital in the forms of racism, ethnocentrism, and religious intolerance. Consequently, groups achieve internal cohesion at the expense of hatred for others. Since bonding capital creates social fragmentation and, subsequently, violent conflict, Ostrom (2000) has called it the 'dark side' of social capital. For that reason, opposing worldviews and different identified categorizations of social capital provide a useful, but complex, framework for analysis of strategies of NGO leaders.

\section{Perspectives on Resilience}

Researchers from various disciplines define and conceptualize resilience as either a trait or a process (Earvolino-Ramirez, 2007; Longstaff, 2009; Fletcher \& Sarkar, 2013). According to Coleman and Ganong (2002), "it is a dynamic process encompassing positive adaptation within an adverse context" (p.101-102), whereas Rutter (1999) states it is a "phenomenon of overcoming adversity" (p.119). Most of the definitions of resilience are based on two key concepts: adversity associated with negative circumstances and positive adaptation (Agaibi \& Wilson, 2005; Vanderbilt-Adriance \& 
Shaw, 2008). Nevertheless, researchers have suggested that positive life events can also be relevant in defining resilience (Fletcher \& Sarkar, 2013). Thus, there is a need to examine both accounts to better understand how resilience could be helpful in investigating advocacy strategies of NGO leaders in all circumstances.

When assessing the effectiveness of advocacy work of NGO leaders in a challenging environment, it is appropriate to examine resilience from a psychological perspective for two reasons: (1) Psychological resilience is linked with individuals, but other disciplines have taken up the concept of community or social resilience (Reid \& Botterlli, 2013). (2) It also conceptualizes resilience as a process and focuses on adaptation and growth rather than simply recovering or bouncing back in the face of disruption (Waller, 2001; Richardson 2002; Mahoney \& Bergman, 2002; Ungar, 2008). Whereas engineering resilience (Gunderson \& Holling, 2002; Bonanno 2004) is concerned with equilibrium, ecological or social resilience (Adger 2006; Walker \& Salt, 2006; Berkes, 2007; Walker, Holling, Carpenter, \& Kinzig, 2004) centers on persistence and robustness.

Wagnild, (2010) argues that every human being faces adversities in the course of life, nevertheless by strengthening his/her resilience core one can overcome extraordinary challenges. She further identifies the five characteristics of resilience core: purpose of life, perseverance, self-reliance, equanimity (balance) and existential aloneness (know yourself). Therefore, resilience could be a good supporting mechanism, which could be constructed by individuals on their own, for survival in harsh times.

Coutu (2002) discusses that resilient individuals not only accept the harsh ground realities but also have a knack for discovering meaning during difficult times. In 
addition, due to their reliance on their intelligence, they successfully make progress on whatever is available in given circumstances. Accordingly, the author cautions that the triumph of individuals in changing environments depends upon their level of resilience more than their education, experience and training.

Campbell (2009) explicates further on how personal resilience fosters organizational resilience. In her qualitative design study, she interviewed leaders from public, for profit, and nonprofit organizations and explored how these leaders revitalize themselves amidst disruptive changes. However, only resilient leaders can do this successfully because they have a purpose in life as well as an adaptive capacity to use the right strategies for meeting that purpose. According to the findings, interviewees from all sectors unanimously concurred that the personal resilience of leaders cultivates organizational resilience. These leaders further pointed out that a command and control culture is a major obstacle in fostering organizational resilience. Finally, leaders should take measures to create an environment which links individual ambitions with organizational goals because consistency of trust among leadership and staff, consensus, and a learning culture are the key elements of organizational resilience.

\section{Conclusion}

This literature review has found important support for the notion that like other developing countries NGO leaders in Pakistan have been using an array of strategies for an effective advocacy. They harness their social capital through engaging volunteers and collaboration with other sectors. The literature also indicates that effective outcomes resulted from collaborations and partnerships. The literature does not support a key

finding that resilience is a central strategy of NGO leaders with regards to their effective 
advocacy work. Resilience and adaptation enable NGO leaders to create an organizational environment that supports resilience of both the staff and the organization.

Finally, there is scant literature on the concepts of self-care, geographic variations, religious marginalization and gender dimensions of advocacy work of NGO leaders working in challenging environments. This enquiry will seek to find a theoretical framework that ties all the parts together and integrates the research findings related to these concepts into a unique contribution built on a theoretic paradigm of the organization as a transformative system. 


\section{CHAPTER THREE}

\section{METHODOLOGY}

This is an exploratory qualitative study that focused on the lived experience of NGO leaders in Pakistan. Specifically, the purpose of the study was to explore the strategies NGO leaders use in a Pakistani context. Through in-depth interviews with a sample of five NGO leaders from various provinces throughout Pakistan, I made an effort

to better understand how these leaders navigated their advocacy approaches and how they nurtured their personal capacity for effective advocacy work. I employed a narrative inquiry approach, which has the power to enhance understanding of phenomenon by studying one's lived experience through stories (Connelly \& Clandinin, 2006). My qualitative design involved both narrative analysis and analysis of narrative (Polkinghorne, 1995).

This chapter begins with a brief review of the research questions, followed by a detailed description of the research methodology or plan of inquiry (Josselson \& Lieblich, 1993), including the general research design, participants, data collection methods, data analysis procedures, ethical considerations, and credibility and dependability issues. A discussion of these topics is prefaced by a section that reminds readers of the research questions that the study's methods has attempted to answer.

\section{Research Questions}

The overarching research question of this study was: What strategies do NGO leaders use for effective advocacy work in a Pakistani context? The following research sub-questions were used, initially, at least, to guide the study. 
- How do external factors influence NGO leaders in developing their strategies for effective advocacy? How do the leaders attempt to influence the external environment?

- How do internal factors influence NGO leaders in developing their strategies for effective advocacy? What do the leaders do internally to create what is hopefully an effective organization?

- What strategies do NGO leaders use to nurture their personal capacity for effective advocacy?

\section{Research Design}

Since this inquiry focused on the lived experiences of NGO leaders to better understand the strategies they employ for effective advocacy in a Pakistani context, the methodology needed to be consistent with the purpose of the study. Therefore, by contrasting qualitative research with quantitative research, I concluded that a qualitative approach met the purpose of the study better as "it emphasizes qualities of entities - the processes and meanings that occur naturally" (Denzin \& Lincoln, 2000, p. 8).

Furthermore, Patton (2002) suggests that, contrasted with the controlled experimental design of quantitative research, the interpretive and open-ended nature of qualitative research does not allow the researcher to manipulate the inquiry. Also, it permitted me to conduct research with an insider perspective rather than as an outsider. Lincoln and Guba (1985) refer to this as "etic research versus emic research" (p.27).

As noted in the literature review, there has been robust research on the role and character of leaders in for-profit organizations, especially in the West, but there is a lack of research on NGO leaders involved in advocacy work in parts of the world where 
environments can present significant challenges, including the actual survival of NGOs and their leaders. Therefore, a qualitative research design enabled this inquiry to focus on the voices and experiences of NGO leaders in the advocacy arena.

Since I intended to obtain a better understanding of the NGO leaders' strategies related to the effectiveness and impact of advocacy, I chose to employ narrative inquiry from a broad range of qualitative designs to gain the perspective of each participant. Grounded in phenomenology, narrative inquiry focuses on stories of participants for meaning-making (Andrews, Squire, \& Tamboukou, 2008). However, Clandinin, Pushor, and Orr (2007) note that, "narrative inquiry is much more than telling of stories," and the researcher needs to pay particular attention to the "quality and impact" of the inquiry (p.21). In addition, Connelly and Clandinin (2006) identify the need for "simultaneous exploration of all three common places-temporality (ongoing process covering a past, present, future), sociality (relationship between participant and inquirer), and place (specific boundaries)-which specify dimensions of an inquiry space” (p. 379).

Bruner (1986) provides solid ground for using a narrative inquiry approach for this study by making a clear distinction between two kinds of knowledge or modes of thought. Narrative cognition is related to the understanding of human actions, whereas paradigmatic cognition seeks common themes or concepts emerging inductively from the data. Since I wanted to explore the strategies of NGO leaders involved in advocacy work, using these two modes of thought supported my desire to gain a better understanding of each participant's perceptions.

Polkinghorne (1995) uses the terms narrative analysis for narrative cognition and analysis of narrative (also called cross-case analysis) for paradigmatic cognition. He 
argues that narrative analysis is an "emplotted narrative" that could be considered as a case or life story because it shapes data elements in the form of a story without using codes and categories, while analysis of narrative relies on codes and categories and seeks to uncover commonalities within stories through a cross-case analysis. Therefore, utilizing both forms of analysis allowed me to translate the rich data in the individual stories that may be lost in paradigmatic procedures.

Finally, as most qualitative research designs focus on cross-case analysis and pay less attention to narrative analysis, my decision to use both approaches for getting a thick description to understand the phenomenon was also justifiable at a personal, practical and social level. Being an NGO leader involved in advocacy work for more than 15 years, this inquiry helped me to personally understand how effective advocacy is conferred onto experience in the often challenging context of Pakistan. The research participants may revisit their existing strategies related to advocacy in light of the deeper understanding they gain through the research process, and, subsequently, they may take some practical steps at the organizational level. The social implication of conducting narrative inquiry is to bring some change in the policy arena, particularly related to donors' policies for the assessment of advocacy work.

\section{Participants}

In designing this research, my first major challenge was to identify the advocacy organizations. This was challenging for two fundamental reasons. First, there is neither a definition of advocacy nor a criteria for advocacy organizations within the legal provisions for NGO registration in Pakistan. Second, there are two kinds of NGOs involved in advocacy work in Pakistan. One category of NGOs focuses exclusively on 
advocacy work, while the other utilizes a hybrid advocacy approach by working both for service provision and advocacy.

Since I was not an authority in defining the criteria for an advocacy organization, for this study I chose a broader criteria to define the NGOs involved in advocacy work: (1) The ones who are members of national advocacy networks such as, the Joint Action Committee, Insani Haqooq Ithad, Aman Ithad and Insaf Network, etc., which have been recognized nationwide for increasing the power of their groundbreaking strategies through advocacy campaigns. (2) The NGOs that engage themselves either individually or collectively in advocacy work at the United Nations (UN).

Once the criteria for an advocacy organization was defined, I selected only a small sample size of five NGO executive directors whose strategies and advocacy skills have enabled them to influence a shift in the balance of power in Pakistani society. Table 1 presents a brief description of the research participants.

Since the goal of qualitative research was not to obtain large, representative samples nor to generalize findings to populations (Donmoyer, 1990), even a sample of one or a few cases was suffice in order to meet my purpose of gaining insights into specific processes and practices within a particular setting (Onwuegbuzie \& Daniel, 2003).

However, to reach this small number of participants, I used a variety of sampling strategies including criterion, maximum variation, convenience, and snowball sampling as discussed below. 
Table 1:

Participants Descriptions

\begin{tabular}{llllll} 
Name & Gender & Religion & $\begin{array}{l}\text { Area of } \\
\text { Operation }\end{array}$ & $\begin{array}{l}\text { Involved in } \\
\text { UN Advocacy }\end{array}$ & $\begin{array}{l}\text { Current } \\
\text { Position }\end{array}$ \\
\hline Rehana & Female & Muslim & All provinces & Yes & $\begin{array}{l}\text { Executive } \\
\text { director }\end{array}$ \\
Peter & Male & Christian & All provinces & Yes & $\begin{array}{l}\text { Executive } \\
\text { director }\end{array}$ \\
Tahseen & Male & Muslim & All provinces & Yes & $\begin{array}{l}\text { Executive } \\
\text { director }\end{array}$ \\
Shad & Female & Muslim & FATA ${ }^{1}$ and & Yes & $\begin{array}{l}\text { Executive } \\
\text { director }\end{array}$ \\
Tanveer & Female & Muslim & All provinces & Yes & $\begin{array}{l}\text { Executive } \\
\text { director }\end{array}$
\end{tabular}

\section{Criterion Sampling}

Since I was not selecting the participants randomly from any network, I developed criteria about who can qualify as a participant of this study. According to this criteria, besides being a member of an advocacy network, each participant had at least two years' experience as an executive of an NGO, which claims to be an advocacy organization by fulfilling one of the following standards: 1) launching an advocacy campaign individually or collectively, 2) developing advocacy resource material, 3) conducting awareness raising and capacity building programs for advocacy, and/or 4)

\footnotetext{
${ }^{1}$ The Federally Administered Tribal Areas (FATA) is a semi-autonomous tribal region in northwestern Pakistan, bordering Pakistan's provinces of Khyber Pakhtunkhwa and Baluchistan to the east and south, and Afghanistan's provinces of Kunar, Nangarhar, Paktia, Khost and Paktika to the west and north.

${ }^{2}$ Province Khyber Pakhtunkhwa.
} 
producing and endorsing policy statements and reports for the UN and consulting on UN policy and program matters as a UN system partner.

\section{Maximum Variation Sampling}

Besides criterion strategy, I also used maximum variation strategy before the data collection step. This strategy was more appropriate for "capturing and describing the central themes that cut across a great deal of participant variation" (Patton, 1990, p. 172). I attempted to conduct in-depth interviews with both male and female, and Muslim and Christian NGO leaders from advocacy organizations and advocacy/service delivery organizations. In addition, I interviewed NGO leaders working in all four provinces of Pakistan, the capital of Islamabad and FATA ${ }^{3}$. This allowed me to keep a balance of gender, religion, sector and region as "maximum variation is the ideal when a holistic overview of the phenomenon is sought" (Kitto, Chesters, \& Grbich, 2008, p. 244).

\section{Convenience and Snowball Sampling}

To save time, money, and effort, I started collecting the data by using convenience sampling strategy to study easily accessed individuals or groups (Creswell, 1998). Since I have been involved in advocacy work for the past 15 years and have connections to advocacy networks, my positionality was helpful in accessing three participants who were involved in advocacy work for more than ten years and who met the other major qualifications of the study. However, to identify other participants who were interested in the study and who met the sample selection criteria, the fourth strategy that I used was snowball sampling. I asked the three primary research participants to

\footnotetext{
${ }^{3}$ The Federally Administered Tribal Areas (FATA) is a semi-autonomous tribal region in northwestern Pakistan, bordering Pakistan's provinces of Khyber Pakhtunkhwa and Baluchistan to the east and south, and Afghanistan's provinces of Kunar, Nangarhar, Paktia, Khost and Paktika to the west and north.
} 
recommend potential participants, and I eventually selected two more NGO leaders who agreed to join the study.

This sample size provided me with saturating data (Strauss \& Corbin, 1998) which "ensures replication in categories; replication verifies, and ensures comprehension and completeness" (Morse, Barrett, Mayan, Olson, \& Spiers, 2002, p. 18)

\section{Data Collection Methods}

I used two data collection methods for this study: interviews and document analysis. I chose to integrate creative methods, particularly for documents, into the data collection process. Therefore, besides gathering each organization's documents and reports, I also collected advocacy campaign posters, songs and slogans to get a deeper understanding of what advocacy means to NGO leaders and how the meanings spread out to the general masses. As detailed below, I first collected the documents, and then I interviewed the NGO leaders.

\section{Document Collection}

I began with document collection. I secured a number of relevant extant documents to analyze, including documents about the organization's history, mission, training modules, press releases, resolutions presented to policy makers, and advocacy reports, particularly the reports the NGOs presented at international forums such as the United Nations. Also, I looked at the advocacy campaign posters in order to understand the advocacy messages disseminated through these posters. This thorough document analysis not only helped me in developing my interview guide, but it also provided me with an initial understanding of the advocacy work of the participants and their 
organizations. Consequently, this understanding helped to keep me at ease while conducting the interviews.

\section{Interviews}

For this study, I conducted individual interviews with all five participants. Whenever possible, I preferred to use a face-to-face interview. However, depending upon the circumstances, some of the interviews were conducted on Skype. A recording device was used with the permission of each participant to ensure that the actual words of the participant were captured for analysis. By using a recording device, I was also able to focus on the framing of clarifying questions rather than concentrating on note taking. Although all five NGO leaders were fluent in English, four participants spoke both English and Urdu during their interviews, while one preferred to use only the Urdu language. I transcribed the interviews and then translated the interviews into English.

Before beginning the interviews, I contacted each participant to explain the purpose of the study and to obtain permission for the interview. I presented the Consent Form (Appendix C) for appraisal and acknowledgement of all issues that might be of his/her concern before, during, and after participation in this study on the ubiquitous, but intricate, phenomenon of effective advocacy. After getting consent, I scheduled interview times with the participants at their convenience, and I selected environments favorable to conducting the interviews in a quiet setting. Three interviews were conducted at the participants' homes, while two were done on Skype. Every interview was semi-structured by employing an interview guide (Patton, 2002) consisting of preplanned initial questions and probes which I formulated after the document analysis. (See Appendix B). 
Since the research topic was multifaceted, in a quest for themes and meaningmaking, I collected the data through two interviews with each participant.

First interview. The duration of each interview was not more than 90 minutes including the time for administrative details, such as signing the consent form and explaining the purpose of the study. The first interview started with an informal discussion in order to create a conversational flow with the participant (Patton, 2002). I began the conversation by focusing on demographic information aiming at bridging the detachment between interviewer and interviewee and engaging the interviewee as coresearcher. This process of engagement created an openness of purpose environment (Kvale \& Brinkmann, 2009) which I hope was a catalyst for fully capturing the data in a comfortable setting by smoothly shifting towards a more formal interview. I used an interview guide to facilitate focused communication of thoughts but without restraints. However, I was mindful to conduct the interview with an approach that an interview is "literally an inter view, an inter-change of views between two persons conversing about a theme of mutual interest" (Kvale \& Brinkmann, 2009, p.2). This first 90 minute interview focused on the influence of external and internal factors on NGO leaders and the strategies NGO leaders employ in response to this influence.

Second interview. In the second interview, questions were concentrated more on the participant's life experiences, specifically related to the strategies he/she used to nurture a personal capacity for effective advocacy. I used an interview guide and organized the questions by type of question-i.e., semi structured and open-ended (Creswell, 2005)-to make sure that the required data was collected. Open-ended questions that began with "tell me about a time" or "think of a situation" helped to 
engage the interviewees retrospectively by assessing the effectiveness of their advocacy work in relation to their strategies in different times. I formulated the questions for the second interviews after I analyzed the transcripts of the first interviews. This procedure helped me to understand and clarify the main themes that each participant discussed in the first interview. These two interviews for each participant provided sufficient data for the study, however, I also made some follow-up telephonic calls as a backstop strategy for auxiliary questions, as needed (Glesne, 2011).

\section{Data Analysis Procedures}

This research employed a narrative inquiry approach. Within the narrative inquiry approach, I used two different types of analysis, defined by Polkinghorne (1995) as Narrative Analysis and Analysis of Narrative.

\section{Narrative Analysis Procedures: The First Phase}

The narrative analysis was the first phase of data analysis. I developed an "emplotted narrative" for each of the NGO leaders from the transcribed data through a narrative analysis process as described by Polkinghorne (1995). I considered each narrative as a case study that captured the unique complexities of the situation (Patton, 2002). Since each case was an individual who has his or her own distinctive experiences of effective advocacy in tremendously varying socio-cultural and political situations across provinces in Pakistan, the narrative analysis approach permitted me to capture the unique components of each case. Polkinghorne (1995) notes, "whereas paradigmatic knowledge is focused on what is common among actions, narrative knowledge focuses on the particular and special characteristics of each action" (p.11). 
To collect the accounts of strategies of NGO leaders, I followed their life stories after their involvement in advocacy work. Therefore, I began with specifying the outcome of the narrative as a retrospective explanation, "having linked past events together to account for how a final outcome might have come about" (Polkinghorne, 1995, p. 16). In this study, the outcome was the current strategies of NGO leaders for effective advocacy. The "bounded system" (Stake, 1988, p.255) that I utilized was the time period that each participant, as an executive director of an NGO, had been involved in advocacy work.

Since Polkinghorne asserts that narrative analysis presents diachronic data (as opposed to synchronic), which contain "temporal information about the sequential relationship of events" (p. 12). Therefore, I attempted to gather data using an input and output framework, which inquired about the actions taken by leaders as well as the consequences of those actions, to make sense of two independent happenings. I organized the data chronologically and constructed a plot which Polkinghorne (1988) describes as "the logic or syntax of narrative discourse... a linguistic expression that produces meaning through temporal sequence and progression” (p. 160). I adhered to Polkinghorne's (1995) four strategies for developing a plot: “1) delimiting a temporal range, 2) providing criteria for the selection of events, 3) temporally ordering events into an unfolding movement, and 4) clarifying or making explicit the meaning events have as contributors to the story as a unified whole" (p. 7).

In the same vein, Emden (1998) devised eight strategies to construct a plot: 1) Read the interview text several times, 2) Delete interviewer questions and comments, 3) Delete words distracting from key ideas, 4) Read the remaining text for sense, 5) Return 
to full text as often as necessary for rechecking, 6) Identify subplots, 5) Move subplots together to weave a coherent story, and 8) Return the story to participants for member checking (p.35).

By employing these strategies, I moved back and forth reflectively from data to an emerging plot to ensure that the plot did not influence the selection of events, and, consequently, I made modifications with the plot outline, as needed, according to the principle of 'best fit' to fill the data elements in the outline.

In addition, I also followed the seven guidelines for narrative analysis suggested by Dollard (as cited in Polkinghorne, 1995) that yielded appropriate knowledge for the development of narratives of NGO leaders working in particular situations in a Pakistani context. Dollard suggests that the researcher must pay attention to: 1) descriptions about cultural context, 2) the embodied nature of the protagonist, 3) significance of people who affect the actions and goals of the protagonists, 4) choices and actions of the protagonist, 5) historical continuity of characters, 6) bounded temporal period, and 7) construction of a meaningful story of the protagonist's responses and actions (pp, 16-18). Since the research participants had working experience in the various cultural contexts of all provinces of Pakistan, Dollard's guidelines prepared me to pay particular attention to descriptions about cultural context.

After completion of the narrative analysis, I shared the findings with the participants to ensure the accuracy of the data. Glesne (2011) refers to this as member checking. I sent them the initial drafts of the narratives via email, and then via conference calls I inquired whether the participants' viewpoints were accurately interpreted. In some cases, the participants sent me their comments via email. 


\section{Analysis of Narrative Procedures: The Second Phase}

After each case was constructed, I employed an analysis of narrative approach. I revisited the original data that I used for the first phase of narrative analysis. In this analysis of narrative approach, I created categories (paradigmatic typologies) aiming for individual cases to be compared and contrasted (Polkinghorne, 1995). Finally, I coded and organized the data from the interviews and document reviews into major themes and categories in order to move the analysis from stories to elements.

Data coding. I began coding with the documents and used structural or open coding methodology, which relies on conceptual phrases related to the research questions, for the basic organization of the data (Saldaña, 2009). Then, I coded the data collected through individual interviews. I initially coded the data using descriptive and in vivo coding as suggested by Saldaña (2009), who stated that in vivo and descriptive coding are "appropriate for all qualitative studies, but particularly for those studies that prioritize and honor the participant's voice" (p.74). Therefore, in some instances I used a word or a short phrase to summarize a certain passage from the text (Saldaña, 2009), while in other instances I employed "the terms used by the [participants] themselves" to summarize passages from the transcripts (Strauss as quoted by Saldaña, 2009, p. 74). As a researcher, it was important for me to give voice to these NGO leaders who often feel ostracized and silenced in the literature on the leadership domain. I discerned these methods of coding appropriate and, at times, empowering. Historically, certain voices have been disempowered and have been left out of academic and political discussions (Kincheloe \& McLaren, 2005); entire groups have been marginalized by the dominant group. 
After completing this first cycle coding, I used second cycle coding methods in this study. This process enabled me to move from multiple codes in the first cycle to a few major themes (Saldaña, 2009). I used focused coding for discovering conceptual similarities, and axial coding to discern the relationship between categories, properties and dimensions.

During the data analysis process, I made notes about ideas, possible connections, questions and issues that emerged. Maxwell (2013) describes this as analytic memo.

\section{Ethical Considerations}

This study was conducted in accordance with the Institutional Review Board (IRB) policy of the University of San Diego. Since participation in the study was utterly voluntary, I received permission from the participants by having them sign consent forms stating that they fully understand and agree to the purpose of the study, guiding questions, procedures, risks and benefits, assurances of confidentiality, and their role during data collection and data analysis (Miles \& Huberman, 1994). In addition, I was open to protecting their rights to privacy and safety (Merriam \& Associates, 2002) by maintaining confidentiality. Initially, I used pseudonyms to preserve the identities of the research participants.

However, since all the participants are prominent figures both within Pakistan and in the international human rights arena, it was difficult to preserve their identities while describing their exceptional advocacy work. Therefore, I received their consent via email to use their original names as well as the names of their organizations. 


\section{Credibility and Dependability Issues}

Since the established criteria for scientific rigor in quantitative research cannot be applied to qualitative studies, this study used an alternative set of criteria - credibility for validity and dependability for reliability as suggested by Lincoln and Guba (1985).

Therefore, this study aimed at establishing trustworthiness rather than validity and reliability (Wolcott, 1990) because, unlike number-based quantitative research designed for generalizing the results, it focused on uncovering the complexities of participants' behaviors in a Pakistani context (Merriam \& Associates, 2002). Although there were several potential threats to trustworthiness in this study, I focused on two fundamental threats-researcher bias and reactivity as identified by Maxwell (2005).

I was fully aware of potential problems associated with my positionality as I have worked for many years as an NGO leader in Pakistan. I took into account the many ways I could be inadvertently biased or inclined to appreciate particular questions or responses while dismissing others (MacBeth, 2001). To improve the validity of the study findings, besides verbatim transcriptions, I used the strategy of triangulation suggested by Mathison (1988). I attempted to triangulate the cross case learning by using a particular form of triangulation called methodological triangulation-a term that refers to the use of different methods in a study (Patton, 2002)-by intermixing interviews and documents analysis.

For respondent validation, or member checking (Merriam, 2009), I shared the drafts of the case studies with the research participants to ensure the accuracy of the data. I asked them to review the findings and clarify any discrepancies. 
The other threat Maxwell (2013) identifies is the influence of the researcher on the settings or the participants. Instead of making an unrealistic attempt at eliminating my influence, I understood it and used it productively during data collection and data analysis as suggested by Maxwell. Therefore, throughout the study, I engaged in reflective practices and wrote journals to track my own reaction to the various components of the study. This helped me in examining my own biases during my interaction with the participants and when reviewing their data as well. 


\section{CHAPTER FOUR}

\section{NARRATIVE ANALYSIS: STORIES OF FIVE NGO LEADERS}

This chapter presents five case studies developed through narrative analysis as described by Polkinghorne (1995). This “emplotted narrative" process could be considered as a case or life story because it shapes data elements in the form of a story without using codes and categories. The process through which I developed these stories is described in detail in Chapter Three. However, as Clandinin et al. (2007) note "narrative inquiry is much more than telling of stories" (p.22). The case studies presented in this chapter focus on the voices and experiences of NGO leaders in the advocacy arena for assessing the effectiveness of their advocacy work.

The five case studies consist of participants from three (Punjab, Balochistan and Khyber Pakhtunkhwa) of the four provinces of Pakistan. However, the participants have extensive experience with advocacy work in all four provinces of Pakistan and the FATA Region. Initially, I used pseudonyms to preserve the identities of the research participants. However, since all the participants are prominent figures both within Pakistan and in the international human rights arena, it was difficult to preserve their identities while describing their exceptional advocacy work. Therefore, I received their consent to use their original names as well as the names of their organizations.

The narrative analysis was conducted as the first phase of the data gathered for this study. Three participants were interviewed in person, while two were interviewed via skype. Each case study was submitted in draft form to the participants for their review and comments. Revisions were negotiated via follow-up telephonic interviews. 


\section{Rehana: A Frontline Human Rights Defender}

Rehana, a 53-year-old mother of two children, has a master's degree in chemistry and a diploma in gender studies. She has been informally involved in advocacy work since her childhood, when her father was arrested for speaking against the military regime of General Ayub Khan. Rehana was just seven years old. She described her childhood as a "lost childhood" and added, "At the age of 7, you can't really think about advocacy work around human or women's issues." Still, Rehana took on the responsibility not only of looking after her father's shop but also of taking food to him in prison.

\section{Embracing Advocacy Work}

Rehana eventually embraced advocacy work and has worked tirelessly for the promotion and protection of women's rights for almost three decades. She is proud of establishing two of the largest national networks of NGOs in Pakistan and wielding broad influence in a variety of domains-from grassroots organizing to advocacy-and campaigning for advancing women's rights. She is currently executive director of Sisters' Trust Pakistan. She described how she became a part of an NGO working for women's rights:

I was the president of the student union in 1978 and wanted to join politics [in the future] but I learned how politicians used students for their own interests... When I saw the first murder of a student leader, I decided to stay away from politics. Therefore, after completing my studies, I started work as a lecturer in Chemistry. However, within a period of three months, because of this uncreative and monotonous work, I discerned that this was NOT what I wanted....I joined one of the country's largest NGOs, Agha Khan Foundation, in 1987 as a field coordinator but within a few months, due to my leadership and innovative strategies, I became the head of the women's empowerment program. 


\section{The First Job: A Saga of Accomplishment in the Face of Resistance}

Rehana described herself as being a "challenge to them [men]" during her first job. As she recalled, “There was strong resistance against the women's empowerment program that I was going to start for the first time in the most remote region of Pakistan." On the first day her male colleagues warned her that she "could never do this because 17 women staff who had previously tried to initiate the program had left their jobs due to resistance from the community."

Nevertheless, Rehana plunged ahead. To counter the community resistance, Rehana adopted various strategies, including learning the local language of Khowar, in order to effectively communicate with and engage women from Sun'ni and Ismaili communities to resolve tensions between the two sects. Within a period of five years, she established 160 women's organizations involved in organizing women of diverse sects to come together to improve their lives. Women in this region had never before been allowed to form organizations or make decisions side by side with men. However, the patriarchal and feudal mindset inside the organization did not accept Rehana and saw her innovative strategies as a threat to male leadership. Rehana's boss was from the local Mehtar tribe, the elite class in the region, and he endlessly detested her, not so much because she was a woman, but because she was not local.

Following her first hostile conversations with male colleagues, Rehana had a number of other experiences that allowed her to understand the hardships women leaders face in finding a space in the NGO sector. Despite doing remarkable advocacy work at Agha Khan Foundation, she describes her work with the Foundation as a somehow 
painful experience where she either was denied assistance in doing her work or faced propaganda by her male supervisors. She was forced to resign when her boss launched a strong campaign against her, claiming that she was "a non-local, city girl destroying our culture by involving women in development and advocacy work." In the end, she left the peaceful Ismaili community, the community she loved most in her life. "I built the trust of the community," she concluded, "but did not win the trust of the male staff."

\section{A New Environment, New Organizations, and New Challenges}

Rehana moved from Chitral to Islamabad, Pakistan's capital, with a broken heart but with the same passion for women's rights advocacy that she had brought to her earlier work with the Agha Kahn Foundation. Rehana joined another advocacy organization, Strengthening Participatory Organization (SPO), as a provincial head of province Khyber Pakhtunkhwa (KPK) and later acquired a country position as the director of the gender and development program. Besides forming small organizations for women's rights throughout the province, Rehana established and headed the largest NGO advocacy network, called Sarhad NGO Ithad (SNI). Under her leadership, the network did remarkable advocacy work. Rehana's most significant advocacy achievement at SPO, on behalf of the network, was successfully lobbying against a newly introduced NGO bill that would have limited NGO work.

Rehana remembered that the working environment, both at Strengthening Participatory Organization and Sarhad NGO Ithad, was very conducive to accomplishing her advocacy goals. Her family, particularly her mother and her husband, were also very supportive. Rehana traveled all over the country, from urban to rural communities, engaging NGOs in advocacy work for women's rights. Meanwhile, she got some 
international exposure of advocacy work such as participation in the World Conference on Women in Beijing in 1995. Through these experiences, she discerned that there was a huge trust deficit between the government and NGOs. She realized that NGOs' efforts would not bear any fruit without engaging government officials in efforts designed to promote policy change.

\section{Working Within the Government and as a Conduit Between the Government and the NGO Community}

Because of the realizations discussed in the previous paragraph, Rehana deliberately chose to work for the government in 2000 as an advisor to the minister for women's development, aiming to bridge the gap between government and NGOs. She then established a voluntary organization, Women for Women Trust Pakistan (WFWT), which was officially registered as an NGO in 2010. WFWT provided shelter to the victims of domestic violence, particularly those who lived in the most conservative region of Waziristan.

Rehana considers her work with the ministry as challenging but real. "By working with NGOs or donors, we learn skills related to project development and implementation," she said, "but working with government means developing good rapport, understanding the file system, lobbying strategies, principles and policies, negotiating, and working as a group both inside and outside the sector, and, particularly, balancing power within the sector to make policy change." Rehana became a bridge between government and NGOs, and, for the first time, the government of Pakistan submitted its pending CEDAW (Convention Eliminating All Forms of Discrimination 
Against Women) reports to the CEDAW committee of the United Nations after rigorous consultations with NGOs. All these consultations were facilitated by Rehana.

Rehana's increased comfort in the ministry allowed her to create more space for NGOs to lobby with members of parliament. These efficacious meetings set another historical milestone: the establishment of a separate Ministry for Women Affairs. In addition to these successes, however, Rehana often faced negative criticism from NGOs who classify her as a government ally rather than an NGO devotee. Such attitudes disappointed her often, but a succession of incredible accomplishments enhanced her confidence that, given the circumstances, her work within the governmental arena is the most appropriate and fruitful work to engage in for NGOs.

During the governmental phase of Rehana's advocacy work, she had many other accomplishments. It is worth noting, for example, that, in 2004, Rehana became the national project manager of the Women Political School under the Ministry of Women Development and the United Nations Development Program in 2004. Under her leadership, that school provided political education (especially education about the policymaking process) for 23,000 women counselors and 11,000 male mayors and deputy mayors.

\section{The Bottom-line Concern}

Throughout her career, whether working within the government or attempting to influence governmental action through NGOs, Rehana remained very focused on prowomen policies and laws, which is why she was on the frontline in facilitating NGOs to push the landmark women's rights bills when she was national project director for the Gender Reform Action Plan with the Ministry of Women Development in 2008-2011. 
Since Rehana was channeling the information between the NGOs and government, the process went quite smoothly and seven bills, including the Prevention of Anti-Women Practices (Criminal Law Amendment) Act 2011 and the Protection Against Harassment of Women at Workplace Act 2010, were approved. She also conducted extensive consultations with NGOs before submitting a Universal Periodic Review (UPR) report of Pakistan to the Human Rights Council of the United Nations.

\section{Falling Out of Favor}

Thus, Rehana's multi-sectorial approach could legitimately be judged to have been successful. And, on a personal level, Rehana was equally satisfied with her paid government work and her voluntary work with Women for Women Trust. Nevertheless, the situation became problematic in 2010 when WFWT established its office in district Dera Ismail Khan of province KPK and started working with flood affected people, primarily the Shia community. Now Rehana was more visible to the Taliban as executive director of WFWT helping Shia communities on the ground. The anger of the Taliban was amplified when Rehana was on the frontline of protests against the assassination of Punjab's governor, who spoke against the misuse of blasphemy laws. Working on minority issues revealed to Rehana that the resisting forces are outnumbered. Since the intensity of threats was increasing, Rehana registered a first information report (FIR) in the police station against unknown entities, but, unfortunately, the media breached her privacy, illegally obtained the copy of the FIR, and reported sensationally that Rehana was under severe threats by the Taliban. The news was covered by both national and international media, placing Rehana under fire. 
UN Women and the Ministry for Women terminated her job contract because she was a risk for the entire system. Rehana faced thick investigations by Pakistan's intelligence agencies since her name was marked as a person in conflict with the Taliban. The Taliban killed her nephew to warn her about the potential loss she might face in the future. Rehana was frequently changing living and working locations, and, except for a small circle of friends, people denied that she was a friend. Her extended family was pressuring her to either take a low profile or stop her human rights work. She could not find a support system for human rights defenders inside Pakistan or abroad. As she recalls, "The European Union has guidelines for human rights defenders but no one supported me in Pakistan when I came across the worst situation." Rehana received the same response when she approached Scholars at Risks, an organization that arranges "positions of sanctuary" at academic institutions for human rights defenders who are forced to flee due to high threats.

Nevertheless, Rehana was ready to pay the price for defending human rights. Her office was attacked and finally closed. The son of one of her employees was also killed. The feudal lords of the tribal region where WFWT was providing services to survivors of domestic violence became allies of the Taliban. They considered Rehana's work for violence survivors as a threat to tribal culture. The staff left their jobs and a few started to work from home.

\section{Resilience Has Been Her Ornament Since Childhood}

Considering the intensity of adversities, Rehana sent her only son abroad to save his life, but she declined opportunities to settle abroad. She remembered with tears in her 
eyes: "The day Sonu [her son] left the country, I felt like someone had separated me from part of my body." But she believed that "Sonu will be able to continue his studies abroad." Earlier in her life when she was almost the age of Sonu, Rehana was expelled from her city by the government because she led a protest of college mates against the military dictator Zia-ul-Haq. However, because of her resilient nature, Rehana always viewed adversities as a challenge to confront rather than stressors to avoid. "I went to another district. I could not continue my studies for two years; nevertheless, within these two years I read [experienced] sufficiently about the hardships of real life and learned how to cope with hardship."

Rehana has always been very aware of her island of competencies, as well as the turf of her weaknesses. Recalling the adversities of her childhood, she said, "I lost my childhood, but I learned political activism from the shop of my father I was looking after." Whether enduring internal challenges in Chitral or external challenges in Islamabad, Rehana nurtured her resilience and found the strength to accomplish what she could. Her husband was no doubt an immense support for her in this journey of triumph and destitution.

When the situation grew out of control, Rehana's husband took a job at a university in Europe, where they both stayed for one year. Rehana returned home recently with the same spirit she had in the past but many more risks to confront. Nevertheless, when Rehana landed in Pakistan, she went directly from the airport to the court to record her statement in favor of a petition about women voters in the Nowshehra and Lakki Marwat constituencies who were barred from voting. Rehana did this because 
she has always been-and will continue to be-a frontline human rights defender, no matter the circumstances, no matter the risks.

\section{Peter: "We Are Carrying the Legacy"}

With three master's degrees in law, political science, and rural development, as well as a business background in pharmaceuticals, Peter could not be stopped from an informal involvement in advocacy work. He worked voluntarily for years with diverse organizations ranging from church groups to political and international organizations such as Amnesty International. Eventually Peter joined the NGO sector professionally, working with the National Commission for Justice and Peace (NCJP) from 1988 to 2013. He is currently the executive director of the Centre for Social Justice (CSJ).

\section{Little Feet Marching for a Big Cause}

A father of two sons and the youngest brother of ten siblings, Peter, in his words, "grew up in an environment where justice was the central question." Peter vividly recalled his childhood: "I joined the first protest at the age of 11 when the government of Zulifiqar Ali Bhutto nationalized educational institutions including missionary schools.” The justice cascade remained a key focus of Peter's struggle in later years as well.

Peter recalled how the crusade for justice began at the end of his secondary school years: "On the $5^{\text {th }}$ of July, 1979 we had our final exams of matriculation. When we came out of the examination hall, we were told that the military had taken over the government," he remembered with detail. Two months after his graduation from secondary school, Peter was enrolled in college and "the environment of college was totally changed: agitations by students, arrests of students, arrests of teachers, 
campaigning for their release." Influenced by this environment, Peter joined the National Students Federation and used his natural writing skills to draft bills, petitions and newsletters. Initially he worked quietly, so quietly, in fact, that he did not get arrested. Later, however, he became engaged in public speaking. Peter particularly remembered that "someone who watched me making a speech predicted that I would become a good lawyer." Nevertheless, Peter's family believed that the advocacy work would ruin his life and, consequently, he said, "They wanted me to stay away from this context."

\section{Making a Conscious Move Towards Advocacy}

That observer's prediction came true: Peter did become a good lawyer, not a practicing solicitor but a strong advocate for human rights. During his education, Peter joined the family business; however, he gave up his role in the business after a few years because his heart was not in it. Peter recalled fervently, "The political environment and the resistance of political parties against military dictatorship made a huge impression on my consciousness towards a socio-political change." He added, "I [eventually] made a conscious decision to join the National Commission for Justice and Peace (NCJP) as executive secretary during fall of 1988." This was the high point of NCJP's campaign against bonded labor ${ }^{4}$.

As Peter remembered, the campaign "was the environment where unionizations of laborers started and, subsequently, those who joined unions were forced out of work." In the midst of this turbulent milieu, Bishop John Joseph, NCJP chairman, was providing food and shelter to evicted families while, simultaneously, Peter was consciously

\footnotetext{
${ }^{4}$ Bonded labor is the most widespread - yet the least known - form of slavery in the world. A person becomes a bonded laborer when their labor is demanded as a means of repayment for a loan. The person is then tricked or trapped into working for very little or no pay.
} 
employing various advocacy strategies such as agitations, press briefings/releases, research studies and litigation for protecting the rights of laborers. The advocacy phase ended with Peter's first success: "The high court went on to ban...advancing money to laborers, the money which inevitably becomes a trap for enslavement." After this success, big expectations and more challenges were ahead for Peter.

\section{Broadening the Horizon, Bridging the Divide}

"Bishop John Joseph went on hunger strike," headlines in the country’s newspapers proclaimed. Other headlines about what specifically Bishop Joseph was challenging with his hunger strike followed his demand that the government reverse its decision to include a religious column on the national identity card: "The inclusion of [a] column for religion in National Identity card is a discrimination against minorities." The daily headlines left a lasting impression on people inside and outside the country. People were especially concerned that the bishop had gone on a hunger strike. The Christian community was determinedly mobilized leaving an opening for Peter to exercise his leadership. Besides "preparing press releases and talking to press" and being the executive secretary of JPC Major Superiors, a sister organization of NCJP, Peter was on the frontline in this countrywide campaign or movement. He was engrossed in designing and shaping the campaign, expanding and ensuring multi-stakeholders, preparing campaign material, and "making public speeches" about the negative consequences of the government's decision to include a column for religion on the National Identity card.

People soon realized that the government was not paying any attention to the matter. When the campaign reached a tipping point, the Christian community took a rather dramatic action: Eight villages came together and "blocked the national highway 
for eight hours." Since these were predominantly Christian villages, thousands of people were on the road, blocking the national highway but in a peaceful manner. The government eventually stepped back from its decision to include the religion column. In 2003, because of his tireless efforts for this campaign, Peter became the executive director of the National Commission for Justice and Peace. Under his visionary leadership, NCJP grew from a small organization of three people established by the Catholic Church into one of Pakistan's largest faith-based human rights organizations with eight offices all over the country, 500 volunteers and 46 staff members.

\section{A Difficult Balance}

NCJP has a very unique character as a church-based human rights organization. Consequently, Peter noted "It is a difficult balance to keep our neutrality in the civil society. We have difficulties in maintaining the requirements of both a secular society organization and a faith-based organization." Because donors prefer to fund the interreligious or inter-denominational organizations, "our impression as a Catholic organization was a reason for reluctance of donors," Peter explained. He also felt that donors require tangible results within a limited time span, but it is difficult for an advocacy organization like NCJP to point to solid short-term results.

Peter remembered that NCJP submitted the CEDAW (The Convention on the Elimination of all Forms of Discrimination Against Women) shadow report, which was the first ever civil society report to the CEDAW committee of the United Nations. In 2012, NCJP submitted the CEDAW report jointly with the Aurat Foundation, the most distinguished advocacy organization in Pakistan. Despite all these obvious accomplishments, however, some donors preferred to work with religiously neutral or 
religiously more diverse organizations. Peter recalled that UN Women financed the study on religious minorities and women, but they were reluctant, at the end, to lend their name to the study because they wanted to keep out of trouble and to avoid criticizing the bureaucracy of Pakistan. So Peter's organization complied with the donor's demand by leaving the donor's name off of the report. Still, because of this report, the CEDAW committee, for the first time ever, mentioned minority women of Pakistan in their recommendations.

The unconventional work of NCJP, such as taking care of victims of blasphemy laws, "further increased the difficulties, particularly the security of the staff." Peter knew that activists having majority (Muslim) faith backgrounds could manage the risks of their work because of their "socio economic influence and linkages with the government body, but non-Muslim activists do not have many contacts within power circles."

\section{Paying the Price of Advocacy Work}

Despite employing thoughtful and somewhat cautious (but still effective) advocacy approaches during his 26 years of involvement with a church-based human rights organization, Peter has a bucket of harsh memories resulting from his advocacy work. He agonizingly recounted several painful incidents:

I received my first threat in 1998 when I had to send my sons and wife to live with a family friend. In 2001, our Karachi office [Sindh province] was targeted by extremists. Seven of my colleagues were assassinated. That was our first office, very well managed, very well respected in civil society. It was a huge shock. Consequently, we first shut down our office and later all of the activities in that region.

Although this particular situation was not repeated in the rest of his years with the organization, 2008 was another perilous year for Peter when "the whole commission 
[National Commission for Justice and Peace] was targeted.” The government accused NCJP of distributing banned material. Consequently, besides threats from various corners, the intelligence agencies started a massive investigation that disturbed Peter's organization and family equally. Peter sent his sons abroad to save their lives when they were quite young. Also, Peter noted, "In 2011, information was leaked that my name appeared on the hit list of an extremist organization. In 2012, one of my staff was shot fired and another was kidnapped when an unknown person barged into my office." Sadly, such threats were not limited to the provinces of Sindh or Punjab; Baluchistan province also was increasingly becoming a dangerous area for Peter and his employees, too, and subsequently their activities became limited to only Quetta City.

\section{The Legacy of Passion and Compassion}

In addition to all of these threats, it was also very intimidating and harassing for Peter when, on the one hand, extremists were making public announcements that NGOs were following Western agendas, while, on the other hand, government agencies consistently were monitoring both the advocacy work and the personal lives of NGO leaders like Peter. Nevertheless, Peter's great sense for fairness and justice encouraged him to believe that, while his struggle was hard, it was also meaningful, and, therefore, he must continue.

Passion and compassion are the defining characteristics of Peter's soul. Since he had learned to live for others, his work was his contentment. He passionately stated that he is carrying forward the prophetic legacy of Jesus, who lay down his life and did not disappoint his people, his disciples or his followers. Peter added that he is also carrying on the legacy of the founder of NCJP, Bishop John Joseph, who offered a self-sacrifice 
when innocent Christians become the victims of blasphemy laws. Peter posed a question: "Why would someone [staff] who was being detained still be willing to work with NCJP?" Then he quickly answered his own question: "It is all because of the legacy."

Peter believed that his staff and board members of NCJP also will carry this legacy of passion and compassion forward. As he recalled, "We laid down, we buried our dead, we cried, we laughed during our hard but meaningful struggle." Unquestionably, the situation on the ground was not happy, but the shared joy and success kept him and the members of his organization going.

\section{Morning Walks and a Circle of Friends}

During an interview, Peter mentioned a number of things he did to sustain himself during difficult times. One thing was maintaining his physical well-being. Despite the fact that Peter could not go for morning walks without someone watching his security, he continued to take morning walks. Through walking and exercise, he said, he nurtured his personal capacity for advocacy: "I take care of myself. I take my morning walk, my exercise. I take my pills and some rest along with healthy food."

Peter also relied on family and friends to sustain him. Although Peter's family strongly opposed his work in the early years, with the passage of time, they recognized the importance of the work. Peter's appearance on national and international media, as well as his meetings with important people to advocate for human rights, built the family's confidence. Knowing the worth of his work, Peter's wife and sons always encouraged and supported him. The story was the same with his friends. "It is a circle of friends who will give you a [safe] place if you need, who will go to court accompanying 
you, and, of course, be a moral support." Peter's friends also included the people and villagers who supported him during various campaigns.

But Peter was not only concerned about himself. He also employed several strategies for cultivating the personal capacity of his staff so they could sustain their advocacy work. Such strategies included in-house trainings, participatory planning and implementation of projects, and using writings published in newspapers or magazines as a means of indirect conversation with colleagues and volunteers.

\section{Conscious Adaptation: A Resilient Pathway}

Over the course of his 26 years working with NCJP, Peter has gone through many ups and downs, but the last seven to eight years have been especially hard on his organization. As a consequence, he and others in his organization have become more conscious of their environment and built their resilience to reduce professional burnout and other ill effects of a stressful work environment. Therefore, NCJP staff turnover has been exceedingly limited. In his 26 years working with NCJP, in fact, Peter encountered only one staff member who refused to work under scary conditions. Nobody was naïve about the risks associated with working for an organization such as NCJP, but Peter and his organization have done what they could to manage and minimize the risks. Several security measures that Peter employed included security trainings on physical and digital security, developing a security plan and functional protocol, putting up a security grill, recruiting a security coordinator, setting aside some money for each staff member to take care of security expenditures such as having extra telephones.

In addition to these security measures, Peter developed strong personal resilience strategies that enabled him to undertake his work for decades in a turbulent environment. 
He described his staff as "resilient" and "courageous," and he indicated that staff members actually helped him in developing strategies to promote resilience. "We almost stopped giving press statements," he said, indicating that communication with the press occurs less frequently now. He added: "We have modified our working strategy for the national issues. So we would rather work on campaigns through channels and personal meetings than by relying on media campaigns and mass mobilization." For instance, "an NCJP campaign on biased education ran for nearly two years in a very controlled session. We switched to working through channels to reach out to decision and opinion makers rather than engaging fierce public advocacy."

Since English print media is less prone to problems, Peter stopped publishing the report "Insani Huqooq ka Ja'ayza" in Urdu because "it carries several mentions of very sensitive issues such as blasphemy and forced conversions that can be manipulated." But his organization continued to publish the report in English. Peter also became more cautious about the issues his organization addresses. "After 2011's two high profile assassinations of men in the same vision and movement, Salman Taseer ${ }^{5}$ and Shahbaz Bhatti $^{6}$, we have kept the issue of blasphemy laws and repeal of these laws on the back burner," Peter said. Nevertheless, despite all these measures, the situation became even more precarious for Peter. Eventually, in 2013, he took a sabbatical leave to complete his law education in the United States and to take time for reflection and assess his capabilities and limitations.

\footnotetext{
${ }^{5}$ Salman Taseer, governor of Punjab, was shot dead by his guard because the guard was in disagreement with Taseer's opposition to the blasphemy law.

${ }^{6} \mathrm{He}$ was the first Federal Minister for Minorities Affairs from November 2008 until his assassination on 2 March 2011 in Islamabad. Bhatti, a Roman Catholic, was an outspoken critic of Pakistan's blasphemy laws and the only Christian in the Cabinet. Tehrik-i-Taliban Pakistan claimed responsibility for his killing and called him a blasphemer of Muhammad.
} 
After one year, Peter returned home to continue his advocacy work, and he established the Centre for Social Justice (CSJ). While the new leader has assumed full responsibilities at NCJP, Peter remains involved in the NCJP as an advisor for one project, editing a study on textbook content analysis, and a resource person for seminars. Moreover, he has assumed the role of a convener of Awaz-e-Haq Ittehad (Voice for rights), a network of 12 likeminded organizations working on unbiased education. His reinvigorated involvement in the movement for human rights in Pakistan is evidence of Peter's skill at overcoming roadblocks. It also demonstrates his commitment to carrying on the legacy of passion and compassion in his resilient journey.

\section{Tahseen: A Fearless NGO Leader}

Tahseen, a 58-year-old father of two children, has a master's degree in Public Administration. He started his career as a government employee during General Zia's last years of dictatorship in the 1980s but was, in his words, "fortunately kicked out." $\mathrm{He}$ then worked for three years with the Family Planning Association Pakistan where he directed youth programs and was responsible for organizing unskilled, unemployed rural youth. Nevertheless, the prevailing political environment in the country led him to set up an "advocacy and development organization," the South Asia Partnership Pakistan [SAP$\mathrm{PK}]$ in 1987, just one year before the lifting of martial law in Pakistan. Within a few years, Tahseen became the executive director of SAP-PK and under his 30 years of insightful leadership, SAP-PK has grown into a huge organization with 241 staff working at the national level. 


\section{Yearning to Speak Out}

Although Tahseen has been diligently working for more than three decades to chase his dream of a democratic Pakistan and a peaceful South Asia, he does not consider this work “anything extraordinary." He recalled the 11 years (1977-1988) of martial law when fundamental rights, particularly the rights of freedom of expression and freedom of association, were totally put on hold. He remembered, specifically:

We started working right at the last leg of martial law when people were dying to speak out. Therefore, I didn't do anything extraordinary. Rather this kind of advocacy work was a need of the time. It was truly political commitment, courage and a dream for peace.

Tahseen traced his footprints of advocacy work as a student: "During my student years, I voluntarily worked for the trade union movement and then took part in leftist politics. We were going to universities for group organization and mobilization.” He added: "I never thought I needed a degree in people's mobilization because it was all there.” Following that experience of political activism in student life, Tahseen embarked on a larger journey of learning related to his advocacy work - a journey that would never end.

\section{Meeting the Gurus and Finding a Path}

Tahseen described himself as "very fortunate for having a lot of learning opportunities from the big names" of the NGO sector in South Asia — people such as Rajni Kothari, Akhter Hamid Khan, Nigar Ahmed and Arif Hasan who served on the board of SAP-PK. Despite the vindictive experience of Pakistan's martial law period, Tahseen learned from these gurus "to bring together common people's voices in South Asia." South Asian commonalities, he explained, are poverty, illiteracy, disease, and 
water crises - issues that could only be addressed if "we bring peace in the region and talk about friendship and brotherhood; it's actually an advocacy."

Because Tahseen's organization empowers communities to advocate for their rights and to get their services through government, SAP-PK is not, Tahseen argued, a service delivery organization. And their focus with women and minorities is to demand peace, justice and equal rights for all Pakistanis. "I would say we are more of an activist development advocacy organization," Tahseen said, but "if we become a health provider organization or water or sanitation experts, naturally we will be crediting all those powers that the government doesn't like. As an advocacy organization we have enormous challenges."

\section{Good Days Are Gone}

Tahseen immersed himself in the past to recall stories of struggle and sanctuary. He vividly remembered the early days of advocacy work with SAP-PK when working in the Sindh and Baluchistan provinces was the easiest thing to do and the most successful. "We would openly say 'Oh, Sindh was like a heaven," Tahseen whispered. Now, sadly, the growth of extremism in Sindh is unbelievable. The madrasahs ${ }^{7}$ are no longer limited to male madrasahs but now include girls' madrasahs as well. And in Baluchistan, those "who never wanted to be part of any nationalist militant organization have now become members." Tahseen quoted an activist who told him: "When a Punjabi barber who cut my hair and my family's hair for the last 25 years was murdered for being a Punjabi, I could not mourn his death because I am a Baloch." Tahseen explained that NGO leaders are under threat, "threats from militants, threats from local boundaries and threats from

\footnotetext{
${ }^{7}$ A madrasa is an educational institution offering instruction in Islamic subjects including, but not limited to, the Quran, the sayings (hadith) of the Prophet Muhammad, jurisprudence (fiqh), and law.
} 
both military and intelligence agencies." He added that the state and state institutions are still very colonial and, consequently, activists do not have the right to speak out with independent opinions.

\section{We Have Lost Many Activists}

"I lost my friends in province Pakhtunkhwa," Tahseen said, describing the killings of NGO leaders as his biggest challenge. "They have been killed either by agencies or militants, but it's absolutely difficult to differentiate who killed them." His organization has been pursuing those cases, however, Tahseen emphasized: "It's unfair to say that the military agencies killed them." He reported that a dozen of his colleagues, all innocent, were killed in Baluchistan. They were neither part of any nationalist movement nor part of any agencies. A doctor sitting in his clinic was killed just because he was not part of a political party.

Local ethnic politics, coupled with other issues, deeply affect the people involved in advocacy work, Tahseen explained. He also mentioned that in Pakhtunkhwa the religious factor is more significant because the people are literally Talibanized. Therefore, working in the Hazara community, where many have been killed by the militant organization Lashkar-e-Jhangvi, has been very difficult. "We lost many of our activists," Tahseen said.

\section{Feeling No Fear}

Despite being disheartened by the killings of dozens of his organization's activists, Tahseen has been committed to moving forward with this understanding: "If you get into this kind of work [advocacy], then these are the challenges one has to face." 
He added, "I am not scared at all but I am, of course, concerned about the security of my colleagues."

Tahseen emphasized that so-called intelligence agencies could impede advocacy work rather than killing the NGO leaders. He believed that "intelligence bureau people would assign people to impede my work, but I never said that my life was at risk."

Tahseen indicated that he recently received threating phone calls from Taliban agents but not from agencies, and even then he did not feel threatened. With the passage of time, he learned how to convert his opponents into allies. "I know some characters," he said, laughingly, "majors of military intelligence, who later became family friends."

Tahseen also discerned that many NGO leaders are now well known to intelligence agencies, and the intelligence agencies consider NGO leaders to be major stakeholders. "In the old days, if you went to India," he remembered, "you would get hounded by agencies. But within the last 15 years, agencies know that these are characters [NGO leaders] who would not stop." The government feels particularly scared of his work, Tahseen said, when he and other group members advocate for the rights of marginalized sections of society at international forums. Although some NGO leaders felt the heat for speaking at international forums after returning home, Tahseen never felt any fear, despite his organization working on some reports, submitted to the U.N. that did not always portray the Pakistan government in a positive light.

\section{Working with the Government: A Strategic Engagement}

Tahseen's receptive and impartial attitudes towards government and government institutions were developed over the years through his several interactions with various governments. He remembered a time in the 1980 s when "it was [a] martial law period 
and, since we didn't recognize the military government, most of the time we were in the streets demanding a democratic government." But even with the restoration of democracy, "we agreed that there is a need to work with the government for defending our position on government policies in front of our government."

Subsequently, along with other NGO leaders, Tahseen started working with various government departments, such as the "home department, [the] education and health department and [the] planning division, to bridge the gap between government and society." Tahseen believed that NGO leaders needed to work with the government at all levels to define government policies. Tahseen recognized that "people like us [i.e., advocates] should be part of various government committees at local and national levels." He, himself, became a member of several committees, such as the Federal Planning Commission's committee working on rural development and devolution.

\section{The Role of Donors}

Tahseen's strategic shift toward collaboration with the government seemed like quite a fervent effort to make advocacy work effective; however, he described an utterly conflicting opinion about for-profit institutions. He noted that Shell, Toyota and Unilever have been giving money for education and the elimination of violence against women with a sense of their responsibility towards the community and environment. Nevertheless, for Tahseen, "It's guilt money. 1\% does not make sense. Why not give one car per day? I do not go to such companies because of our clear political and strategic position."

Despite having a very strict strategic position towards for-profit institutions and knowing that "it's very challenging to find funders in Pakistan," Tahseen's organization 
remained very fortunate in getting regular financial support. He worked with a maximum of four to five donors during a period of more than three decades. Tahseen also denied any pressure from donors regarding their disinclination for supporting advocacy work, so “it is entirely up to us to pick up [an] area of work which suits us." He also mentioned, "We have huge funding from DFID [The Department for International Development] for our accountability program which is advocacy work."

During his years-long advocacy work in Pakistan's turbulent environment, donors have been well aware that the whole Pakistani society is the captive of extremists and militants, and, therefore, "they could not expect tangible results of advocacy work from NGO leaders." Furthermore, "it would be foolish for any funder to think 20-25 organizations in any country can bring a political change." Tahseen believes that "change will come through parliamentary democracy," and NGO leaders need to support and facilitate democratic governments, regardless of the turbulent circumstances they may be going through.

\section{Taking Care of 241 Employees}

As a director of an advocacy organization, Tahseen acknowledged that his colleagues have been working in a very risky environment and, therefore, need special security measures. Five years ago when Swat Valley was totally under the Taliban's control, Tahseen, as director, reformulated some strategies and asked his colleagues to continue their work but in a different manner. As he described it, "We started working with widows who lost their sons and husbands in war and generated economic activities for them rather than doing advocacy work." 
Tahseen also arranged security training for his employees to minimize their risks. Tahseen remembered, in particular, that "when my male and female colleagues were chased by militants in Bannu, they immediately took a reverse and went back, due to the security training they'd gone through." But the most significant aspect he shared was his strong bonding with his employees: "I have 241 full-time employees and I know the families of every one - from cleaner to coordinator. I visit their houses. It takes some extra burden and time, but this is what I do to keep their morale high. I care about them. I miss them. And they miss me."

Despite this care and affectation for his staff, Tahseen kept telling them that they are in this business because of their own choice: "If they don't feel secure, don't do it." Tahseen believed that people came into this kind of work with a clear, conscious decision.

\section{Friends in Triumph and Turbulence}

Since this bonding is reversible, Tahseen described himself as "fortunate, very fortunate" because he has a large number of close-knit friends who care for him sometimes overly care for him. He has a circle of friends, both inside and outside the country, who immediately respond to him if something happens. As Tahseen remembered, "When there was a bomb blast in Lahore, the first phone call I received was from a Canadian friend working in Jordan....'I hope you and your children are safe."” He added, "When there was a firing in Gulberg next to my neighborhood, the first call came from India; a friend of mine inquired, 'Are you safe?"' Tahseen received an unbelievable number of emails and phone calls from all over the world after a school 
attack in Peshawar. Tears of joy flowed down from his eyes as he posed the question: "This is the kind of friendship I have. Is it not rare?"

Tahseen learned to trust people and established district level forums comprised of people from all walks of life. He considered these people his all-time friends who escorted him in triumphs and turbulence. Tahseen felt that with the support of friends, he has made some difference during the last 20 years. He proudly shared that he sent a single email to friends after the school attack in Peshawar, encouraging them to organize an event, whether small or big to condemn the incident. He continued, "Suddenly from every district I got responses and events were organized in all four provinces.”

\section{You Cannot Stop Breathing}

Tahseen took a deep breath before noting that "there is a bad policy or incident of violence every day in Pakistan." He wished he could do something more to respond to the violence. Nevertheless, whatever he did or has been doing is like breathing for him and, as he said, "You cannot stop breathing." He has done more than his share to make Pakistan a peaceful country. His organization, he explained, "changed the strategies [over the years] but never changed our principle position." He noted that after the assassination of Governor Salman Taseer, all advocacy work was shut down and a complete silence followed, but our "principal stand was that this is a discriminatory law that should be repealed." Nevertheless, this was a strategic silence, one that showed that "this is not the time to take the same position." 
Tahseen found himself "quite deeth". As he described it, "there is a stubbornness in me to fight against injustices. You may call it resilience, but it's more than that." And, surprisingly, he has remained hopeful. Tahseen believes that there is change, sometimes visible and sometimes less visible.

\section{Shad: Inspired by Her Father's Social Work}

Shad, a young NGO leader and the mother of two children, was born in 1979 in the backward Talash area of the Lower Dir District of the Malakand Division of Pakistan. Inspired by her father's social work ${ }^{9}$, Shad stepped into the human rights movement at an early age, and, eventually, founded her NGO, Association for Behavior \& Knowledge Transformation (ABKT), in her native village. Unfortunately, her organization was uprooted during the Taliban take-over and the massive displacement of people in the Swat Valley in 2009-2010. Shad then moved to the capital, Islamabad, to continue her advocacy work.

Shad is an Ashoka fellow ${ }^{10}$ and the executive director of ABKT. She was awarded the "International Women of Courage Award" in 2012 by the U.S. Department of State.

\section{Wonders of Childhood}

Although Shad's family was very conservative and had a political affiliation with a religious political party, Jamaat-i-Islami, Shad, at the young age 8 or 9 , often sat on the

\footnotetext{
${ }^{8}$ An Urdu language word for determined.

${ }^{9}$ Her father was a senior volunteer with Idara Khadimat-e-Khaliq, local community based welfare organization.

${ }^{10}$ Ashoka Fellows are leading social entrepreneurs who we recognize to have innovative solutions to social problems and the potential to change patterns across society.
} 
stage with her father and other male politicians during political events. Shad recalled great memories of childhood: "Jammat-i-Islami was the strongest political party of the area," she said, "and my father was one of the most active and influential political leaders. He often took me to political demonstrations, and I memorized many slogans and chanted them loudly again and again in the processions and political gatherings." However, when her father started engaging her in the social work activities, the party leadership and other members criticized him. Shad stated, "When my father realized that his affiliation with this political party is becoming hurdle in engaging his daughter in social work, he decided to become politically inactive and supported me in pursuing my career as a woman social activist."

When Shad graduated from school, her father took her to Peshawar, the capital of Province Khyber Pakhtunkhwa. Shad met many of the most renowned and respected female NGO leaders, such as Hashmi, Maryam Bibi and Rakhshanda Naz. "My father told me that I wish to see you a leader like these women," Shad stated. Nevertheless, when Shad returned to her village, she questioned:

Why are the women of Peshawar so different from the tribal women of my village? Why are they so bold and inspirational? Why don't our women have access to education, health and livelihood? Why don't we have choices on how to live our lives?

\section{Self Versus Community}

The differences between the women's status in the capital and their lives in her village impacted Shad so deeply that she refused to pursue higher education after high school graduation and announced that she immediately wanted to begin serving the women of her area. She recounted, "My father was surprised when I told him that I was 
not interested in regular studies, and that I wanted to help uplift my community while continuing my studies privately." Her father, who dreamed of sending Shad to a university, finally consented to support his beloved and only daughter. Shad continued, "I was so happy my father agreed with me. He established an office for me at home so I could work in a well-organized manner." Shad started traveling to far-flung tribal areas to listen to women's problems and to seek solutions at the platform of Idara Khadimat-eKhaliq, a local community based welfare organization. Shad experienced many ups and downs while working with these women. She recalled:

Initially women were very shy and were not ready to form a group. I worked hard and organized them. Some of them were married. They joined us, but later they left the group because their husbands stopped them from working with us.

However, Shad never lost hope and worked with more power and passion. In the meantime, she learned that working with Idara Khadimat-e-Khaliq somehow limited her options, and she successfully negotiated with the Idara Khadimat-e-Khaliq leadership to get their support for establishing an independent organization.

\section{First Ever Registered NGO in Malakand Division}

In 1994, Shad and her fellow women finally established Anjman Behbood Khawateen Talash [ABKT], which later became known as the Association for Behavior $\&$ Knowledge Transformation with the same abbreviation [ABKT] as the original name of the organization. This was the first registered NGO under the social welfare act in Lower Dir, Malakand Division (Tribal Area influenced by the Taliban). Shad joined the $\mathrm{ABKT}$ as a member, but soon she became the executive director not only because of her leadership skills but also due to the freedom her family gave her. Shad noted, "I was allowed to go anywhere to mobilize communities. Unfortunately, other women, despite 
being active, do not have the freedom to take part in all activities of the organization" because of restrictions imposed by the male members of their families.

While other NGOs were working on regional and global networking, Shad's organization was struggling to link this much excluded tribal Malakand Division with Peshawar and Islamabad. Shad recalled:

First we worked for education, free tutoring and enrollment of girls in schools, and then we focused on registration of national identity cards for women so they can get their national identity so they can be allowed to vote or own property.

Finally, Shad's passion and dedication to her team helped ABKT develop strong linkages with public and private institutions in Malakand Division, Peshawar and Islamabad. After completion of a successful project on forestry with the Dir District Development Program (DDDP) and Social Forestry, ABKT focused equally on women's empowerment and organizational development with the support of national and international donors, such as Trust for Voluntary Organizations [TVO], Civil Society Human and Institutional development Program [CHIP] and Asia Foundation. "With the support of CHIP, we developed our strategic plan and new management system," Shad shared joyfully. The people were so proud of Shad's leadership and her remarkable work in the area, and they often called her Benazir Bhutto. ${ }^{11}$

When ABKT's advocacy work and Shad's activism were highly successful, the Taliban took over the area, resulting in a massive displacement of people in 2008. With sadness, Shad said:

\footnotetext{
${ }^{11}$ Mohtarma Benazir Bhutto was a Pakistani politician who chaired the Pakistan People's Party (PPP), a centre-left political party in Pakistan. Bhutto was the first woman elected to lead a Muslim state, having twice been Prime Minister of Pakistan (1988-1990 \& 1993-1996). She was Pakistan's first and to date only female prime minister.
} 
I left Dir in 2008 because of severe threats from the Taliban. When I left Dir, I left everything. I left behind my two kids with my mother-in-law and my husband. It was all very painful to save my life at such a high cost.

Shad lived for six months in Islamabad without any support. She was neither able to move around in the town due to threats on her life, nor could she continue her work. There also was a mismatch between skills and orientations developed in a rural area, on the one hand, and the way advocacy work was undertaken in the city. Shad summed up her situation as follows: "Islamabad was a big city and my expertise of grass roots activism didn't match with the advocacy work of NGOs in the capital. Everything was just like a zero."

\section{Starting from Scratch, Then Moving Toward Success}

Since Shad had to start her work from scratch and find a space to rebuild her advocacy work, she moved from Islamabad to Peshawar, the capital of Province Khyber Pakhtunkhwa. "I used my savings and established an office, and I asked the Ashoka network to help me," she reported. According to Shad, this was the time when, besides the enormous presence of INGOs and UN agencies in Pakistan, a large number of internally displaced persons (IDPs) from Shad's area were settled in IDP camps in Swabi, Mardan and Peshawar. She was again with her people: "I was regularly visiting IDP camps, working tirelessly with IDPs, listening to their stories and establishing linkages between IDPs and UN agencies plus INGOs." Shad came back to her advocacy work with more expertise and a greater appreciation from her people. Subsequently, through her leadership and her strong linkages with INGOs and donors, she established three offices in Malakand with a staff of 45 people. 


\section{Practicing What She Preached}

Although Shad advocated for education, political empowerment and health improvement for women by challenging cultural taboos and harmful traditions, she, herself, decided to run for political office when people in her area threatened other women for participating in elections. She declared, "I challenged Jirga (customary court) decisions, and I challenged the people who were propagating against women.” Consequently, she received severe threatening letters and had to swallow abusive talk from her husband, father and other family members who feared that her enemies, in her words, “will kill me, my kids and family if I don’t stop this election campaign." Shad won the election and became the tehsil councilor ${ }^{12}$ as an independent candidate. She was very happy that "despite a huge opposition, I won the election....a big victory for me." Since Shad was now having her feet both in politics and social work, the two dimensional nature of her work enhanced her intellect and visibility.

\section{Advocacy, Awards and Alarms}

In the midst of severe threats, Shad's name was announced for the "International

Women of Courage Award" in 2012 by the U.S. Department of State. She said:

It was the most critical time to decide if I should go to the USA to receive this award. I consulted many people and finally accepted the award with an understanding and pride that this award recognizes the talent, hard work and hardships of all Pakhtun women.

The hype generated by international and national media created an inner conflict for Shad. On the one hand, severe threats suggested that she should stay abroad for her own safety, but she rejected this idea, arguing, "Risk is everywhere if I continue my advocacy work." On the other hand, Shad felt honored when Michelle Obama and Hilary Clinton

\footnotetext{
12 The tehsil is the second-lowest tier of local government in Pakistan. Each tehsil consists of a tehsil council comprised of tehsil councilors who plan and implement government policies and programs.
} 
praised her work at the award ceremony, and even her opponents spoke highly about the achievements of a Pakhtun girl as well as her appearance (she wore traditional dress to respect her culture) during the ceremony.

Nevertheless, the net result was nerve-wracking. The evening Shad received the award, her family received acute threats. "My kids were very happy to see their mom on TV that evening, but suddenly the awful threats shook and frightened the family," Shad recalled.

\section{Between Highs and Lows}

After receiving the award, Shad went back to Peshawar to continue her advocacy work; however, sensing the gravity of threats, "security agencies suggested that I leave Peshawar." Shad moved to Islamabad again and maintained a very low profile for several months. "I still keep a very low profile because of threats, but I have managed and expanded our advocacy work from Malakand to Hazara Division," Shad said. After many years of working successfully with the government, ABKT created a sense of support from security agencies; however, Shad observed that, sometimes, "it's hard to recognize where the threats are coming from." She also mentioned that, besides threats on their lives, leaders of NGOs face ongoing financial threats: "I wish I could get even a small regular financial aid grant, so I could put all my energy into my work rather than paying attention to finding resources for survival," Shad noted. She said that her staff is very committed to working in a friendly environment, but she argued "when a project ends, staff often leave the organization because they have to meet their own financial needs." 


\section{Staff Commitment to Advocacy}

Despite all the threats and challenges, Shad affirmed, “I can't compromise with my advocacy work, particularly for women." Therefore, to continue her work, she used various strategies internally such as security training for staff and volunteers, security guards, security cameras, and friendly relationships with her staff. Shad prefers to recruit local staff members who understand the cultural sensitivities and power dynamics within communities. Shad keeps the staff close to her heart, so they can convey their problems to her with great confidence. She said:

My staff knows about the threats, but they are equally aware of the importance of the advocacy work we are engaged with. They saw a lot of people killed in the area. A number of NGOs stopped working in Dir, but our staff, including female workers, are running projects with incredible commitment and courage not only in Dir but also in Hazara and the FATA region."

\section{Community Engagement, Networking and Litigation}

To cope with the external threats she wisely expanded the strategies she employed in her advocacy work. Shad's staff extensively engaged the communities in advocacy work and, as a result, Shad's organization has a large number of volunteers. She ecstatically described the strength and activism of ABKT: "Our staff and volunteers are very committed to organizing activities even in hard areas." Shad elaborated on her strategies: "I am using two sorts of networks: social networks (such as Facebook and Twitter) are messengers for getting support on women's issues through information sharing; while national and international networks are tools for policy change." Shad, as a member of the End Violence Against Women (EVAW) Alliance, contributed the material on the issue of violence against women for the Convention on Elimination of All 
Kinds of Discriminations against Women [CEDAW] Shadow Report, submitted to the CEDAW Committee at the United Nations.

Shad acknowledged the care she got from her friends from the NGO sector who supported her whenever she "challenged the decision of a Jirga against women or filed a petition in the Election Commission of Pakistan on behalf of women voters in her area who were barred from casting their votes." While living in Islamabad for many years, Shad acquired the expertise required to do advocacy work through an elite NGO based in Islamabad. Shad remembered that once, due to a dearth of expertise, she left Islamabad and moved to Peshawar. However, the learning and sharing nature of Shad always fortified her to, "have some friends, experts and supporters around to maximize the impact of my work." Shad felt fortunate to have messages of support and solidarity from inspirational NGO leaders whenever she received serious threats. She was also grateful to the media who always profiled her positively.

\section{Resilience is Her Motivation}

Although Shad received encouragement from friends in the NGO sector and consistent support from her father, brothers and husband for her advocacy work, she believes that during adversity, "motivation comes from inside." Shad expressed frustration that her family expects a great deal from her: "From my father to my kids, they see me as a strong woman. Even knowing that I am a full-time working woman, my mother-in-law wants me to take care of everyone and everything at home." These family expectations and her long meticulous struggle for human rights sporadically brought some weaker moments in Shad's life. She lamented, "I never had the opportunity to enjoy vacations or even weekends with my family or friends. I often feel that I should set 
aside all these responsibilities and find sometime for myself." However, Shad continues to find "power from inside" to manage her stress because her family, staff, and community all want to see her as a "strong woman." This innate energy enabled Shad to fulfill the needs of family, staff and communities. She described that "I take care of my kids, their education and even their small needs. I love them, but I also prepare them for any adversaries."

Shad commented that "Since I have a lot of flexibility, I survived in all critical situations." She further shared her personal practices that promote transformation: "Every day I reflect on my working strategies. I learn a lot of things but never get disappointed. I review my work to improve it further." Clearly, it was Shad's resilience that kept her and ABKT thriving during times of turmoil.

\section{Tanveer: Evolving from a Challenger to a Leader}

Tanveer, a renowned human rights advocate, is a 53-year-old woman with a Master's degree in philosophy and a number of diplomas in international human rights. Besides being the executive director of the Democratic Commission for Human Development [DCHD], an NGO, she also holds several important concurrent positions. She is an executive member of the National Commission on the Status of Women, a consultant for the Norwegian Human Rights Fund, and a country representative for the Label STEP Switzerland. Tanveer traced the roots of her efficacious advocacy work to her childhood when she was completely unfamiliar with the word advocacy, but she was fully aware of her responsibility for helping the most marginalized members of society. 


\section{Understanding and Supporting the Marginalized}

Tanveer was born and raised in a mostly poor community where communal culture and community ownership were the fundamental features. She recalled some childhood memories where "people were so much engaged with each other that we were not able to recognize our individual belief systems or sects."

Gender discrimination was Tanveer's biggest challenge in childhood, she also learned to face these challenges at a very early age. "Even in my childhood; I was a kind of a Tom boy playing Guli Danda [a traditional game for boys in Pakistan], but having sufficient leadership skills," Tanveer stated. For example, she made conscious efforts to convince neighboring aunts to allow their daughters to attend school.

Although there were mostly poor students in the co-educational community school where Tanveer studied, some students from influential families often acted superior and inhumane towards the poor students. Tanveer joyfully recalled a series of her childhood actions through which she courageously supported the most marginalized:

Once a poor child told me that the rich guys had beaten her, so I consoled her and asked her to wait till the end of school. When the school day ended, I quickly found an appropriate place at the school gate and beat all the guys one by one with my takhti [wooden writing board].

Tanveer added another story that had a similar theme of protecting marginalized. One of the girls told Tanveer that a man, aged 40 to 45 , followed her to school and used obscene language. The next day, Tanveer accompanied the girl and "when the man followed us as usual with offensive words, I turned robustly and banged him with my heavy leather bag full of books. Impulsively, the surrounding people gathered and started beating the man who was harassing the girls." Although currently Tanveer is a strong 
believer of non-violent approaches, she frequently used violence as a defense strategy in her childhood for defending the defenseless.

\section{Walking through Contextual Challenges}

Although Tanveer does not believe that "leaders are born," to lead, she confessed, "My personality is very challenging and since childhood my sensibilities provided me a direction for advocacy work in a challenging environment." Tanveer recalled that after high school her parents tried to prevent her from continuing her education because of poverty, but she challenged their decision with arguments: "If my brother can go to college even with lower grades than me, why can't I?" Nevertheless, her parents continued to reject her arguments until she "went on a hunger strike for 5 days." This made her parents nervous, and they finally gave her permission to attend college. However, they refused to offer any financial support. She said, "I never got a single penny from my parents for my education." Instead, she tutored students to earn money while she studied. Tanveer commented that one of the biggest challenges during her university life was the ideological difference that produced a sharp division between progressive and conservative students. Since Tanveer was a student leader, a radical group was absolutely intolerant of her. Tanveer noted, “They engaged a girl for my character assassination." When the vice chancellor of the university stopped the students from taking a study trip of male and female students together, Tanveer, along with some male students, stood up to dialogue with the vice chancellor. She announced, "He can't stop us just because he is the vice chancellor. He must have some logic behind his actions." Her voice was heard and the trip was allowed; however, the girl later made false accusations against Tanveer and the male student who participated with her in the 
dialogue with the vice chancellor. Tanveer went straight to the girl and said, "If you are so interested in knowing who my lover is, just ask me rather than making false accusations." The girl was so ashamed that she left the university.

\section{First My Mother, A Clear Decision}

Due to her outstanding academic career, being well-connected with the intelligentsia, and her leadership qualities, Tanveer was offered an important position within the NGO sector even before completing her education. She joined a women's rights NGO, Shirkat Gah, as a research officer. However, she was soon offered a scholarship for higher education from the Australian government. Tanveer was on her way to Australia when she got the news that her mother was paralyzed because she could not accept the reality of living without her daughter. "My mother had a very strange relationship with me," Tanveer explained. Since Tanveer was responsible for all the outside household tasks, her mother was quite dependent on her. She felt emotionally insecure without Tanveer, and her health quickly deteriorated when Tanveer decided to move to Australia for three years. Tanveer continued, "This was the toughest decision of my life. I was floating between moving forward and stepping back.”

Eventually, Tanveer quit school, returned to Pakistan, and joined a development organization for three and one half years as the lead trainer for a Human Resource Development Program. Tanveer then worked for eight years with the Human Rights Commission of Pakistan as a project manager for women's rights projects, until she left for the United States for further studies in international human rights. 


\section{Managing Risk: Surviving in the Sector}

Since the Democratic Commission for Human Development (DCHD) was facing serious problems, Tanveer accepted a longstanding offer of becoming the organization's executive director after she completed her studies. Tanveer had a clear understanding that her crises management skills could strengthen the organization. Concurrently, she also accepted the position of country representative for the Label STEP of Switzerland in order to work against child labor. Nevertheless, Tanveer soon realized that leaders like her, i.e., leaders who advocate for human rights and take a clearly defined policy stand, must face some significant challenges in Pakistan. She explained:

I have zero tolerance for discrimination and can't compromise...my principles. In 2000, almost all the NGOs were working on local bodies' elections ${ }^{13}$ through a devolution plan ${ }^{14}$ proposed by the military dictator, General Pervez Musharraf. Donors channeled their funding for the devolution plan due to pressure of supporting government policies, but DCHD refused to work on it. If there are neither provincial nor national assemblies, then what is the worth of local bodies?

As a result of this decision, her organization suffered repercussions and faced serious financial crises.

\section{Juggling with Police/Mapping the Way Forward}

Tanveer offered a few examples to elaborate further on the political challenges she and her organization have faced. In 1999, General Pervez Musharraf came to power via a bloodless coup. Consequently, Tanveer's organization raised its voice strongly for the restoration of democracy. The voice got especially robust in 2002

\footnotetext{
${ }^{13}$ It is devolution of government to district administrations. (Districts are the third tier of government, being sub-divisions of provinces.

${ }^{14}$ Pakistan's military government launched a campaign for political devolution in 2000 that it said was aimed at transferring administrative and financial power to local governments. The scheme was to strengthen local control and accountability and, according to President Pervez Musharraf, "empower the impoverished."
} 
at the annual human rights conference of DCHD when hundreds of human rights defenders gathered in Lahore to protest against the military dictatorship. Tanveer recalled, "We asked for a route to protest in front of the Punjab Assembly building, but the police didn't permit us. However, we entered through the back route and robustly started chanting slogans, 'Down with dictator, long live democracy'.” Media reported the event widely.

Nevertheless, two months after this event, Tanveer received news that the state had registered a complaint against her, accusing her of damaging state property and blocking traffic for several hours. Tanveer contacted her lawyers and friends and managed to obtain bail before being arrested. The case lingered in the court for four years before Tanveer was finally acquitted. She recalled the challenges of her fight for justice: "Since I was traveling a lot due to my work, it was really very hard to appear in the court frequently. Thus, I often needed to fabricate a new reason for my absence, sometimes medical and sometimes family...."

Tanveer described her way of operating as follows:

I am a fast runner who prefers to wear joggers during protests, so I can run away if needed. Once in a protest against the inclusion of a religious column on the national identity card, the police charged us with their batons. I ran away hurriedly to the adjacent public park and started jogging with them pretending that I was not part of the protest. The police could not arrest me.

\section{Coming Under Fire}

The range and the intensity of problems that NGO leaders involved in advocacy face is enormous. If they succeed in managing the police, they frequently encounter 
harassment from intelligence services and militant groups, according to Tanveer. She recalled:

After making an oral statement about minority rights during a UN human rights session in Geneva, I faced tense and rigorous inquiries from Special Branch and Inter-Services Intelligence, one after the other, to ensure them that I was not working against the state.

These challenges were neither limited solely to Tanveer nor were they merely from state actors. Her organization faced severe setbacks when a militant group published and distributed salacious material against the organization's personnel.

Tanveer noted:

Once they launched a hate campaign against our organization, particularly our teachers, for a carpet weaving program. They accused our organization of turning program participants into sex workers. It was a major setback. Our work was stopped and teachers were defamed.

Tanveer wanted to file a defamation case against the offenders, but "the poor traumatized families preferred to forgive the offenders who subsequently published a refutation in their magazine, stating they had falsely blamed our Muslin sisters." Tanveer further noted, "A militant organization posted disparaging material against us on their website for 6 months until some of our friends negotiated with them to remove this." Similar incidents continue to put her staff at high risk, but Tanveer has learned to keep them all calm and composed during times of turmoil.

\section{Commitment, Clarity and Celebrations}

Tanveer believes that conceptual clarity about critical issues has helped her staff to remain contented during adversity. She explained:

When $50 \%$ of our staff give their consent to work on a certain issue, we do it. For example, the staff decided that Pakistan's blasphemy issues are a significant subject, so we conducted research. However, due to an increase in threats 
throughout the region and a higher level of risk, staff subsequently decided not to launch the study.

After the assassination of Governor Salman Taseer, who had the courage to stand up for a woman from a religious minority who had been imprisoned because of the blasphemy law, it was extremely risky to talk about him. Nevertheless, Tanveer noted that her staff "made a courageous decision to publish the full volume of our magazine, Nawai-e-Insan, in tribute to Taseer." She added, "We then faced a rigorous inquiry by intelligence agencies who classified our publication as instigating material."

The level of commitment of staff is so high that they agreed to a salary reduction when DCHD sank into serious financial trouble as a result of their decision to oppose the devolution plan under the rule of a military dictator "who was enjoying lot of international support because of Pakistan's role in the war on terror." A shared decision making process not only builds the confidence of staff, but it allows them to determine the amount of risk they are willing to take. "I don't centralize things," Tanveer stated. The learning and familial culture of the organization encourages her staff to celebrate their good times and it helps them cope with problematic periods. According to Tanveer, "They [those who work in her organization] are accustomed to receiving rewards and a sense of belonging from the organization, and that's why we have very little staff turnover."

\section{The Universe Supports Her}

Despite working with visionary and committed staff, the stressful advocacy work sometimes negatively impacts Tanveer, and she embraces nature to reduce her stress. "I sit on [the] floor and keenly observe the movement of ants," she said during an interview. "It makes me strong and soothing." 
Tanveer also has a good circle of friends who support her in turmoil, and she loves to spend her time with children. "I converse with children. I play with them. I can spend hours and hours with them to relax myself," Tanveer stated.

Although Tanveer's family has never been very supportive of her education or work, they are proud of her remarkable achievements. When she got the first position in the university at the completion of her masters in philosophy program, her mother proudly spoke to the media, saying: "We worked hard to bring Tanveer up to this achievement." This and other sources of support brought joy to Tanveer's life and motivated her to keep going in times of stress.

\section{From Street Protests to the Negotiation Tables: A Resilient Move}

Tanveer believes that the most important contribution that she has made to her organization's advocacy work is her working methodology. She found that advocacy work in Pakistan has gone through two eras. In the past, according to Tanveer, "we focused on street protests and demonstrated our power to pressure the government. In fact, that era was quite successful as the government passed some important pro-women legislation." She went on to say that the advocacy work in contemporary Pakistan is very challenging and difficult, and the non-state actors, such as militant groups, have become stronger than the state organs. Tanveer logically explained that "in the past, when NGO leaders protested and confronted the state, they were arrested, imprisoned and lashed, but there was always a legal recourse available for them." She sadly elaborated further that "her two good friends and strong human rights defenders were killed by militants, but there is no legal recourse available to stop this violence." 
Tanveer concluded, "If you are in a confrontation with the state, there is room for dialogue; nevertheless the militants can't be engaged in dialogue because they directly shoot you." Therefore, both the state and NGOs have learned through this experience that they need to enhance their mutual understanding to combat militant groups, and, subsequently, both sides have been showing some flexibility. Tanveer's working methodology was very much based on the principle of decentralization within the organization, and that also allowed her to engage in dialogue not only with her staff but also with other stakeholders including the government.

Nevertheless, Tanveer is very much aware of the harsh reality that militant groups completely reject human rights advocacy work. She has survived so far because of her working methodology of keeping a low profile and being democratic, but she stated clearly, "It is a matter of time who will be hit and when, and my number has yet to come." 


\section{CHAPTER FIVE}

\section{CROSS-CASE ANALYSIS_FIVE CASES IN SEARCH OF A THEORY}

This chapter presents the results of the second phase of the analysis of interviews and document data for the five research participants in this study. Polkinghorne (1995) termed the approach employed in this analysis as an analysis of narrative. In this analysis of narrative, I have revisited the original data that I used for the first phase that entailed doing what Polkinghorne calls narrative analysis rather than relying on the cases constructed and presented in Chapter Four. I have created categories (paradigmatic typologies) that allowed me to compare and contrast individual cases.

Data from interviews and document reviews were coded and organized into major categories and themes that cut across the cases. The method I have used is explained in detail in Chapter Three. This chapter focuses on five major themes that I have distilled from an initial list of 22 categories. These themes are Getting Involved in Advocacy, Overcoming External Barriers, Meeting Internal Challenges, Becoming Resilient, and Assessing Impacts. The themes more or less align with the study's research questions. Table 2 presents the five themes and the particular categories subsumed under each theme. 
Table 2:

Themes and Categories

Key Themes Categories Under Each Theme

Getting Involved in Advocacy Childhood incidents

Political environment

Vision

Legacy of martyrs

Overcoming External Barriers Collaborating with government

Negotiating with intelligence agencies

Embracing culture

Maintaining a low profile

Harmonizing with media

Partnering with donors

Meeting Internal Challenges Decentralizing power

Motivating communities

Developing security policies

Strengthening networks

Becoming Resilient

Reflective practices

Self-care

Gaining family support

Cultivating a circle of friends

Assessing Impacts

Changes in laws

Increased awareness among masses

Recognition and respect

Women in leadership

This chapter elucidates all five major themes and the categories subsumed under them.

The number of categories associated with each theme varies because the data were richer 
for some themes more than for others. I will also discuss some categories that were not found in the data for all the cases but, nevertheless, were important in the cases in which they were found.

\section{Getting Involved in Advocacy}

This theme covers the data mainly related to the early experiences of all participants in their advocacy work. The data here describe how, why and when the participants embraced advocacy work and why, throughout their lives, they found it meaningful to attempt to protect and promote human rights and to bring about change in their country of Pakistan. Four categories associated with the theme of getting involved in advocacy emerged inductively from the data: childhood incidents, political environment, vision, and legacy of martyrs.

\section{Childhood Incidents}

Four of the five participants first became involved in advocacy work during early childhood, and because of incidents that occurred during their childhood years they remained involved in advocacy throughout their lives. Rehana recalled, "I was pushed into advocacy work" when her father was arrested for criticizing the military dictator, General Ayub Khan. Although Rehana was only 7 years old at the time, she courageously walked onto the prison grounds every day to deliver food to her father. During my interview with her, Rehana noted, "We didn't have a brother." Consequently, she had to take up the task of doing advocacy work, a task that entailed learning about power dynamics, the complexity of society, and the significance of advocacy work. Over the years, Rehana learned these lessons well, but, years later, during my interview with 
her, she characterized this experience of being pushed into advocacy activity at an early age as a "lost childhood."

Other participants portrayed their early experiences with advocacy much more positively. Shad, for example, felt "happy about the various occasions of chanting slogans at the age of 8 or 9" in favor of the military dictator, General Zia-ul-Haq, who imposed Sharia Law in Pakistan. Likewise, Tanveer appeared to relish her efforts to "beat the rich boys....[to protect] the poor class fellows."

Peter also traced his involvement with advocacy to his childhood, though without recounting his emotions, neither positive nor negative. He remembered his "participation [alongside his teachers] in [the] protest against unfair nationalization of Catholic schools when...[he] was only 11-years-old.”

All four of the participants who traced their advocacy work back to childhood confessed that, as children, they were unfamiliar with the word and even the concept of advocacy. They also advocated for different things. Shad supported a military dictator's discriminatory policies, while the others protested against military dictators and supported the restoration of a democratic government and pluralistic society. Despite the differences in their advocacy activities in their childhood years, all the participants eventually became advocates for human rights.

\section{Political Environment}

Each participant recalled the impact of political environment, particularly the martial law periods of General Ayub in the 1960s and of General Zia in the 1980s, as having influenced their involvement in advocacy work. In some cases, the charisma 
of left-wing politics ${ }^{15}$ and active participation in student wings of various political parties became an inspiration for the participants' involvement in advocacy work, while, in other cases, military regimes negatively or positively compelled participants to become involved in advocacy work.

Tahseen, the one participant in this study who did not become involved in advocacy work as a child, indicated he learned "group organization and mobilization for change" by being part of left-wing politics as a student, and this involvement in left-wing politics inspired him to pursue advocacy work. During the Cold War era of the 1980s the Soviet invasion of Afghanistan made Pakistan a frontline ally of the United States, and consequently a Jihad culture was promoted. Furthermore, according to Tahseen, "[The] US supported military regime enforced martial law and suspended many basic rights, such as freedom of expression and freedom of assembly," and, therefore, Tahseen began to speak up for those rights. The political environment further motivated Tahseen and his fellow activists to establish an advocacy organization. Tahseen stated, "The stifling political and social environment acutely necessitated that civil society be developed and strengthened. Keeping that critical need in view, a group of intellectuals and social activists laid the foundation of South Asia Partnership, Pakistan [SAP-PK].”

The political environment of the country also permitted Tanveer to emerge as a student leader. Tanveer felt fortunate to have been a student leader, a position that provided numerous opportunities in her youth to meet great politicians and highly respected NGO leaders such as Dr. Mubashir Hasan, Professor Azizuddin Ahmad, Nighat Saeed Khan and Mumtaz Khawer. She indicated that these experiences positively

\footnotetext{
${ }^{15}$ Left-wing politics are political positions or activities that accept or support social equality, often in opposition to social hierarchy and social inequality.
} 
impacted her advocacy work throughout her life. Tanveer proudly recalled how she strongly, and successfully, criticized the controversial polices of Jamait-i-Islami, a conservative political party, to protect the rights of students, particularly female students. The experience of student politics impacted her so positively that she fearlessly took a clear political position on women and minority issues during later endeavors of her advocacy work.

Shad also worked to protect women's rights but, in her case, by working within the government. She indicated that her participation in political processions during General Zia's military regime not only enhanced her mobility as a woman, but it also helped her in "safeguarding women's rights in [a] conservative tribal area."

Involvement in student politics was not a pathway to successful advocacy work for everyone, however. Both Rehana and Peter indicated they were negatively impacted by their active involvement in student politics during military regimes. Rehana was expelled first from her college and then from her town to punish her for leading a student protest against the military dictator General Ayub. Rehana had to interrupt her education for two years.

Peter believed that "the political environment made a huge impression on my choice towards a socio-political change," but, as was the case with Rehana, there were negative consequences for engaging with the political environment as a student. In Peter's case, however, the costs were not imposed by the government. Peter vigorously participated in protests against military dictators when his teachers and classmates were arrested for demanding the restoration of democracy. Subsequently, this political 
involvement negatively affected his studies, and he was forced to make a shift from science to arts classes in order to secure more time for his political ventures.

So, for both Rehana and Peter, student activism had costs, either because of the government's punishment or because political activism was a distraction from their studies. In both cases, however, student activism led to consistent involvement in advocacy work throughout their lives.

\section{Vision}

For each of the five participants, vision remained a key factor in their involvement in advocacy work. The findings revealed that all the research participants talked, at least indirectly, about their visions during childhood, which essentially laid the foundation for their visionary leadership as well as the visions of their organizations. Peter reflected that he joined his "first protest against the unjustified nationalization of missionary schools" when he was very young, and this event helped him develop the National Commission for Justice and Peace's vision as stated in strategic review document of NCJP (2013) "an organization sees its role in building a just society in Pakistan based on principles of peaceful coexistence, mutual respect and dignity of human being and all creation on earth." Tanveers's childhood events (such as working for both churches and mosques or punishing her rich classmates for hurting poor students) evolved as the commitment of her organization, Democratic Committee for Human Development, to create "a tolerant, democratic and pluralistic society based on human rights principles and ideals." Rehana carved her passion and vision for girls and women's rights even in the name of her organization-Sisters' Trust. 
The findings revealed that, Tahseen as a young student leader firmly believed in democracy and these beliefs were retained into adulthood and helped him in formulating South Asia Partnership - Pakistan’s vision “to create an engendered, critical society in South Asia based on the universal principles of human dignity, justice, democracy and peaceful coexistence (SAP-PK, 2015).”

Shad's childhood dream of seeing the women of her village given the same opportunities as women in Islamabad eventually led to the creation of the Association for Behavior and Knowledge Transformation's [ABKT] vision "to contribute to the development of a democratic, prosperous and peaceful society that guarantees equal opportunities for all citizens of Pakistan (ABKT, 2015).” Although Shad initially supported a military regime for safeguarding women's rights, in later years she concluded that women's rights can only be protected through strengthening democracy.

Similar visions were also reflected in the organizational documents, particularly posters, aiming to mobilize their volunteers and communities around their visions. Table 3 below shows the similarities between the organizational visions and the advocacy messages depicted in posters for mobilizing masses.

The findings also revealed that the research participants modestly talked about their visionary leadership as NGO leaders. Rehana indicated that visionary leaders must not only inform staff on how they can strategically and logistically enact change but also fortify their commitment to their work. She stated, "Regardless of all these threats to my life, my staff supports me because they get inspiration from me when they see me and how I have been fighting over circumstances rather than becoming a victim of circumstances." Peter indicated that his staff is resilient and courageous because of the 
NGO's visionary leadership: "Despite the incidents of killing, kidnapping, torture, arrests and shooting, the staff still would like to continue to work with us because we have the legacy of visionary leaders.” This finding suggests that vision/visionary leadership continues to be a fundamental reason for initiating and sustaining advocacy work.

Table 3:

Vision in Documents and Advocacy Messages on Posters

Name Vision in Documents Advocacy Messages Depicted in Posters

Rehana

Not shared

Not shared

Peter

A just society in Pakistan

Advocating for elimination based on principles of of discriminatory laws peaceful coexistence, mutual respect and dignity of human against minorities, biased being and all creation on earth.

Tahseen

An engendered, critical Advocating for equal society in South Asia based education on the universal principles of human dignity, justice, democracy, and peaceful coexistence.

Shad A democratic, progressive, and peaceful society where everyone enjoys equal rights and opportunities. human rights (women, children, laborers), and religious tolerance Advocating for women's rights, particularly for political participation of women

Tanveer

A tolerant, democratic, and pluralistic society based on human rights principles and ideals.

Advocating for children's rights, interfaith harmony, and democracy 


\section{Legacy of Martyrs}

Only one participant, Peter, described his involvement in advocacy work as "carrying on a legacy of martyrs." The other participants clearly suggested that, in addition to childhood incidents, the political environment and/or their "inner-self" were motivating factors for their long-term involvement in advocacy work. Consequently, they initiated and sustained their advocacy involvements through the establishment of their respective organizations.

Peter, however, talked about the treasure of compassion and passion for equal rights and equal opportunities that he attained from the founder of his organization, the National Commission for Justice and Peace (NCJP). Peter added that he "is...carrying on the legacy of the founder of NCJP, Bishop John Joseph, who offered a self-sacrifice when innocent Christians become the victims of blasphemy law ${ }^{16}$." The other participants did not comment on having this debt of carrying a legacy forward.

\section{Summary of Findings on the Theme of Getting Involved in Advocacy}

This section highlighted four main points about how and why the participants in the study got involved in advocacy work. First, various childhood incidents deeply impacted the lives and advocacy work of four of the five participants. These incidents informally set the direction for their advocacy work during their youth and, later, shaped their respective organizations to continue the advocacy work up until today. Even the one participant who was not involved with advocacy work as a child developed ideas about the value of democracy that later became hallmarks of the organization he headed.

\footnotetext{
${ }^{16}$ Blasphemy law is a law limiting the freedom of speech and expression relating to blasphemy, or irreverence toward holy personages, religious artifacts, customs, or beliefs. Blasphemy laws are generally used to protect the religious beliefs of a majority or those who control the law.
} 
Second, the political environment was a major factor in engaging all of the participants in life-long advocacy activity. In some cases, they responded willingly to the call to become involved in political activity; in other cases, they became involved in the political process rather reluctantly. Whether they were willing or reluctant participants, engagement in the political environment set the stage for advocacy work throughout the lives of all five participants.

Third, vision was a factor in the lives of all five participants. Four of them continue to hold virtually the same dreams and values they had in childhood. However, one participant's vision gradually evolved from support for a dictatorship, which she believed would support the rights of women, to a struggle for democracy.

Finally, carrying forward the legacy of martyrs motivated only one participant. The other four participants, however, could be considered to be modern-day potential martyrs because of the constant threats on their lives and their persistence in spite of these threats.

\section{Overcoming External Barriers}

This theme includes data related to the hardships, challenges and obstacles that the participants faced when initiating and carrying out their advocacy work. The data illustrate the complexity and uncertainty of the political, cultural and economic environments in which the research participants worked. All participants spoke about how they continually changed and evolved their strategies to handle these external factors in order to ensure effective advocacy work. Six categories related to the theme of overcoming external barriers emerged across participants: collaborating with government, negotiating with intelligence agencies, embracing culture, maintaining a low profile, harmonizing with media, and partnering with donors. 


\section{Collaborating with Government}

Despite the fact that various governments appeared to be hostile towards NGOs involved in advocacy work and passed harsh laws (particularly NGO Bill $1999^{17}$ ) to curtail NGOs' work, all the participants spoke about networking and lobbying with political representatives as a key strategy for sustaining their advocacy work. Rehana fervently told me that she believes in a multi-sectorial approach that motivates her to work simultaneously with the government, donor agencies, and NGOs: "I worked voluntarily with my organization at the same time when I worked as a consultant with [the] Ministry for Women Affairs, and I developed a strong liaison between NGOs and women parliamentarians." She added, "For me, unless and until you work with the government, you cannot meet the goals. I give credit to women parliamentarians who worked across party lines in coordination with NGOs for the approval of several prowomen legislations."

Tanveer, being a member of the National Commission on the Status of Women ${ }^{18}$, deeply analyzed the political challenges and observed that "non-state actors (such as militants) have become stronger than the government organizations, therefore, both the NGOs and the government have learned to work together for change." Tahseen rationally described why he believes that collaborating with government is a key strategy: "A few NGOs can't bring change. It has to come through the government. ...We [NGOs] can't fight out terrorism, however, if the government seriously takes curbing

\footnotetext{
${ }^{17}$ The revival in 1999 of the NGO Bill, pending in the Senate since 1996, highlighted the motivation for greater 'control' of non-profit organizations.

${ }^{18}$ National Commission on the Status of Women was established as a statutory body in July 2000 under an Ordinance. Since then NCSW has functioned under the wing of the Ministry of Women's Development to fulfill the promise of a life of dignity and justice to women of Pakistan.
} 
terrorism on its agenda, why shouldn't we support the government?" He further noted that NGOs have started working with various government departments "to bridge the gap between government and NGOs."

Shad discussed in detail how she had "implemented some major projects on women empowerment with the help of [the] district government." She acknowledged that "these projects resulted in attitudinal change" at the grassroots level regarding a woman's place in public and private spaces. Likewise, Peter talked about the benefits of networking with parliamentarians. When I asked him, pointedly, about his experience, as a non-Muslim activist, working with parliamentarians, he said, "In 2011, we worked on a draft to make changes in the personal laws, lobbied with parliamentarians, and the National Commission on [the] Status of Women gave its approval to make it into a bill to introduce in Parliament."

Peter, however, also highlighted that non-Muslim activists do not have the same social influences and linkages with government bodies as Muslim activists. This lack of access results in a less efficient networking ability for non-Muslims, according to Peter.

The findings indicate that, despite all the challenges and limitations, all the participants found that collaborating with government was a useful strategy. However, Peter, with his Christian background, noted that he had less access to power structures than the four Muslim participants.

\section{Negotiating with Intelligence Agencies}

All participants, except Shad, reported that NGO leaders receive severe threats from intelligence agencies in the country. They mentioned various human rights 
defenders who were kidnaped or killed by the agencies. However, despite this alarming situation, they believe in negotiating with the personnel of various agencies in order to sustain their advocacy work. These negotiations are not always successful, however.

Rehana noted, for example, that, as a prominent NGO leader, she paid the price for her advocacy work:

The people from intelligence agencies, such as Inter-Services Intelligence [ISI] and Federal Bureau of Investigation [FBI], rigorously interrogated me. They have been visiting [interrogating] me extensively for [the] last eight or nine months because they think I am working for [a] Western agenda.

Rehana made several attempts to negotiate the continuation of her advocacy work but could not fix the issues related to her security, and she finally left the country.

On the other hand, Tanveer discussed her successful negotiation with intelligence agencies. "I was accused of provocation after presenting an analysis of a blasphemy case, and, subsequently, intelligence agencies initiated a rigorous interrogation against me," she stated. She indicated that she found it very unsettling to answer all the questions of the interrogating officer "for at least 3-4 hours every single day for two weeks." But the story ended happily when the officer said, "You are doing positive work and let me know if you need my support." Likewise, Peter successfully negotiated with agencies and criminal charges were dismissed after his organization was "accused of distributing banned material."

Tahseen described how he "is not scared of agencies who impede our work....My continuous open interaction with them very often ended with friendship." However, Tahseen does not underestimate the hardships and challenges created by agencies: "I am concerned about the security of my colleagues and my comrades," he noted. 
In contrast to other participants, Shad clearly stated, “I don't have threats from security agencies." She quickly added: "But [I] have [threats] from [the] Taliban."

\section{Embracing Culture}

All of the participants lamented that the fundamentalists often accuse NGO leaders of being Western agents and enemies of Islamic norms and values, and these sorts of accusations continue to be one of the biggest cultural challenges for them in their advocacy work. Pakistani culture is influenced by religion, and the religious extremists frequently misinterpret Islam in order to justify the harmful traditions against women. This intensifies the challenges of NGO leaders working for women rights.

The findings indicate, therefore, that all the participants needed to assimilate into the existing culture to prevent drawing attention to themselves as Western agents. At times, however, culture can have a negative impact on their advocacy work in a turbulent environment. Still the participants believed they had no choice but to become part of the local cultures in which they worked.

Rehana, who worked in all provinces of Pakistan, for example, stated the following: "I learned their language, Kowar, so I wouldn't be a stranger to them. In fact, I learned seven languages for better understanding and embracing different local cultures in Pakistan." Shad demonstrated her respect for tribal culture by "wearing traditional Pashtun dress" while meeting with Michelle Obama and Hillary Clinton at an award ceremony in the United States. Tanveer described embracing culture as the central strategy for her advocacy work: "I have a strong capacity of cultural limitation. When I worked in province Baluchistan, I covered myself with [a] chader [big scarf], however, I showed more flexibility while working in province Punjab and sometimes didn't cover 
my head with [a] scarf." This sensitivity to differing dress codes helped Tanveer develop a trust relationship with communities in various provinces of Pakistan.

Tahseen spoke about the cultural limitations, particularly related to women's issues, of the FATA Region and how he strategically created educational opportunities for young girls who had limited mobility:

In FATA, we first started economic activities for widows, and then we started a girls' education program. A widow voluntarily took girls to school and collected them back [after their classes]. It worked out successfully because it was culturally acceptable.

Peter also acknowledged cultural challenges and argued that "the social acceptability of our work (was) enhanced by integrating cultural norms and practices." These cultural expressions provided unique opportunities for all the research participants for inclusion in diverse communities.

Perhaps it was not surprising that all the research participants discerned that embracing culture is a strategy for advocacy work. What may be surprising, however, was that one male participant seemed to ignore the gender dimensions of culture. Peter entirely rejected the gender dimensions of culture and argued that, "culture is not a resisting force for us. I would give credit to the flexibility of our agenda rather than my masculinity ${ }^{19}$,

All the female participants spoke about how Pakistan's patriarchal culture assigns different roles to men and women. For Tanveer, being a girl meant she was "not allowed

\footnotetext{
${ }^{19}$ Possession of the qualities traditionally associated with men.
} 
to play outdoor games with boys," while Rehana recounted how she was not accepted as a leader by her male colleagues:

Culture is also a big barrier for women. I really respect and adopt local culture. I behave the way people behaved to sustain my work. However, when I started work on women's rights as a team leader, the elite class (Mehtar) played games against me, stating that this woman is not local and she is changing our culture so we don't need her. They pressured my boss for my resignation. I was forced to resign. I didn't want to leave the community, but I left with heavy heart.

Pakistan's cultural perspective of favoring a "big man” for leadership positions often constrained women from pursuing leadership roles. Tanveer described a cultural scenario when a hatred campaign was launched against her organization, particularly the female beneficiaries of a carpet weaving program. "They accused our organization of turning program participants into sex workers. Our work was stopped and teachers were defamed." Although Tanveer considered this to be a major setback, it also strengthened her commitment to work for women's rights by eliminating cultural barriers for women.

\section{Maintaining a Low Profile}

Because of severe threats from militants, all the participants found maintaining a low profile to be an effective strategy for continuing their advocacy work. They kept their low profile either by limiting their areas of operation or by curtailing their work. Four of the participants, in fact, all except Shad, reported they stopped working on blasphemy issues after receiving threats. Tahseen stated that "after the assassination of Salman Taseer, we were not in a position to advocate for the repeal of blasphemy laws, so there was a complete silence." Peter also acknowledged using this same strategy to minimize threats. "After the assassinations of Governor Salman Taseer and Minister Shahbaz Bhatti," he stated, "we placed the issue of blasphemy laws on the back burners and decided to not...demand for repeal of laws." 
Tanveer also kept her low profile by reducing the blasphemy-law-oriented work of her organization after the assassination of Salman Taseer. She stated, "We conducted a research on blasphemy laws but, due to an increase in threats throughout the region and a higher level of risk, we decided not to launch the study."

Rehana, as a strong campaigner for the repeal of blasphemy laws, faced the worst consequences of Taseer's assassination. After becoming a regular target of threats, Rehana not only stopped working on blasphemy issues but also "frequently moved locations, occasionally going into hiding" to keep her low profile.

The findings also revealed that, to maintain a low profile, the research participants restricted their areas of operation. After the assassinations of his seven colleagues and persistent threats by militants who consider NGOs as Western agents, Peter described how his organization closed its office in Karachi and has been operating from offices in Punjab Province. He argued, "I would say my key strategy is keeping a low profile to respond to the level of risks and threats." Likewise, Rehana's small organization was forced to close its only office due to severe threats from militants. She indicated that now "the staff was [has been] working from home."

Both Tanveer and Tahseen shared that Baluchistan is increasingly becoming a dangerous area for NGOs, and, consequently, they both have restricted their activities. In reflecting on the Baluchistan situation, Tahseen disclosed, "We had to withdraw from at least three districts and change the nature of our work due to high threats from militants." Shad not only stopped working in her native districts due to the Taliban's occupation but also "moved to Islamabad for minimizing the risk." All the participants expressed that 
the strategy of maintaining a low profile works well, and this enables them to survive in a turbulent environment and to sustain their advocacy work.

\section{Harmonizing with Media}

Four participants spoke in detail about how the media has impacted their lives either positively or negatively. Although the media has enhanced the vulnerabilities of some participants, they still acknowledged the importance of the media and espoused the strategy of harmonizing with the media. For instance, Shad indicated, "Media played a very supportive and positive role in highlighting my achievements and my work. They never wrote anything negative about us. You can Google and confirm it.” Peter also disclosed a very unique role of media. He said:

We have some contacts among the journalists who are strength in times of turbulence. For instance, we can get information from them if there is any expected move against us from militants or agencies. They can at least give us a hint about how to cope with that.

Efforts to harmonize with the media can become problematic, however. Rehana, who efficaciously worked for changes in community norms and policies through media advocacy, also reflected on a painful experience with the media that drastically changed her life. Rehana indicated that when she registered a First Information Report (FIR) in the police station against unknown entities, the media breached her privacy and illegally obtained a copy of the FIR, and reported falsely (but sensationally) that "Rehana was under severe threats by the Taliban." The news was covered by both national and international media, and, as a result, the Taliban placed Rehana on a hit list and alleged that Rehana slandered their repute through false accusations. After that, Rehana never appeared in Pakistani media. 
In a similar vein, Peter's organization came into the limelight because of his appearances on Voice of America and the British Broadcasting Corporation (BBC) to discuss human rights issues. This exposure increased the risks to his organization, and, consequently, they revisited their media strategy. Peter commented, "We are not issuing press releases regularly. We are working on advocacy campaigns through meetings rather than relying on media."

Tanveer judged the media as an opposing force in the current scenario: "Media advocacy is important for policy change, but we don't use media because now more risks are involved in media advocacy in [the] turbulent environment of Pakistan." However, in contrast to these three participants, Shad reported that she successfully employed the harmonizing with media strategy, and, thus, "the media always profiled me and my work positively," while Tahseen did not discuss how the media related to his advocacy work.

\section{Partnering with Donors}

All the research participants acknowledged that they strategically partner with donors for initiating and sustaining their advocacy work. However, in some cases, pressure from donors became one of the biggest challenges for an effective advocacy program in a turbulent environment. Reflecting on donors' support, Peter told the story of an equitable partnership with a donor and how his NGO transformed from a social movement into an advocacy organization with the technical and financial support of the donor. He said that for the first ten years, "the organization was running very much on movement style without any office or sufficient paid staff, but after that, with Misereor Germany, a donor partner organization, we started working on a project basis in a more organized, structured and focused way." 
In recognition of her expertise on issues relating to gender, donors helped Rehana establish her organization. The Canadian government had money left over from the Tarbela Dam Project ${ }^{20}$, and according to Rehana:

Wendy Miller of CIDA [Canadian International Development Agency] contacted me and [said] they wanted to put that money in a development project for women. Eventually, we established an NGO, Strengthening Participatory Organization, for uplift of women, and I worked as head of the program.

Shad also developed her organization with the support of "big donors, such as Trust for Voluntary Organizations [TVO], Civil Society Human and Institutional Development Program [CHIP] and Asia Foundation." Likewise, Tanveer managed her NGO through her equitable working relationship with donors, while Tahseen's organization was very fortunate to have regular financial support from a few donors. The findings revealed that the participants acknowledged that donors respect and support their vision and work.

Nevertheless, all the participants, except Tahseen, described several incidents in which they were pressured by their donors, and they had to struggle to maintain an equitable partnership with the donors. The findings indicate that, despite knowing the significance of advocacy work, donors do not fully support the NGO leaders either because of the government's influence on them or because the donors prefer to advocate for their own policies or pet projects. Consequently, the participants came up with various strategies for partnering with donors.

For instance, due to her strong commitment for democracy, Tanveer refused to accept financial support for a political education program for women which supported the devolution plan. Consequently, she noted, "Our staff worked unpaid during this severe

\footnotetext{
${ }^{20}$ Tarbela Dam on the Indus River in Pakistan is the largest earth filled dam in the world and second largest by structural volume. The dam was completed in 1976 and was designed to store water from the Indus River for irrigation, flood control, and the generation of hydroelectric power.
} 
financial crisis, but we lived a principled life." Likewise, Rehana lamented about her donor's unsupportive attitudes toward NGO leaders. She stated, "I was working as an advisor to the Ministry for Women under UN Women contracts, but when I was under threats, instead of supporting me, they terminated my contract to keep themselves safe." Even then, Rehana voluntarily continued her advocacy work with the EVAW Alliance ${ }^{21}$, established by UN Women, because her "commitment for advocacy work was higher than personal gains."

Shad analyzed donors' support critically by posing a question about how projectoriented short term support can sustain long-term advocacy work. She elaborated, "We had little support for advocacy work. It's an ongoing pressure to seek funding for advocacy work. I wish I could have my own finances to support my advocacy work which is so important for all of us." To compensate for the absence of donor support and also to minimize pressure from donors, Shad's NGO engaged a large number of volunteers to sustain its advocacy work in the absence of donors' support.

When speaking about donors' pressure, Peter described how the government influences donors to restrict advocacy work. He indicated that, "UN Women financed our study on religious minorities and women, but they were reluctant, at the end, to lend their name to the study because they would not like to have any criticism from the bureaucracy of Pakistan for their engagement in advocacy work." To sustain its advocacy work, Peter's organization halfheartedly fulfilled the donor's demand by leaving their name off the study. Peter further pointed out, "Donors go into development work because it is acceptable for governments and has tangible results, but advocacy

\footnotetext{
${ }^{21}$ UN Women has taken a lead in conceptualizing, establishing and facilitating an alliance on Eliminating Violence Against Women known as the EVAW Alliance Group.
} 
work is all about change which brings the fruit at a later stage or it may be not in prescribed terms."

In contrast to the other participants, Tahseen presented a different perspective of partnering with donors. During his years-long advocacy work in Pakistan's turbulent environment, Tahseen believed that donors were well aware that the entire Pakistani society is the captive of extremists and militants, and, therefore, "they could not expect tangible results of advocacy work from NGO leaders." He was fortunate, however, to have secured long-term financial support. He worked with only four or five donors over more than three decades, and he denied receiving any pressure from donors regarding their disinclination to support advocacy work. He added, "It is entirely up to us to pick up [an] area of work which suits us."

\section{Summary of Findings on the Theme of Overcoming External Challenges}

This section summarized six main points on how external factors influence the research participants negatively or positively in initiating and carrying out their advocacy work and how they continually changed and evolved their strategies to handle these external factors in order to ensure an effective advocacy work.

First, the participants believed that, in contemporary Pakistan, collaborating with government was indispensable for effecting policy changes and sustaining their advocacy work. Despite the government's hostile posture towards them, the NGO leaders often found a window for consultation and lobbying with legislators in order to successfully effect changes, such as introducing pro-women legislation.

Second, intelligence agencies, who disliked advocacy work, often posed a major threat to NGO leaders. Nevertheless, some NGO leaders minimized these threats through 
successful negotiations with intelligence agencies. In other cases the negotiation process was disastrous, and those NGO leaders eventually left the country to ensure their own safety. The bidirectional influence of negotiation with intelligence agencies requires NGO leaders to be resilient so they can meet the adversities.

Third, culture influenced by religion was a factor that impacted the lives of all five participants. Despite gender discrimination, female participants particularly recognized the importance of embracing culture to overcome barriers in their advocacy work. This awareness about the cultural sensitivities often led the participants to become more flexible and creative.

Fourth, all participants had the vision, skills and capacity to revisit their strategies in changing environments, particularly when the political system influenced them negatively. They believed that NGO leaders could work effectively by maintaining a low profile. Therefore, the fifth point was to avoid media appearances so as not to draw the attention of the extremist elements of the society. However, the participants all believed that developing a working relationship with the media was important for an effective advocacy. In some cases, participants faced adversity when they failed in their attempts to harmonize with the media. It indicates that the media in turbulent settings carries potentially high risks and occasionally can be beneficial, forcing the NGO leader to make tough-minded decisions regarding relating to the media.

Finally, opportunities for partnering with donors improved and expanded the advocacy work of all participants, but at the same time, dependency on donors, either positively or negatively, affected their organizational policies. However, the NGO which forges solid partnerships with Donors, combining vision, funds and sustained 
commitment, can adequately counter the negative pressure from Government and maintain its advocacy efforts.

\section{Meeting Internal Challenges}

Participants commented on several internal challenges that significantly impacted the advocacy work of their respective organizations. These challenges, which mainly related to managing both the human and financial resources of their organizations, were discussed in response to various questions throughout the interviews. In general, participants believed that creative and committed NGO leaders could successfully manage a range of internal challenges. The categories across participants related to the theme of meeting internal challenges were: decentralizing power, motivating communities, developing security policies, and strengthening networks.

\section{Decentralizing Power}

The data in the category of decentralizing power were concentrated on staff involvement in decision making, but the participants also spoke about benefiting from the knowledge and ideas of staff when their organizations faced internal challenges. Tanveer and Tahseen were the two participants who clearly talked about the decentralized structure of their organizations. Tahseen stated, "We are a flat organization. We empower our employees to take charge and make decisions.....We accept, respect and benefit from the distinctive talent and characteristics of each other." He added that the sharing of responsibility and authority truly enhanced his employees' commitment to the organization. Tahseen, who believed in the "dignity and unique role of each individual," also shared how he relates to his staff: "I have 241 full-time employees, and I know the families of every one-from cleaner to coordinator. I visit their houses." $\mathrm{He}$ 
acknowledged that this involvement may take some extra time, but by doing this he kept their morale high. He concluded, "I care about them. I miss them. And they miss me."

Nevertheless, despite all this care and power sharing effort, Tahseen indicated that the tactic does not always produce the desired results, especially with younger employees:

Over the past 20 years, we have hired many university-educated young people who do not have any kind of commitment or understanding. They come for this job because, unfortunately, our government is not able to provide jobs. So their motivation is different.

Tanveer's working methodology was very much based on the principle of decentralization within the organization, and this method ensures equal participation of staff in decision making. Tanveer stated, "Since we work on some very sensitive issues [e.g., blasphemy laws], we get opinions of staff before working on such issues. If more than $50 \%$ of staff approved, then we did that task." According to Tanveer, this commitment to group decision making about crucial issues was the reason that Tanveer's organization had a very low turn-over of staff.

Peter, Rehana and Shad stated that the open and friendly culture of their respective organizations enabled the staff not only to share the vision of the organization but also resulted in the distribution of power within the organization. Rehana commented that she loved her staff like "her children," and she tried to keep them at ease and free to communicate their concerns, especially during stressful situations. Shad vividly recalled, "My staff is my family and I take care of them; we work together in bad and good times and equally own the successes and failures." However, Shad also softly explained the reasons some of her staff leave "the family": "Staff join and leave the organization 
because short-term projects end, and we should try to understand that everyone had financial need." Consequently, Shad indicated she was not annoyed when her staff (i.e., her "family members") left her. She did not seem concerned about high turnover of staff.

Peter described many of the same internal practices as the other research participants described. He, however, had a somewhat different justification for these practices. He noted, "The government introduced strict laws to restrict our work which is intimidating and harassing." In this situation, he argued, sharing decision-making power with staff increased their "courage, commitment and compassion" which play a key role in continuation of an effective advocacy work.

\section{Motivating Communities}

In the analysis of data, it became clear that all participants faced the internal challenge of insufficient human resources. Consequently, they relied on the people's power not only for sustaining their advocacy work but also for their own protection in a hostile environment. Although all participants were committed to engaging the community in advocacy work, the degree of involvement and the methods for gaining community involvement varied. For instance, Tahseen and Tanveer motivated their communities through a large network of volunteers established by their respective organizations in various districts of Pakistan.

Similarly, motivating the community on a large scale was an obvious concern articulated during Shad's interview, and she too spoke about utilizing volunteers. She stated, "Since we have very limited financial resources to sustain our advocacy work, we motivate our communities through our thousands of volunteers." She added that these communities own her organization, particularly her, because they know, "She is one from 
us." This mutual respect enhanced the "trust relationship" between the community and Shad's NGO, and this is at the heart of sustained advocacy work.

In contrast to other participants, Rehana and Peter stated that community involvement in advocacy work also provided protection for NGO leaders. Rehana attained personal security with help from community members. She emphasized that rural communities are faithful defenders of those who are associated with NGOs. "In capital Islamabad I can't knock at any door," she noted; "but rural communities support us in difficulties. When I was hiding, I lived at our survivor's [beneficiary's] house in Hyderabad."

Peter also discussed at length how the communities played an important role in sustaining his advocacy work during hard times. The following is a small excerpt from a much longer conversation that illustrates the support Peter received from his community during a period of policy upheaval when he and members of his organization were threatened:

We are not political entities, therefore, people love us and you [we] feel better protected. For instance, if someone comes to arrest you in the city, I don't think the neighbors are going to resist, but in a village they would definitely ask the police about arrest warrants, etc. If you need to go "underground," villages are the best place. .... When a nation-wide campaign was started against the column for religion [on the national identity card] introduced by the government...we blocked the national highway for 8 hours with the help of thousands of villagers because the government was not listening to our demands. Finally, the government took its decision back.

\section{Developing Security Policies}

All participants agreed that the key political challenge for sustaining advocacy work was the severe threats from militants. This threat compelled them to develop security policies. Nevertheless, their responses to questions regarding measures taken 
were different, in large part because the intensity of threats was not the same for everyone. Tahseen, Tanveer and Shad knew about the killing of other NGO leaders, but, fortunately, none of their own staff members were killed. Consequently, none developed comprehensive security plans for their organizations. However, they did organize security training for their staff, and they found this to be sufficient. Tahseen's comment on a specific incident largely speaks for all three of them: "When my male and female colleagues were chased by militants in Bannu, they immediately took a reverse [course] and went back, due to the security training they'd gone through.” Eventually they approached a police check post, and police officials safely escorted them from the area, according to Tahseen.

In contrast to Tahseen, Tanveer, and Shad's relatively limited approach to security, Peter shared that seven of his colleagues were assassinated and numerous others had been arrested, incarcerated, or threatened by militants. As a result, his organization not only immediately organized security trainings but also developed a set of security policies and procedures: "We set aside some amount for each staff to take care of their security expenditures such as extra telephones, putting up grills. We appointed a security coordinator who visits all offices. We maintained a security guard in the street as well as in the office."

Although four NGO leaders took small or big security measures in light of the intensity and severity of the risks, the availability of resources was another factor linked with security measures as described by Rehana. Despite the killing of her colleague, Rehana's small organization, which advocates for women rights, was unable to generate resources to develop and implement a security plan. Rehana lamented that, because of 
their inability to provide security to the staff, they closed their office and "the staff worked from home."

\section{Strengthening Networks}

Developing relationships and strengthening networks that facilitated coordination with other NGOs was another important category mentioned under the theme of meeting internal challenges. All the participants said that established relationships and being part of networks helped them to assess and manage their work in times of crisis and to sustain their organizations in a turbulent environment.

The findings revealed that strengthening networks was not only a support mechanism for all the participants in hostile environments, but it also helped them to better manage their organizations' financial and human resources by sharing the work among partner organizations. For instance, according to Peter, the military was ruling Pakistan in 2005, and a lot of big organizations who worked for women's rights did not want to bring themselves into the limelight by approaching the CEDAW [Convention on the Elimination of all Forms of Discrimination Against Women] committee to submit a CEDAW shadow report ${ }^{22}$. However, Peter's organization took the lead and started working on the CEDAW report, and, in 2007, drafted the first report ever submitted from Pakistan to an international body. Peter's organization employed this strategy of strengthening networks and asked other organizations to join them. Consequently, they not only attained technical support from the network and submitted a joint report, they also shared strategies for dealing with threats. Tanveer also provided technical support to

\footnotetext{
${ }^{22}$ Shadow reporting is an important tool for NGOs supporting women's human rights. By submitting a shadow report to a UN treaty body committee, NGOs can highlight issues not raised by their governments or point out where the government may be misleading the committee from the real situation.
} 
Peter related to the submission of their report. Shad reported similar experiences when they worked with other networks to submit shadow reports in later years.

Rehana, Tanveer and Tahseen also spoke about the effectiveness of strengthening networks and multiplying the impact of their advocacy work. Rehana volunteered to run the biggest network of NGOs, the Ending Violence Against Women Alliance (EVAW). She said, "I was the head of the EVAW Alliance, and we jointly launched the campaign all over the country for women's rights, particularly to end violence against women, to maximize the impact and minimize the threats from religious and tribal opponents." Tahseen added, "We have a large pool of vibrant human resources. If I send one email to these networks, we can organize a protest simultaneously throughout Pakistan" to highlight an issue and put pressure on the government to resolve that issue.

However, participants responded differently when they were asked to elaborate on their ability to strengthen their networks particularly of international non-governmental organizations [INGOs]. For Rehana, networking with INGOs was ineffective and timeconsuming because of their complex systems and procedures, while Peter acknowledged a high level of support from INGOs ranging from capacity building to collaborating.

Rehana expressed disappointment that INGO networks, like Freedom House and Front Line Defenders, did not support Pakistani NGO leaders appropriately at the time of severe threats. According to Rehana:

I sent a note to them [Front Line Defenders] that I am under severe threats and asked them how they can help me because I was out of home, out of job, and out of everything. I sent it in January by email, and their response came in June.

In contrast, Peter stated, "We have been helped in our advocacy work by INGOs in Brussels, Geneva, New York and Washington.” Peter and Rehena's quite different 
INGO experiences suggest that collaboration with INGOs may be more helpful in proactive rather than reactive (i.e., crisis) situations. It indicates that networks are sufficiently active in regular planning and partnerships but are unable to handle the emergency situation.

\section{Summary of Findings for the Theme of Meeting Internal Challenges}

This section summarized four main points on how NGO leaders meet the internal challenges for carrying out their advocacy work effectively. First, the research participants adjusted their organizational structures in order to sustain their advocacy work in reaction to economic crises and political instability. Particularly, the decentralization processes in organizations not only enhanced the effectiveness of their advocacy work but also strengthened their commitment and lessened the staff turnover.

Second, besides making adjustments with organizational structures, participants also acknowledged that community engagement not only sustained their work during hard times but also provided protection for their organizations. This resulted in enhancement of trust relations among communities and NGOs and, consequently, the growth of social capital.

Third, although some research participants were not afraid for their own security, all were concerned about the security of their organizational personnel. As a result, they developed security measures for the safety of their staff.

Finally, recognizing the significance of collective efforts, all participants agreed that working in networks was helpful in managing human and financial resources, but some international networks proved ineffective in protecting participants from threats. 


\section{Becoming Resilient}

Resilience is the theme that explains where the participants find personal support and what they do as a practice to care for themselves physically, mentally, emotionally and spiritually. The data subsumed under this theme include a wide variety of commentary by the participants about self, family and friends. This theme covers four categories: (a) reflective practices, (b) self-care, (c) gaining family support, and (d) cultivating circles of friends.

\section{Reflective Practices}

Reflective practices emerged as a common strategy among all participants, and they recalled various aspects of their reflective practices that they saw as a driving force for continuing their advocacy work. Rehana remembered how the reflective practices at the Joan B. Kroc Institute for Peace and Justice (University of San Diego) helped to bolster her confidence. She added, "During my two months stay at $\mathrm{Casa}^{23}$, I renewed my personal commitment to my work. I confidently decided to continue my work from abroad rather than stopping it because of death threats in my country of birth."

Peter strengthened his commitment to his work through a deep reflection on the purpose of his life. "Through a meaningful struggle, we are carrying forward the legacy of martyrs," he stated. However to meet this purpose, Peter shared a series of events when his reflective practices enabled him to, willingly or unwillingly, compromise with donors or the government rather than clashing with them. He stated, "To avoid any hostility from government, our organization reduced its local advocacy work but

\footnotetext{
${ }^{23}$ The Casa de la Paz is a private residence adjacent to the Joan B. Kroc Institute that overlooks Mission Bay and the Pacific Ocean.
} 
amplified our engagement in UN advocacy." He regularly attended UN sessions, submitted various shadow reports, and became a member of various international advocacy networks.

Tanveer's reflective practices enabled her to deeply analyze the negatives and positives of her work in times of turmoil. To counter the hostile posture of the government towards NGOs, Tanveer creatively changed her advocacy strategy "from protesting against government to engaging government in a dialogue process." Eventually, she accepted a position as a member of the National Commission on the Status of Women, which functions under the wing of the Ministry of Women's Development. Likewise, Tahseen, a strong grassroots activist and an out-spoken critic of discriminatory laws and policies, engaged himself in reflective practices and concluded that "we should support and encourage government if they take serious actions to curb terrorism.”

Shad was accustomed to always evaluating her actions or activities during times of crisis. Her reflective practices concentrated on "thinking critically [about] what I was doing for others, what I have done, what I have been doing better than my previous work." She believed that reflection is the niche of her sustained advocacy work.

\section{Self-Care}

Self-care was another important strategy discussed by only two participants in relation to becoming resilient. Though all the participants confessed that they work under extreme stress, only Tanveer and Peter spoke clearly about how they reduce the stress and take care of themselves. During stressful moments, Tanveer often makes time to "play with children to amuse myself, but I also learn a lot from them: the creativity, 
acceptance and struggle." Tanveer noted, "Sometimes I sat on the ground and observed the movements of ants walking slowly but steadily on the ground." She added that this "encouraged me to move forward no matter how difficult circumstances may be. There are always others in more difficult situations." Peter recounted his self-care strategies in a very precise way. "I take care of my health. I take my morning walk, exercise regularly, take enough sleep, and maintain proper food and medicine.”

\section{Gaining Family Support}

Each participant commented on how support from family members helped to sustain his or her advocacy work. All participants spoke of family support during two major phases of their work: at the beginning of their careers and later on after establishing themselves in the advocacy arena. The findings revealed that the participants all received family support later in their careers, however, Peter, Rehana and Tanveer faced family opposition while initiating their advocacy work at the early stages of their lives.

Peter's family believed that advocacy work would ruin his life. He added, "They wanted me to stay away from this context." Although Peter's family strongly opposed his work in the early years, with the passage of time, they recognized the importance of the work. Peter's appearance on national and international media, as well as his meetings with important people to advocate for human rights, built the family's confidence. Knowing the importance of his work, Peter's wife and sons always encouraged and supported him.

Rehana's family strongly discouraged her student activism for the restoration of democracy, but in later years they (particularly her mother and her husband) were very 
supportive. Likewise, Tanveer's family opposed not only her activism but also tried to limit her education. Nevertheless, they eventually expressed pride in her achievements. When Tanveer earned the first position in the university at the completion of her masters in philosophy program, her mother proudly spoke to the media: "We worked hard to bring Tanveer up to this achievement."

In contrast, although Shad's family was very conservative and had a political affiliation with a religious political party, Jamaat-i-Islami, Shad, at the young age 8 or 9 , often sat on the stage with her father and other male politicians during political events. She enjoyed this same support from her father, brothers, sons and husband in the later years of her work. "No matter how harsh circumstances are, my husband is always there to support me. He left his job and came to Peshawar to join me, so I could continue my work," Shad explained with gratitude and adoration.

Nevertheless, Shad also highlighted the gender dimensions of her familial relations. Shad expressed frustration that, being a working woman, she needed to pay equal attention to her work and her family: "Even knowing that I am a full-time working woman, my mother-in-law wants me to take care of everyone and everything at home." She lamented, "I often feel that I should set aside all these responsibilities and find sometime for myself."

Interestingly, Tahseen was the only participant who enjoyed the full support of his family throughout his life. "My family is involved in political activism. My advocacy work was nurtured through my family, my parents, in fact," according to Tahseen. 


\section{Cultivating a Circle of Friends}

There are no services available in the NGO sector for NGO leaders to heal their trauma or reduce their stress. It is hardly surprising, therefore, that all participants spoke of their circles of friends that helped them through the stress of tough times. They cultivated their circles of friends within the NGO sector either from their sister NGOs or the communities they work with.

Interestingly, both Rehana and Peter used the term circle of friends for their sister NGOs and considered these NGOs as their greatest support, both at a personal and professional level, during times of crisis. Peter commented, "It is a circle of friends who will give you a [safe] place if you need [one], who will go to court accompanying you and, of course, be a moral support." Peter's friends also included the people and villagers who supported him during various campaigns. Similarly, Rehana indicated, "When I was receiving threats, I shared that with my circle of friends - close friends in my sister NGOs, and they advised me not to join the protest and go low profile."

Tanveer also has a good circle of friends who support her in turmoil. She mentioned a number of events when her friends fondly supported her. They helped her obtain bail when she was accused of damaging state property and blocking traffic for several hours during a protest for the restoration of democracy. Tanveer's friends were there to negotiate with militants for the removal of hate material when "a militant organization posted disparaging material against us [Tanveer's organization] on their website for 6 months." Shad also acknowledged the care she received from her friends in 
the NGO sector who supported her whenever she "challenged the decision of a Jirga ${ }^{24}$ against women or filed a petition in the Election Commission of Pakistan on behalf of women voters in my area who were barred from casting their votes."

Tahseen spoke at length about his circle of friends. He described himself as "fortunate, very fortunate" because he has a large number of close-knit friends who care for him — sometimes overly care for him. He has a circle of friends, both inside and outside the country, who immediately respond to him if something happens. As Tahseen remembered, "When there was a bomb blast in Lahore, the first phone call I received was from a Canadian friend working in Jordan....'I hope you and your children are safe." He added, "When there was a firing in Gulberg next to my neighborhood, the first call came from India, a friend of mine inquired, 'Are you safe?" Tahseen received an unbelievable number of emails and phone calls from all over the world after a school attack in

Peshawar. Tears of joy flowed down from his eyes as he posed the question: "This is the kind of friendship I have. Is it not rare?"

\section{Summary of Findings for the Theme of Becoming Resilient}

This section summarized four main points on how NGO leaders develop their resilience in order to cope with the adversities resulting from the internal and external factors and how they develop strategies to manage stress and optimize wellbeing for ensuring an effective advocacy work. First, the strongest personal strategy of participants for effective advocacy was their reflective practices which led them towards creativity and confidence as they revisited their strategies.

\footnotetext{
${ }^{24}$ A Jirga is a traditional assembly of leaders that make decisions by consensus and according to the teachings of Islam.
} 
Second, despite working in a very stressful environment, self-care was not even on the radar for most of the participants. They always had a hard time including selfcare in their days.

Third, all participants acknowledged the support of family in their work. However, the three female participants mentioned that their families often limited their support either by stopping them from certain activities or expecting equal attention for home and work.

Fourth, participants cultivated and expanded their circle of friends, mainly within the NGO sector, for coping with adversities and handling their opponents.

\section{Assessing Impacts}

Participants assessed the impact of their years-long involvement in advocacy work from both a personal and societal perspective. While participants were quite modest in their assessments of what they had achieved, they were able to identify some areas where they believed their struggles resulted in a positive change. Impacts on society included changes in laws, promoting more women in leadership, and developing an increased awareness about certain issues among the masses. In the personal area, the impact included receiving recognition, at times in the form of an award and, at other times, by providing representation in the highest governmental structures that generated policy change.

\section{Changes in Laws}

The first key impact, all participants articulated was the changes in discriminatory laws. Participants described ways in which they either successfully advocated to 
implement existing laws or to change discriminatory laws and policies. A glaring example was shared by Shad who "challenged the decision of a Jirga against women" and filed a petition with the Election Commission of Pakistan [ECP] on behalf of women in her area who were barred from voting. Eventually, ECP delivered a landmark judgment, declared the by-election ${ }^{25}$ null and void, and ordered a new election so that women could cast their votes.

Peter assessed the impact of his advocacy work through the restoration of a joint electorate system which ensures the political participation of religious minorities. When asked about assessing the impact of his work, Tahseen first defined effective advocacy as a "change you brought in law making and [the] ruling establishment" before he assessed the impact of his advocacy work: "I would say, I have succeeded. We made a difference through our contribution in the restoration of democracy and amendments to discriminatory laws.”

For Tanveer, the impact of her advocacy was quite evident: "We focused on street protests and demonstrated our power to pressure the government." She added that, eventually, "the government passed some important pro-women legislation."

Besides her contributions in helping to pass pro-women legislation, Rehana's work with government provided her an opportunity to create more space for NGOs to lobby with members of parliament. These efficacious meetings set another historical milestone: the establishment of a separate Ministry for Women Affairs, which Rehana counted as her greatest achievement. All participants judged that, in the turbulent environment of political instability and financial crises, their long struggle impacted

\footnotetext{
${ }^{25}$ A special election, not held at the time of a general election, to fill a vacancy in Parliament.
} 
Pakistani society by safeguarding the rights of marginalized groups and restoring democracy.

\section{Increased Awareness Among Masses}

Besides bringing about changes in laws, participants similarly assessed the impact of their advocacy work related to attitude changes among the masses. This category was particularly important for the research participants who all believed that involving communities and volunteers in advocacy work increased awareness among the general public. Tahseen pointed out that increased awareness had evolved into a form of sustained advocacy because the changes in laws frequently become the values of the communities. He described the impact of his advocacy work through a unique demonstration of the attitudinal change when he sent a single email to volunteers in various districts about the burning of a couple of workers at a brick kiln. "Almost from every province people spoke against it. So there is a change," he declared.

Some other examples of increased awareness mentioned by participants included integration of minority groups into mainstream politics, condemnation of terrorism, the acceptance of increased mobility for women, initiation of education for girls, and protection of women's voting rights. This increased awareness by the general masses was particularly evident in tribal areas. The participants argued that these changes came solely by involving volunteers and communities in advocacy work.

\section{Recognition and Respect}

Their advocacy work not only impacted society but also has a positive effect on the personal lives of the participants. Several participants believed that their personal 
recognition and respect has increased as a result of their advocacy work. For example, when Rehana created two large national networks to support and advance the rights of women, she not only discerned the stark differences between the remote expanses of Pakistan and its bustling cities, but she also gained a great deal of respect from both urban and rural communities.

The participants referenced the ability to regularly deal with professionals and to be recognized as valuable peers as significant impacts of their work. Unique examples of this were Tanveer, who became a member of the National Commission on the Status of Women (the highest body to fulfill the promise of a life of dignity and justice for the women of Pakistan), and Tahseen, who was selected as a professional representative for various government committees/structures for policy monitoring and policy making.

Tahseen, Peter and Shad also received several prestigious national and international awards in acknowledgment for their advocacy work, however, this was particularly significant for Shad. She saw the recognition of her advocacy work as a way to "give back" to the community that supported her throughout the years. In her opinion, the International Women of Courage Award that she received was actually a recognition of "all Pashtun woman." It presented a "dignified picture" of them rather than merely as victims of violence.

\section{Women in Leadership}

This category that explained how advocacy work resulted in women in leadership included comments by both male and female research participants. They believed that, through their advocacy work, women emerged and flourished in leadership roles even in very conservative and harsh areas of Pakistan. Referring to the Taliban occupied area of 
the Swat Valley, Tahseen described that, by taking into account the strictest culture of the tribal area, his NGO first built the capacity of widows and older women who then emerged as leaders. These women subsequently opened up the realm of leadership for younger women and girls. Likewise, Rehana discussed in detail how through her Women Political School project, she trained over 25,000 elected women leaders to support their political engagement.

Shad mentioned several exceptional examples of how women emerged into leadership roles after learning to speak up for their rights and acquiring knowledge and skills through advocacy work. This was particularly true for women living in Dir, one of the most socially conservative regions of Pakistan. Dir is known as "a man's world," where politics is a men-only affair. The women of Dir courageously stepped out of their homes to challenge the decision of a Jirga and protected their voting rights through litigation.

Despite that minority women face double oppression (Jivan \& Jacob, 2012), Tanveer and Peter sought potential women leaders among minority groups, and their advocacy work provided numerous opportunities for integrating minorities into the larger fabrics of society. However, Tanveer also mentioned that "women belonging to marginalized communities always faced double discrimination ${ }^{26}$." Peter concluded that "there is yet a lot more to do for bringing them into powerful leadership positions."

\footnotetext{
${ }^{26}$ Double discrimination is when a person or a group is targeted for more than one form of discrimination.
} 


\section{Summary of Findings for the Theme of Assessing Impacts}

This section summarized four main points on how NGO leaders assessed the impacts of their advocacy work both at the policy and practice levels. First, participants believed that they had been able to impact and change the law-making and lawmonitoring structures in a variety of small and large ways. Consequently, implementation of existing laws and review of discriminatory laws were made possible.

Second, the participants' grassroots advocacy work increased awareness among the masses and encouraged people to challenge harmful traditions and customary laws. Eventually, these marginalized groups revisited and reformulated their value systems in accordance with the basic principles of human dignity and human rights.

Third, the visible personal impact for the participants was increased recognition and respect achieved through the effectiveness of their advocacy work.

Finally, several participants considered that their advocacy work helped to elevate women into leadership roles.

\section{Conclusion}

The findings of Chapter Five, summed in five themes (See Figure 1), show us that resilience remained the key feature for NGO leaders. This enabled them to make strategic decisions and to take courageous actions to sustain their advocacy work during difficult, often violent, times. In certain circumstances, these leaders deliberately strategized and adjusted their organizations' structures and systems in reaction to internal and external challenges. While in other situations, their decades-long advocacy work 
resulted in ongoing emergent strategic changes stemming from compromises and cooperation particularly with government departments and donors.

These findings indicated that whether NGO leaders formulated their strategies purposefully or hesitantly, they effectively impacted both policy and attitudinal changes in the challenging environment of Pakistan.

$\begin{array}{lll}\text { Getting Involved in Advocacy } & \begin{array}{l}\text { Childhood incidents, Political } \\ \text { environment, Vision, Legacy of } \\ \text { martyrs }\end{array} \\ \text { Meeting Internal Challenges } & \begin{array}{l}\text { Collaborating with government, } \\ \text { Negotiating with intelligence } \\ \text { agencies, Embracing culture, } \\ \text { Maintaining a low profile, } \\ \text { Harmonizing with media, Partnering } \\ \text { with donors }\end{array} \\ \text { Assessing Impacts } & \begin{array}{l}\text { Decentralizing power, Motivating } \\ \text { communities, Developing security } \\ \text { policies, Strengthening networks }\end{array} \\ & \begin{array}{l}\text { Reflective practices, Self-care, } \\ \text { Gaining family support, Cultivating a } \\ \text { circle of friends }\end{array} \\ & \begin{array}{l}\text { Changes in laws, Increased awareness } \\ \text { among masses, Recognition and } \\ \text { respect, Women in leadership }\end{array} \\ & \end{array}$

Figure 1. An overview of findings 


\section{CHAPTER SIX}

\section{DISCUSSION}

This chapter includes three sections. The first section provides an overview of the study including the purpose of the study, the research questions, and a review of the methodology, as well as some post-study reflections on the methods I employed. The second section relates the findings reported in Chapters Four and Five to the literature as described in Chapter Two. The last section presents implications and conclusions.

\section{Overview of the Study}

This study investigated how Pakistani NGO leaders use various advocacy approaches and practices for formulating effective strategies to sustain their advocacy work in the challenging environment of Pakistan. To attain this aim, I interviewed five NGO leaders who, despite facing a number of external and internal challenges, continued their advocacy work in various provinces of Pakistan.

The study focused on a central question and three sub-questions. The central question is: What strategies do NGO leaders use for effective advocacy work in a Pakistani context? The sub-questions are:

(a) How do external factors influence NGO leaders in developing their strategies for effective advocacy, and how do the leaders attempt to influence the external environment?

(b) How do internal factors influence NGO leaders in developing their strategies for effective advocacy, and what do the leaders do internally to create what is hopefully an effective organization? 
(c) What strategies do NGO leaders use to nurture their personal capacity for effective advocacy?

I selected a qualitative design to best accomplish the research purpose as "it has the power to enhance understanding of phenomenon by studying one's lived experience through stories" (Connelly \& Clandinin, 2006), and it "emphasizes qualities of entities - the processes and meanings that occur naturally" (Denzin \& Lincoln, 2000, p. 8). My qualitative design involved both narrative analysis and analysis of narrative (Polkinghorne, 1995). Since the narrative analysis approach (which was used here to construct the individual case studies) involved compiling stories and then arranging the particular stories told about the events and experiences of participants' lives chronologically, narrative analysis offered me enriching and often quite personal data to uncover the answers to the research questions. The analysis of narrative approach, which was used to do the cross-case analysis, subsumed the narrative data under categories and themes that may have laid the groundwork for theory development about the topic of this dissertation.

Although I was acquainted with the importance of a qualitative approach before beginning my doctoral studies, my thoughts about using a narrative approach were particularly fortified while taking a qualitative methods course as a doctoral student. I recall how articles by Polkinghorne (1995) inspired me to use a narrative approach when conducting my mini-study on the impact of human rights education in schools, especially when introduced in tandem with a biased education syllabus. Through this experience, I learned that narrative inquiry has the power to reveal the stories behind the 
numbers, and, subsequently, I was determined to use this approach for my dissertation as well.

I thought my selection of a qualitative design worked out well, particularly during the document review. I collected some advocacy posters (See Appendix D) which provided me with enriching information (Kwiatkowska, 1978; Willmuth \& Boedy, 1979) about the advocacy issues and strategies that I could not get through verbal dialogue with the participants. I constructed my interview guide after reading Polkinghorne's guidelines, (1995) and reviewing the documents. Following the interview guidelines, I interviewed five participants, each on two different occasions, for a total of 10 interviews. Each interview lasted 60 to 90 minutes.

My journal reflections recount that I was at ease while interviewing NGO leaders-Tahseen, Shad and Tanveer-whose colleagues were not killed during their advocacy work. Furthermore, since I myself had the experience of being an interviewee for documenting my own narrative, Harmony in the Garden, ${ }^{27}$ I understood how to create a friendly and safe space for an interviewee. Nevertheless, I was very conscious, while interviewing Peter and Rehana that the interview might disturb them, and it may also generate a kind of compassion fatigue ${ }^{28}$ for me, as well. Therefore, I told them, particularly Peter (whose seven colleagues were killed by militants), that they were the two participants whose colleagues had been assassinated by militants and their advocacy strategies would be especially significant for this study. I added that we could abandon

\footnotetext{
${ }^{27}$ Harmony in the Garden is a compilation of narrative stories about a Woman PeaceMaker, Rubina Feroze Bhatti along with additional information to provide a deep understanding of a contemporary conflict and one person's journey within it.

${ }^{28}$ The emotional residue or strain of exposure to working with those suffering from the consequences of traumatic events.
} 
the questions related to these incidents if my questioning became uncomfortable for them. Peter expressed grief and willingness to participate simultaneously, arguing: "But it is important to explore the ways for uncovering such significant but hurting stories." This openness encouraged me to courageously move forward with this study. I translated some of those interviews from the Urdu language to English which left me with mountains of data and "mines of codes" as described by Glesne and Pehskin (1992). I began the analysis process after each initial interview, and that helped me prepare for the second interview. First, I organized the data chronologically and developed an "emplotted narrative" for each of the NGO leaders from the transcribed data through a narrative analysis process as described by Polkinghorne (1995). There were two milestones in this time line: initiation of advocacy work and sustainability of advocacy work in later years. I constructed the cases and felt a special responsibility in interpreting the participants" words so these would be "their stories" and not "my stories."

For instance, I had a very thought-provoking conversation with Peter during his second interview. He shared many accounts of serious threats which he had been facing throughout his involvement in advocacy work, but unlike Rehana (a female interviewee), he was quite conscious about the use of language. I observed that he deliberately (or, maybe, inadvertently) preferred to use the word "we" rather than "I". I suspect by using the word "we," Peter may have been minimizing his threats and vulnerability in a hostile environment. He was struggling to integrate with the support system of NGOs, while Rehana appeared to be more in a kind of isolation. As I noticed, she cried many times while describing her risks in life and the killings of NGO leaders. 
I thought language was a significant factor to examine, including how/why the respondents select certain words/languages and what was their orientation to language. Therefore, in interpreting their stories, use of language relating to gender dimensions remained a major challenge for me, particularly while describing the incidents of character assassination of female participants. Consequently, writing these case studies was no doubt a fulfillment for me, but I was also mindful how participants would think.

After constructing the cases, I sent them to the participants for member check. Rehana responded with a comment that indicated, "The use of pseudonym detached me from my story, and I felt like I am [was] reading someone else's story out there.” Later on, some other issues came up making it difficult to mask the participants' identities while describing their exceptional advocacy work. Therefore, after getting feedback and consent from the other respondents and having a discussion with my supervisor, we made a decision to use real names. The other participants made minor changes regarding dates and duration of their work, but mostly they were satisfied with their stories. Tahseen commented, "I read it with great interest and indeed it is well written." After the individual cases were constructed, I returned to the data and conducted a cross-case analysis. As noted, at this point I used Polkinghorne's (1995) cross-case analysis strategy to organize data from interviews and documents into five major themes and 22 categories.

Interestingly, the sense of responsibility that weighed so heavily on me while constructing the case studies of individuals was not as apparent when I conducted the cross-case analysis and subsumed individuals' stories under codes and categories. My reflection journal recounts only that the cross-case analysis was a very challenging task. 


\section{Discussion}

The findings of this study support previous studies that highlight the impact of various political, economic and cultural factors on NGO leaders involved in advocacy work in developing countries (Reimann, 2006; Cohen et al., 2008; Naim, 2007, Lu, 2009; Tembo, 2003; Fowler, 1991; Mumtaz \& Shaheed, 1987). It further reflects various views and experiences of NGO leaders about the influence of several internal and external challenges on them and, subsequently, the strategies NGO leaders develop to respond to these challenges.

\section{Contributions of This Study}

In contrast to much of the existing research, this study presents some distinctive contributions. I will discuss those contributions individually. The summary of these contributions can be found in Figure 2. Then I will propose a theoretical framework that ties all the parts together and integrates the research findings into a unique contribution built on a theoretical paradigm of the organization as a transformative system.

First, the findings suggest that in the challenging environment of Pakistan, NGO leaders belonging to religious minorities are more vulnerable. Although all research participants mentioned the killing of a relative, friend or colleague, Peter (the only Christian participant) faced the most extreme adversity when seven of his colleagues were killed by militants. 


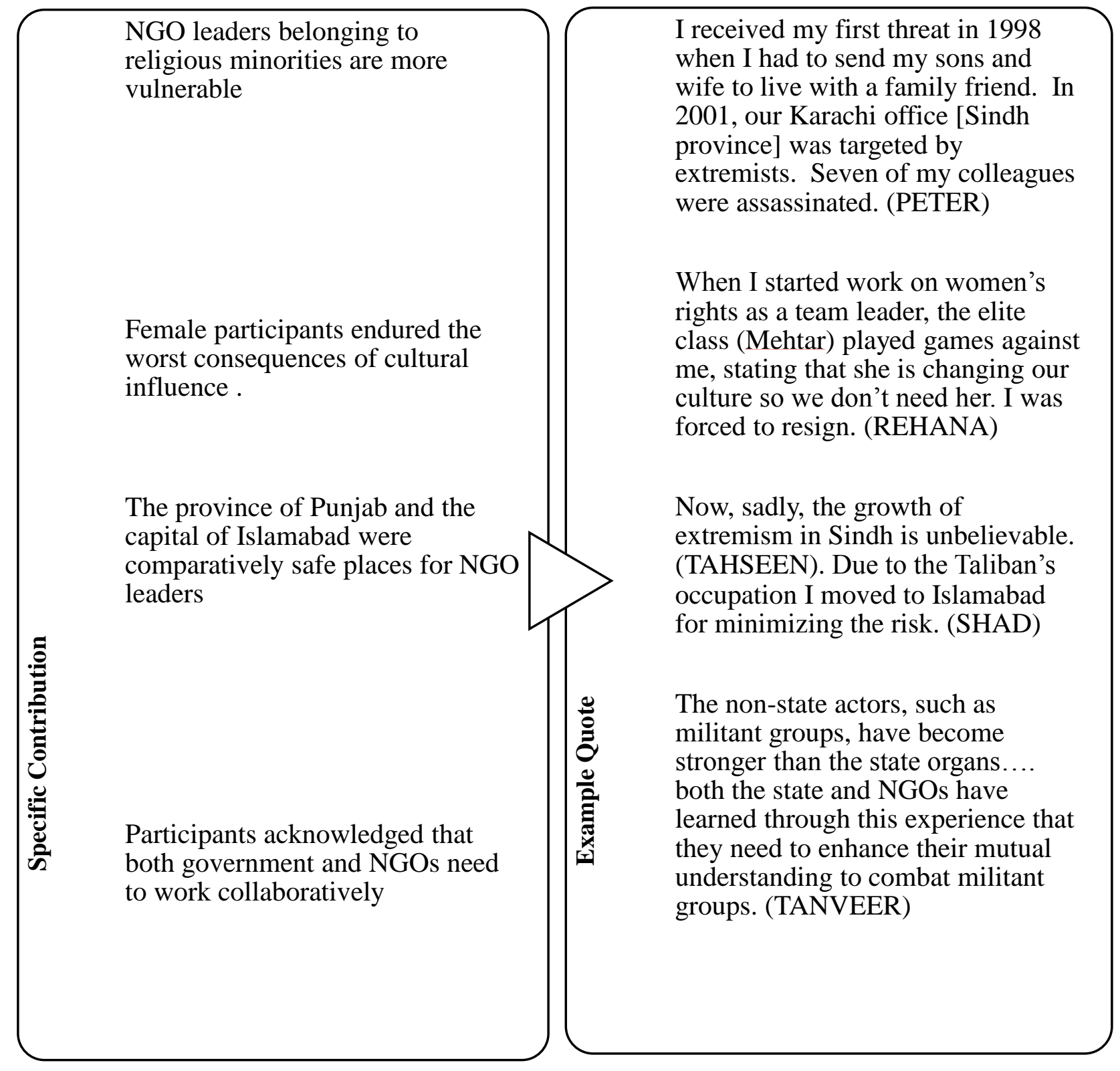

Figure 2. Contributions of the study. 
This suggestion from the research is only tentative because there was only one subject interviewed from a minority religion. However, evidence from this participant is powerful and drawn from extensive experience, justifying this suggestion from the research. The validity of this can be strengthened in the future with further interviews among religious minorities and evidence that can be gathered from the witness of observers from the religious majority.

Second, all research participants respected and embraced the diverse cultures of various communities for the continuation and acceptance of their advocacy work, however, despite their espousal of the local culture, female participants endured the worst consequences of cultural influence and were often rejected by the local communities. For instance, Rehana was considered to be "a stranger ruining their culture" and eventually was forced to resign and leave the area. Likewise, Tanveer experienced an extreme form of gender discrimination when she launched an empowerment program for the women of weaving communities. They were accused of converting women into sex workers. However, no male NGO leader bumped into such incidents of character rejection and assassination by the communities.

Third, the data suggest that the province of Punjab and the capital of Islamabad were comparatively safe places for NGO leaders. For instance, no research participant was forced to close his or her office due to severe threats by militants. However, research participants who operated elsewhere indicated that they, at times, closed offices that were located in Pakistan's other three provinces.

Fourth, a unique finding of this study is that all research participants acknowledged that non-state actors (militants) have been getting stronger and stronger, 
and, therefore, to counter the militants' power, both government and NGOs need to work collaboratively rather than engaging in confrontation. Consequently, a culture of mutual cooperation between NGO leaders and the Pakistani government is growing.

Finally, the findings indicate that, contrary to the literature I reviewed, all research participants described the media as an influential external factor impacting their advocacy work in the challenging environment of Pakistan. The qualitative data from three interviews provide a view that the media was an inhibiting factor that not only increased life threats for these participants but also forced them to maintain a low profile. Nevertheless, one participant found the media to be very supportive in her work. From this data we might infer that the media in turbulent settings carries potentially high risks and occasionally can be beneficial, forcing the NGO leader to make tough-minded decisions regarding relating to the media.

\section{Bidirectional Influence of External Factors and Countering Strategies}

This study reveals that the influence of external and internal factors was bidirectional-positive and negative-and, consequently, Pakistani NGO leaders developed and employed separate strategies to counter the negative and positive influences.

Bidirectional influence of political factors and countering strategies. All the research participants got involved in advocacy work during the martial law periods, either of General Ayub in the 1960s or of General Zia in the 1980s, to speak up for the protection of human rights and human freedoms. A variety of literature (Mumtaz \& Shaheed, 1987; Fowler, 1991; Rais, 1997; NGORC, 1999; Rizvi, 2000; Khawer \& Shaheed, 2004; Bano, 2008; Baqir, 2013) supports this finding and describes military regimes as a period of unprecedented reversals for women and minorities. Consequently, 
prominent organizations involved in advocacy work emerged to raise their voices against discriminatory laws against women and religious minorities. These advocacy organizations were not only discouraged by military regimes but were also perceived by military dictators and their pampered religio-political groups as entities with "an antiIslamic agenda" aiming to make Pakistan a secular state (HRCP, 2000; Iqbal, 2006; Milam, 2009; Naviwala, 2010). In short, in this respect, at least, the pattern in Pakistan with respect to the origins of advocacy work bears a strong family resemblance to patterns seen elsewhere.

The data in Chapter Five and each case study described in Chapter Four, however, further recounted the restrictions put on NGO leaders even by civilian governments. The fact that leaders and their organizations faced severe challenges (such as arrests, kidnappings of their staff by security forces, strict monitoring by government agencies, and false accusations) during democratic regimes is consistent with what other researchers have found. Pasha and Iqbal (2002) found that the democratic regime in 1999 introduced a strict NGO Bill for greater "control” of NGOs.

Besides introducing strict laws against NGOs, unlike other studies, the findings of this study also revealed how the consequences of the government's negative posture towards advocacy NGOs indirectly, but negatively, impacted NGO leaders. It encouraged the militants to use coercive means against advocacy NGOs that they believed were "enemies of Islam" working for a Western agenda. One participant observed the relationship of right-wing political parties with militants, while the other four participants clearly stated that they had received "threats from militants." Although this finding is largely a unique contribution in the Pakistani context, it does align with 
other research from other developing countries (Rais, 1997; Rizvi, 2000; HRCP, 2000; Smillie \& Hailey, 2001; Iqbal et al., 2004; Iqbal, 2006; Jaffar, 2007; Milam, 2009; Naviwala, 2010) which suggests that advocacy NGO leaders, particularly those advocating for women's rights, face more antagonism from religious militants than other types of NGOs.

Given that many of the participants faced the adversities of external challenges, their ability to sustain their advocacy work is admirable. For the continuation of their advocacy work, they employed several strategies such as going into hiding when threatened by militant groups or closing their offices in dangerous areas rather than compromising their values. The work of Smillie and Hailey (2001) supports this finding that the NGO sector in developing countries is growing because NGO leaders have had the ability to develop coping strategies to encounter the influence of a volatile environment. A previous study (Hailey \& James, 2004) also supports the capability of NGO leaders to motivate communities by engaging them in advocacy work.

In contrast to the threats and negative actions, there have also been positive political influences. Pakistani NGO leaders participated in lobbying meetings with parliamentarians for the approval of pro-women and pro-minorities legislations. They also realized that "the war on terror influenced by geo-political factors cannot be fought by NGOs, and they need to collaborate with government" as mentioned by Tahseen. Furthermore, considering the growing influence of militants in the country, the Pakistani NGO leaders and state actors learned that they need to cooperate with each other to counter these militants. This shift toward embracing a strategy of cooperation was illustrated by this study. Tanveer, for example, made a shift from protesting against 
government to initiating a dialogue with government. Rehana, while working with the government, successfully negotiated with women parliamentarians for "approval of prowomen laws."

When NGOs are able to positively collaborate with government agencies and leaders it can reduce risk for the organization and at the same time generate positive impacts for government. A previous study on social capital by Boix \& Posner (1998) supports that collaboration between NGOs and the government also is helpful to the government. These authors, for example, note that collaboration with government can increase the effectiveness of government by fostering a culture of dialogue among communities of conflicting opinions as well as between communities and the government. This sort of dialogue strengthens democratic institutions.

Bidirectional influence of economic factors and countering strategies. The study also reveals the bidirectional influence of economic factors on both the NGO and its donors. Based on the participants' experiences, the findings demonstrate that the government often exerted influence over an NGO's donors through their policies, thus limiting donors regarding their area of operation and type of work. Because of the pressure from the government, these donors negatively influenced NGO leaders by employing a top-down approach and endorsing pro-government policies. NGO's must recognize that the external challenge or opposition from the Government can force donors to withdraw support from the NGO, thus sabotaging the work of advocacy. For instance, Peter pointed out that to avoid the criticism of the government about advocacy work "donors go into development projects" because short-term tangible outcomes of development projects would delight the government. Tanveer further highlighted the 
financial crisis during General Musharraf's era when donors adjusted their policies in accordance with the military regime and provided substantial funding to NGOs, mainly for the implementation of Musharraf's devolution plan. Some previous research supports this finding that in developing countries due to political instability, donors formulate or modify their policies in accordance with the ruling government whether it is a military regime or a civilian government (Riemann, 2006; Cohen et al., 2008; Tembo, 2003; Bano, 2008; Brass, 2011).

Therefore, the NGO, which is dependent on donor funding, must be astute in recognizing how government can strategize to undercut the NGO's funding as a way to restrict effective advocacy.

The research participants found themselves struggling to cope with external challenges when government and donors combined to provide both active and passive pressure for the NGO to reduce their advocacy efforts. For instance, Peter discussed a series of events during which he strategically compromised with donors or government agencies in order to sustain his advocacy work. Likewise, after UN Women terminated their contract with Rehana when she was facing death threats from a militant group, she continued to work voluntarily with them to establish the EVAW Alliance to address the issue of violence against women. However, neither Peter nor Rehana left their advocacy work or started charity work to please the government or donors. In fact, all research participants stood firm with their visions, principles and values, no matter how severe the crises were.

This study refutes the findings of Goodhand and Chamberlain (1996) who indicated that, while working in hostile environments, NGO leaders assume the strategy 
of "dancing to the tune of the prince" whether the prince is a government, a donor or a militant. Consequently, rather than continuing an effective advocacy, they may try to "please the prince" in order to ensure their survival in turbulent environments.

In contrast to the negative impacts, the data in this study also revealed positive economic influences which enabled NGO leaders to enhance their advocacy achievements by building equitable partnerships with donors. For instance, one participant mentioned that donors not only enhanced the capacity of NGO leaders but also supported their vision of a just society in which the rights of minorities will be safe from the whims of intolerant majorities. This means that, when vision and money match, “an equitable partnership emerges" as mentioned by Peter. The NGO which forges solid partnerships with donors, combining vision, funds and sustained commitment, will be able to counter the negative pressure from government and maintain its advocacy efforts.

Examples of such partnering strategies related to donors' substantial support surfaced from the interviews. One female leader received "generous support of donors" for her women empowerment work. In addition, one male leader, who had long-term support from donors, said: "They never interfere in our work." These statements demonstrate that in politically unstable developing countries it is important for NGO leaders to navigate their ways and formulate the right strategies for creating a strategic and equitable partnership with donors.

Brass (2011) supported such countering strategies through partnerships when he noted that donors sometimes make difficult choices about whether to incline towards government or to support NGOs. Some clearly choose to align themselves with NGOs. 
The research by NGORC (1999) affirmed that donors made strategic decisions for explosive growth of NGOs in Pakistan during the Cold War era in the 1980s.

The data presented further shows that during financial crises Pakistani NGO leaders successfully managed human resources by employing the strategies of engaging their communities, establishing volunteer networks, or "working without salaries." Tanveer, Tahseen and Rehana all established large "voluntary national networks" and harnessed a trust relationship among them for timely coordinated action to sustain their advocacy work, while Peter and Shad engaged hundreds of volunteers to mobilize their communities for approval of pro-women and pro-minorities' laws and policies to ensure participation of women and minorities in the political process. The previous studies (Winder \& Mundt, 1998; Petro, 2001) on social capital support this finding that the efficacy of society could be improved by harnessing trust relations among the networks of civic engagement for facilitating coordinated action. This shapes new possibilities on the level of democratic growth and strong democracy.

Bidirectional influence of cultural factors and countering strategies. The data demonstrated that some female research participants reported cultural challenges to effective advocacy. This was triggered by harmful traditions and cultural norms and practices, which left little room for NGO leaders to engage in advocacy work at the community level. The community's resistance to allow female leaders to participate in social action was a main challenge. As this study revealed, it included a belief that only male leaders should join social networks to benefit the community. Shad faced "strong opposition of community" when she organized women in social groups to protect their rights, which also enhanced their mobility. People's perceptions of female leaders are 
especially significant barriers in Pakistani society. Pakistan's cultural perspective of favoring a "big man" for leadership positions often constrained women from pursuing leadership roles. Tanveer concluded, in Pakistani culture, being a girl meant she was "not allowed to play outdoor games with boys." Such a mindset restricts females' mobility and limits women's leadership opportunities.

The influence of culture was evident when Tanveer and her grassroots leaders encountered extremists who started a hate campaign against them. The extremists stated that Tanveer and her grassroots leaders were ruining their culture by making girls into "sex workers."

Rehana also believed that "culture is a big barrier" for women's attempts to exercise leadership. When she emerged as a woman leader, her male colleagues and the elite class (Mehtar) of the area excluded her and accused her, in their words, of "changing our culture." These findings are somewhat similar to that of Jaffar (2007) who noted that women leaders of advocacy NGOs face more antagonism from religious extremists in Pakistani society than other types of NGOs because extremist menfolk think that the secular approach of advocacy organizations brings obscenity and pollution into their culture.

The data also revealed the positive influence of cultural factors. In some cases, when female leaders developed workable strategies for a multicultural Pakistani society, they gained support and respect from communities. Rehana, while working in all provinces of Pakistan, "learned seven languages" to better understand local communities and establish a trust relationship between her and the communities, and she successfully established the largest network of women councilors across the country. Shad and 
Tanveer showed cultural sensitivity by wearing traditional and modest dress. Attention to these cultural factors enhanced their acceptance and respect in tribal and conservative communities and helped to develop trust relationships within tribal settings. These findings align with other research that Al-Suwaihel (2009) conducted in various Islamic countries which revealed that women could be accepted as leaders in traditional communities if they respect the culture.

In sum, in the discussion about developing strategies for countering external challenges, participants in this study indicated that they preferred to develop different strategies in accordance with the changing environment. As an example, under the negative influence of external factors, sometimes they reduced their risk by adopting a low profile in their work style or changed the nature of their work. However, under the positive influence of a conducive environment, they employed many cooperation strategies such as lobbying with parliamentarians, negotiating with donors and INGOs, and engaging communities to increase the effectiveness of their advocacy work and to bring a significant social change. Previous studies also suggest that the role of NGO leaders and the effectiveness of their advocacy work is determined by the strategies they devise within — and in response to - the changing environment in which they work (Fowler, 1997; Smillie \& Hailey, 2001; Hailey \& James, 2004; James et al., 2005).

\section{Bidirectional Influence of Internal Factors and Countering Strategies}

The data presented also documents strategies formulated by NGO leaders to meet internal challenges to organizational effectiveness for advocacy. NGO leaders developed their skills and abilities to create a visionary leadership style that enabled them to lead with integrity by establishing a rapport with their staff and communities to manage the 
internal challenges of human resources. For instance, one participant mentioned that his staff is "committed and courageous" because of the organization's visionary leadership. Another female leader said, through "decentralization I shared power and authority with staff but also enhanced their commitment." In addition, one participant said the "flat structure" of his organization reduced hierarchical power and staff got "inspiration" from him. The values of openness and trustworthiness in the organizational culture allowed staff to communicate their thoughts and concerns with freedom. Previous researchers (Hailey \& James, 2004; Smillie \& Hailey, 2004) noted the same result that NGO leaders have a clear vision, a firm value set, and a strong commitment which they transfer to their staff.

The findings indicate that some participants acknowledged that not all staff members have a clear vision and commitment. For instance, Tahseen clearly stated that some "come for a job" and do not understand the organizational vision. Shad modestly highlighted the issue of high turnover of staff because short-term funded projects could not "meet their financial needs." A previous research study (Bano, 2008) aligns with this finding that, rather than vision or commitment, material incentives inspire people to work for NGOs because the salaries of NGO personnel are larger than salaries on the government scale. However, the higher salary argument does not apply in these cases as some NGO leaders devised a paternalistic leadership style to enhance the commitment of staff. For instance, Tahseen needs to "take care of my 241 staff." Shad and Rehana used the word "family" for staff and developed a rapport with them by taking care of their needs and situations. This finding in some ways agreed with Hailey's (1999) comment 
that the NGO sector has sufficient paternalistic leaders, known as "charismatic autocrats" or "the guru syndrome."

The study further demonstrates that NGO leadership in turbulent environments is not an easy endeavor. The results suggest that though the research participants developed their leadership skills and strategies to accomplish their objectives, they paid a high price for that either in the form of personal loss or professional setback.

Even though personal resilience is critical for sustained work in stressful environments, self-care was not a priority for most of the research participants. As they were not formally trained in the leadership field or the self-care arena to achieve significant outcomes, they neither made time for individual reflection, nor developed formal support systems for reducing risk for themselves and their staff. In a previous research study, Chambers (1997) maintains that "such NGO leaders can achieve many things through their "guts, vision and commitment, but they are equally vulnerable to acquiescence, deference, flattery and placation" (p. 76).

In this study, participants described resilience as one of their central strategies for coping with adversities. The findings revealed that even though they neglected self-care they believed that adaptation that fits with the challenging environment was required at both the personal and organizational levels. For instance, Rehana's personal adaptation strategy involved "frequently moving locations, occasionally going into hiding," while Tahseen's adaptation strategy at the organizational level enabled him to curtail his work in dangerous areas. However, neither Rehana nor Tahseen stopped their struggle for change through a sustained advocacy work. Coutu (2002) supports this finding that 
resilient individuals not only accept the harsh ground realities but also have a knack for discovering meaning during difficult times.

Despite all these challenges and restrictions, qualitative evidence confirms that NGO leaders developed effective leadership strategies to initiate and sustain their advocacy work in Pakistan's turbulent environment. They learned skills, developed their capabilities, revisited their strategies, and lead with integrity to positively influence the society. In a country where political instability, economic crises, cultural barriers, religious intolerance, discriminatory practices, and terrorism are a part and parcel of everyday life, the NGO leaders' assessment of the effectiveness of their advocacy work in terms of changes in laws as well as their contributions to attitude change among the masses are a substantial finding.

\section{Data in Search of a Theoretical Framework}

Based on the research I conducted for this dissertation, I have concluded that a transformative systems framework can be employed to guide NGO leaders in restrictive environments as they seek to impact their world through effective advocacy. A theoretical model, or paradigm, views the NGO organization as an input-output system. The model requires the organization and its leaders to remain highly flexible and fluid in the midst of external challenges and turbulence. Internally, the organization has to develop simple and flexible structures, decentralized power, and create an organizational environment that supports resilience of both the staff and the organization.

The external inputs that come into the organization, both financial resources and people, must be carefully filtered so that they do not redirect the organization away from its core mission. This allows for a process of transformation within the organization to 
occur, affecting staff, structures, programs and policies that enable the NGO to meet the external challenges and generate effective advocacy outputs that impact the external world. The framework also helps NGO leaders to understand the influence of the geostrategic context on the political context of the country while formulating their strategies. Based on my research, I have created a theoretical framework depicted in Figure 3. Systems-Framework for Effective Advocacy to link all the major findings of the research.

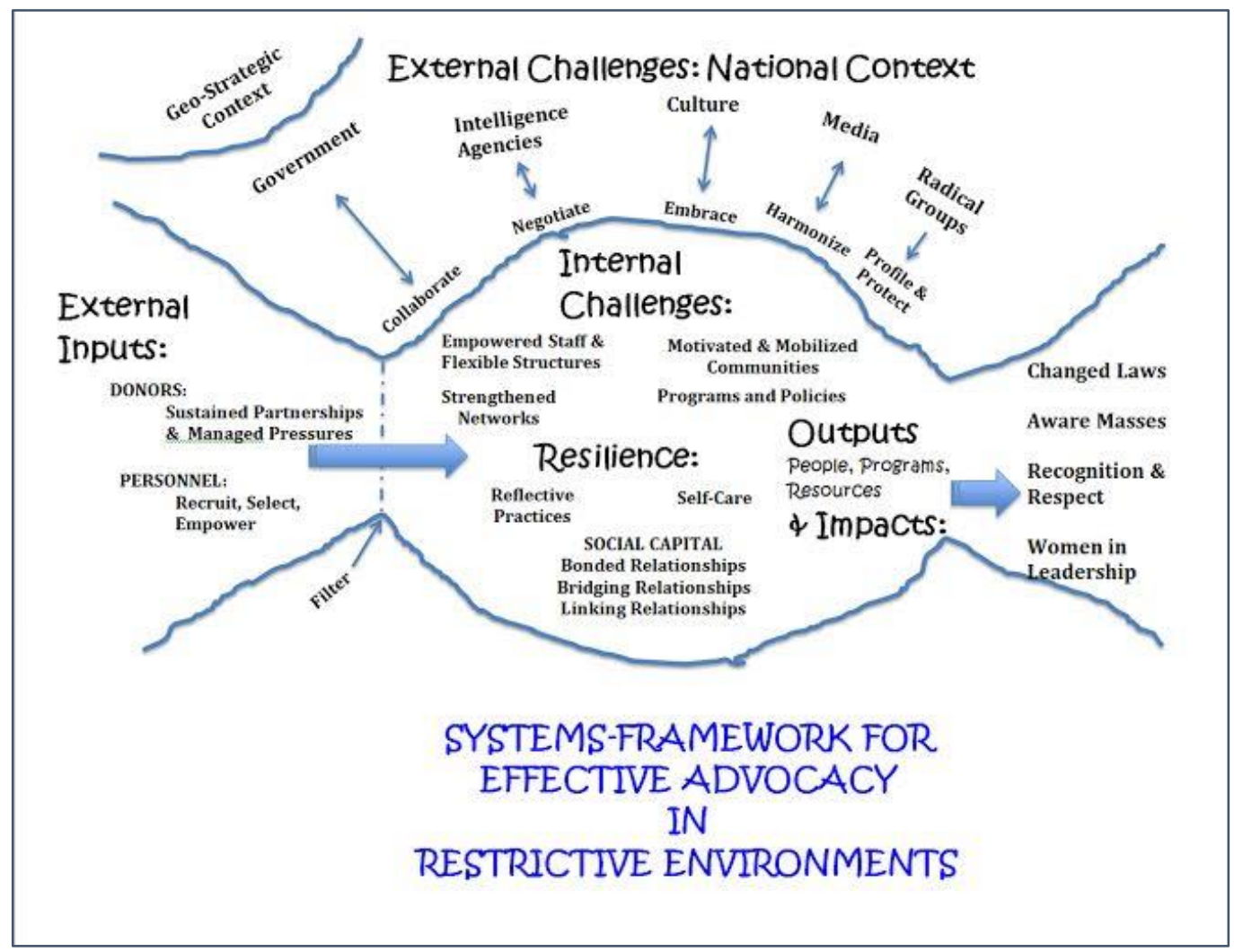

Figure 3. Systems-framework for effective advocacy

Additionally, I have created a set of self-assessment questions that can be used as a guide for NGO leaders as they craft for themselves and their organizations a pathway for effective advocacy in such restrictive environments. The self-assessment is used to 
personalize and apply the systems framework displayed in the diagram. The selfassessment questions can be found in Appendix E.

\section{Conclusion and Implications}

This study represents one attempt to explore the effectiveness of strategies of NGO leaders involved in advocacy work in Pakistan and is among a limited number of papers that address the question in any developing, but politically unstable country like Pakistan. Despite this study's potential for considering the role of NGO leaders in bringing a social change through their effective advocacy, it must be considered in the full light of its limitations and delimitations. Two key delimitations describe the boundaries of this study. First, it includes only Pakistani NGO leaders involved in advocacy work. The second delimitation was the sample selection criteria that I developed for this study.

Regarding limitations related to this study, the first limitation was my role as researcher and my long-term involvement in advocacy work. To address this issue, I tried to maintain an awareness of my own subjectivity throughout the research process, so that as Wolcott (1990) suggests, though I make no claim to getting it all right, "I went to great pains so as not to get it all wrong" (p. 127). My reflective journals helped me to keep my thinking unbiased and positive throughout this journey of exploration.

Ideally, to improve the validity of the study findings, document review and a variety of interviews with those who work for and with each participant would allow for triangulation and more accurate convergence of the findings (Denzin, 1978, as cited in Mathison, 1988). Furthermore, I used a small sample size and the participants in this study were purposefully selected; further research using stratified random sampling 
would be valuable. With all these limitations, the findings cannot be applied to the larger population.

The findings of this study could help the participants to reexamine the effectiveness of their efforts by also considering leaders' nurturing as an important aspect of advocacy work rather than merely focusing on the set frameworks of advocacy program assessment, comprised of goals, activities and outcomes. Consequently, I believe that this study has a three-pronged implication as described below.

\section{Implications for Practice}

Most qualitative research designs focus on cross-case analysis and pay less attention to narrative analysis. The experiences of NGO leaders seems to indicate that they have key roles and authority in making adjustments within their organizations for an effective advocacy work in the often challenging context of Pakistan. The majority of the research participants in this study reported being overburdened and stressed, though this did not stop them from their advocacy work for change. It is recommended that they may revisit their existing strategies related to advocacy in light of the deeper understanding they gain through the research process, and, subsequently, they may take some practical steps at the organizational level regarding self-care and support mechanisms.

Representation and contribution in influential government structures for policy change was reported by the research participants as a successful initiative, nevertheless, further practical steps are needed to be taken by NGO leaders to ensure that community members or volunteer networks are included in such structures for an effective advocacy. This also suggests that there is a need for affirmative action within the NGOs to develop 
female leaders, and this could subsequently motivate other sectors to support women in leadership.

\section{Implications for Policy}

The implications for policy are stemmed into the implications for practices. For instance, according to the majority of the participants, donors sometimes undermine the need and effectiveness of advocacy work and focus more on development work. This narrative inquiry recommends bringing some changes in the policy arena related to donors' policies for the assessment of advocacy work. It further endorses the need for donors to develop a support mechanism for the NGO leaders at high risk.

Though all research participants reported their advocacy achievements through bringing a change in laws, the data did not indicate if these NGO leaders made some serious lobbying efforts for the formulation of a consistent and just government policy for advocacy NGOs. Therefore, the study also offers some suggestions to NGO leaders about improving advocacy work in a challenging environment through using the lessons of the study heuristically (Donmoyer, 1990). There is an implication that both donors and NGO leaders should make a collective effort for devising a consistent policy or an NGO Bill for advocacy NGOs to minimize their risks in challenging environments.

\section{Implication for Future Research}

The study leaves a lot of room for further investigation. Additional research, both quantitative and qualitative, on this topic in other developing countries, especially the war-torn Afghanistan that borders with Pakistan, would provide further understanding of strategies of NGO leaders involved in advocacy work. Different countries have different influences on NGO leadership. Therefore, these findings suggest that further research in 
neighboring countries, particularly the politically unstable countries, can explore the issues and differences related to political, economic and cultural influences. It will further help in discerning the leadership strategies of NGO leaders in these countries to respond to the negative or positive impacts of the external factors. Consequently, this is the first area where further research is required.

Second, the findings point to the strong influence of cultural factors on the women's leadership sphere. More acknowledgment should be focused on the organization's culture in terms of making collaborative efforts toward modifying the organizational structure and developing strategies that include women in leadership for the benefit of the organization. Thus, further inquiry in this area is required to investigate how leaders first understand the existing organization's culture, and then how they evaluate and modify the organization's strategic objectives in a way that enables the leaders to develop actions for cultivating women leaders.

Third, the findings suggest that the media, by publicizing the work of NGO leaders, often places them at greater risk. Therefore, further research is needed to assess the influence of the media in order to get a deeper understanding of the risks of NGO leaders related to the effectiveness of their advocacy work. I also suggest that future researchers focus their efforts on the positive influence of the media on NGO leaders for the sustainability of their work.

Finally, the study found that, when threats were serious, it traumatized NGO leaders regardless of gender, religion, class or academic ability. Therefore, NGO leaders need strong applied support both from donors and INGOs to not only recover from their trauma but also to receive substantial encouragement to develop their capabilities in 
leadership. However, no mandate can assure the sustainability of advocacy work or growth of NGO sectors without the provision of safety nets for NGO leaders that empower them to transform the negative influences of various factors into positive influences. That is the next and most important level of this study. 


\section{REFERENCES}

ABKT (2015) Our Vision. Retrieved from http://www.abkt.org/

Action Aid., Institute for Development Studies Participation Group., \& Just Associates. (2002). Making change happen: Advocacy and citizen participation. Retrieved from http://www.justassociates.org/en/resources/mch1-advocacy-and-citizenparticipation

Adair, J. (2002). Effective strategic leadership. London: Macmillan.

Adger, W. N. (2006). Vulnerability. Global Environmental Change, 16(3), 268-281.

Agaibi, C. E., \& Wilson, J. P. (2005). Trauma, PTSD, and resilience: A review of the literature. Trauma, Violence, \& Abuse, 6(3), 195-216.

Aga Khan Development Network (AKDN). (2000). Enhancing indigenous philanthropy for social investment: A report of the initiative on indigenous philanthropy. Islamabad: Aga Khan Development Network.

Aldrich, H., \& Ruef, M. (2006). Organizations evolving. Thousand Oaks, CA: Sage.

Ali, T. (1983). Can Pakistan survive? The death of a state. Harmondsworth: Penguin Books.

Alinsky, S. (1989). Rules for radicals: A pragmatic primer for realistic radicals. New York: Vintage.

Alinsky, S. (2010). Rules for radicals. New York: Random House LLC.

Allison, M. (2002). Into the fire: Boards and executive transitions. Non-profit Management \& Leadership, 12(4), 341-51.

Almog-Bar, M., \& Schmid, H. (2014). Advocacy activities of nonprofit human service Organizations: A critical review. Nonprofit and Voluntary Sector Quarterly, 43(1), 11-35.

Al-Mughni, H. (1993). Women in Kuwait: The politics of gender. London: Saqi Books.

Al-Suwaihel, O. (2009). Kuwaiti female leaders' perspectives: The influence of culture on their Leadership. Journal of Public Administration and Policy Research, 1(3), 055-062.

American Nurses Association (ANA) (Ed.). (2010). Nursing's social policy statement: The essence of the profession. Silver Spring: Nursesbooks.org. 
Anderson, I. (2000). Northern NGO advocacy: Perceptions, reality, and the challenge. Development in Practice, 10(3-4), 445-452.

Anderson, L. (1998). Contextualizing philanthropy in South Asia: A text analysis of Sanskrit source. In W. F. Ilchman, S.N. Katz., \& E, Queen, Philanthropy in the world's traditions (pp. 57-78), Bloomington: Indiana University Press.

Andrews, K., \& Edwards, B. (2004). Advocacy organizations in the U.S. political process. Annual Review of Sociology, 30, 479-506.

Andrews, M., Squire, C., \& Tamboukou, M. (Eds.). (2013). Doing narrative research. London: Sage.

Anheier, H.K., \& Salamon, L.M. (1998). The nonprofit sector in developing world: A comparative analysis. Manchester: Manchester University Press.

Arts, B. (1998). The political influence of global NGOs: Case studies on the climate and biodiversity conventions. Netherlands: Jan van Arkel (International Books).

Atiyyah, H. S. (1992). Research in Arab countries. Organization Studies, 13(1), 105-110.

Atkinson, D. (1999). Advocacy: A review. Brighton: Pavillion/Joseph Rowntree.

Baig, A. S. R. (2001). Civil society in Pakistan. Civicus Index on Civil Society Occasional Paper Series, 1(11).

Bakuwa, R. C., Chasimpha, F., \& Masamba, J. (2013). Staff retention in developing countries: A case study of an NGO in the health sector. International Journal of Human Resource Studies, 3(1), 158-174.

Bano, M. (2007). Whose public action? Analyzing inter-sectorial collaboration for service delivery: Pakistan country review: History of state-NSP relations. International Development Department (IDD).

Bano, M. (2008a). Contested claims: Public perceptions and the decision to join NGOs in Pakistan. Journal of South Asian Development, 87(3), 87-108.

Bano, M. (2008b). Dangerous correlations: Aid's impact on NGOs' performance and ability to mobilize members in Pakistan. World Development, 36(11), 2297-2313.

Baqir, F. (2002). A module on participatory development. Islamabad: NRSP.

Baqir, F. (2012).The evolution of volunteerism in Pakistan. Unpublished paper. Presented at SPO Discussion Paper Series on Understanding Pakistan, Islamabad, Pakistan. 
Baqir, F. (2013). Civil society movements in Pakistan. Unpublished paper, Akhter Hameed Khan Resource Centre, Islamabad, Pakistan.

Barr, A., Fafchamps, M., \& Owens, T. (2003). The governance of non-governmental organizations in Uganda. World Development, 33(4), 657-79.

Bass, B. M., \& Bass, R. (2009). The Bass handbook of leadership: Theory, research, and managerial applications. New York: Simon and Schuster.

Baumgartner, F. R., \& Jones, B. (1993). Agendas and instability in American politics. Chicago:University of Chicago Press.

Baviskar, A. (1999). In the belly of the river: Tribal conflicts over development in the Narmada Valley. Oxford University Press.

Bayart, J.F. (1993). The state in Africa: The politics of the belly. New York: Longman.

Beck, U. (2000), Risk society revisited: theory, politics and research programmes. In B.Adam, U. Beck, \& J. van Loon (Eds.), The risk society and beyond: Critical issues for social theory (pp.211-29). London: Sage Publications.

Bennis, W., \& Nanus, B. (2004). Leaders. New York: HarperCollins.

Bergan, D. E. (2009). Does grassroots lobbying work? A field experiment measuring the effects of an e-mail lobbying campaign on legislative behavior. American Politics Research, 37(2), 327-352.

Berger, P. L., \& Neuhaus, R. J. (1977). To empower people: The role of mediating structures in public policy. Washington, DC: American Enterprise for Public Policy.

Berkes, F. (2007). Understanding uncertainty and reducing vulnerability: Lessons from resilience thinking. Natural Hazards, 41(2), 283-295.

Berry, J.M. (2005). Nonprofits and civic engagement. Public Administration Review, 65(5), 567-578.

Berry, J., \& Arons, D. F. (2003). A voice for nonprofits. Washington, DC: The Brookings Institution.

Betsill, M. M., \& Corell, E. (Eds.). (2008). NGO diplomacy: The influence of nongovernmental organizations in international environmental negotiations. Cambridge, MA: MIT Press.

Bharadwaj, P., Khwaja, A., \& Mian, A. (2008). The big march: Migratory flows after partition of India. Mumbai: Sameeksha Trust. 
Biklen, D. P. (1983). Community organizing theory and practice. Englewood Cliffs, NJ: Prentice-Hall.

Boix, C., \& Posner, D. N. (1998). Social capital: Explaining its origins and effects on government performance. British Journal of Political Science, 28(4), 686-693.

Boli, J., \& Thomas, G. (1999). Constructing world culture: International nongovernmental organizations since 1875. Stanford, CA: Stanford University Press.

Boli, J., Thomas, G., John, M., \& Francisco, R. (1987). Institutional structure: Constituting state, society, and the individual. Beverly Hills: Sage.

Bonanno, G. A. (2004). Loss, trauma, and human resilience: Have we underestimated the human capacity to thrive after extremely aversive events? American Psychologist, 59(1), 20-28.

Boris, E., \& Mosher-Williams, R. (1998). Nonprofit advocacy organizations: Assessing the definitions, classifications, and data. Nonprofit and Voluntary Sector Quarterly, 27(4), 488-506.

Boris, E. \& Krehely, J. (2002). Civic participation and advocacy. In L. Salamon (Ed.), The state of nonprofit America, (pp.299-330). Washington, DC: Brookings Institution Press.

Boris, E. T., \& Steuerle, C. E. (2006). Scope and Dimensions of the Non-Profit Sector. In W.W. Powell \& R. Steinberg (Eds.) The Non-Profit Sector: A Research Handbook (pp.66- 88). New Haven: Yale University Press.

Boylan, J., \& Dalrymple, J. (2009). Understanding advocacy for children and young people. Maidenhead: Open University Press.

Brandon, D., \& Brandon, T. (2001). Advocacy in social work. Birmingham: Venture Press.

Brass, N. J. (2011). Why do NGOs go where they go? Evidence from Kenya. World Development, 40 (2), 387-401.

Bratton, M. (1989). The politics of government-NGO relations in Africa. World Development, 17(4), 569-587.

Breen, C. (2003). The role of NGOs in the formulation of and compliance with the optional protocol to the Convention on the Rights of the Child on involvement of children in armed conflict. Human Rights Quarterly, 25(2), 453-481. 
Brown, L. D., \& Kalegaonkar, A. (2002). Support organizations and the evolution of the NGO sector. Nonprofit and Voluntary Sector Quarterly, 31(2), 231-258.

Brooks, T. R. (1974). Walls come tumbling down: A history of the civil rights movement, 1940-1970. Englewood Cliffs, N.J.: Prentice-Hall.

Bruner, J. (1986). Actual minds, possible worlds. Cambridge, MA: Harvard University Press.

Bryer, D., \& Magrath, J. (1999). New dimensions of global advocacy. Nonprofit and voluntary Sector Quarterly, 28(1), 168-177.

Bryson, J. M., \& Anderson, S. R. (2000). Applying large-group interaction methods in the planning and implementation of major change efforts. Public Administration Review, 60(2), 143-162.

Buchanan, T. (2002). 'The truth will set you free': The making of Amnesty International. Journal of Contemporary History, 49 (3), 575-597.

Campbell, J. (2009). Resilience personal and organisational. Retrieved from http://www.lifetimeswork.com/index.php?id=101

Carothers, T., \& Barndt, W. (1999). Civil society. Foreign Policy, 1 (117) 18-29.

Casey, J. (2011). Understanding advocacy: A primer on the policy-making role of nonprofit organizations. New York: Baruch College.

Casey, J., \& Dalton, B. M. (2006).The best of times, the worst of times: Community sector advocacy in the age of compacts. Australian Journal of Political Science, 41, 23-38.

Chambers, R. (1997). Whose reality counts?: Putting the first last. London: IT Publications.

Chapman, J., Wameyo, A. (2001). Monitoring and evaluating advocacy: A scoping study. London: Action Aid.

Chaves, M., Stephens, L., \& Galaskiewicz, J. (2004). Does government funding suppress nonprofits' political activity? American Sociological Review, 69(2), 292-316.

Child, C., \& Gronberg, K. (2007). Nonprofit advocacy organizations: Their characteristics and activities. Social Science Quarterly, 88(1), 259-281.

Christie, C. A., \& Alkin, M. C. (2003). The user-oriented evaluator's role in formulating a program theory: Using a theory-driven approach. American Journal of Evaluation, 24(3), 373-385. 
Clandinin, D. J., Pushor, D., \& Orr, A. M. (2007). Navigating sites for narrative inquiry. Journal of Teacher Education, 58(1), 21-35.

Clark, A. M. (2010). Diplomacy of conscience: Amnesty International and changing human rights norms. Princeton, N.J.: Princeton University Press.

Clark, J. (1991). Democratizing development: The role of voluntary organizations. West Hartford, CT: Kumarian Press.

Clarke, G. (1998). Non-governmental organizations (NGOs) and politics in the developing world. Political Studies, 1(46) 36- 52.

CODE-NGO. (1998). CODE-NGO and co-multiversity's approach to the successor generation program. Manila: CODE-NGO.

Cohen, C. P. (1990). The role of nongovernmental organizations in the drafting of the Convention on the Rights of the Child. Human Rights Quarterly, 12(1), 137-147.

Cohen, D., de la Vega, R., \& Watson, G. (2001). Advocacy for social justice: A global action and reflection guide. Bloomfield, CT: Kumarian Press.

Cohen, M., Kupcu, F. M., \& Khanna, P. (2008). New colonialists. Foreign Affairs (16): 74-79.

Coleman, J. S. (1988). Social capital in the creation of human capital. American Journal of Sociology, S95-S120.

Coleman, J. S. (1990) Foundations of social theory. Cambridge, MA: Harvard University Press.

Coleman, M., \& Ganong, L. (2002). Resilience and families. Family Relations, 51(2), 101-102.

Community Empowerment and Social Inclusion (CESI). (2003). Advocacy, communication and coalition building. Washington DC: World Bank.

Connelly, F. M., \& Clandinin, D. J. (2006). Narrative inquiry. In J. L. Green, G. Camilli, \& P. B. Elmore (Eds.), Handbook of complementary methods in education research (pp. 375-385). Mahwah, NJ; Washington, DC: Lawrence Erlbaum Associates; Published for the American Educational Research Association.

Cook, H. (1996). Amnesty International at the United Nations. In: P.Willetts. (ed.), The conscience of the world: The influence of non-governmental organisations in the UN system (pp. 181-213). London: Hurst. 
Corry, O. (2010). Defining and theorizing the third sector. In R. Taylor (ED.), Third sector research (pp. 11-20). New York: Springer.

Coutu, D. L. (2002). How resilience works. Harvard Business Review, 80(5), 46-56.

Cress, D. M., \& Snow, D. A. (1996). Mobilization at the margins: Resources, benefactors, and the viability of homeless social movement organizations. American Sociological Review, 61, 1089-1109.

Creswell, J. (1998). Qualitative inquiry and research design. Thousand Oaks, CA: Sage Publications.

Creswell, J. (2005). Educational research: Planning, conducting, and evaluating quantitative and qualitative research. Upper Saddle River, NJ: Pearson Education.

Davenport, M. (2012). Historical complexities of NGO relationships in Pakistan. Retrieved from http://graphitepublications.com/wpcontent/uploads/2013/04/Historical-Complexities-of-NGO-Relationships-inPakistan.pdf

Davies, R. (2001). Evaluating the effectiveness of DFID's influence with multilaterals. Part A: A review of NGO approaches to the evaluation of advocacy work. Retrieved from http://mande.co.uk/blog/wp-content/uploads/2011/07/AReview-of-NGO-Approaches-To-Advocacy.pdf

De Leon, P. (1992). The democratization of the policy process. Public Administration Review, 52(2), 125-129.

Denhardt, R. B., \& Denhardt, J. V. (2000). The new public service: Serving rather than steering. Public Administration Review, 60(6), 549-559.

Denzin, N. K., \& Lincoln, Y. (2000). Qualitative research. Thousand Oaks, CA: Sage Publications.

DeVita, C., Montilla, M., Reid, B., \& Fatiregun, O. (2004). Organizational factors influencing advocacy for children. Washington, DC: Urban Institute Press.

Dhesi, A. S. (2000). Social capital and community development. Community Development Journal, 35(3), 199-214.

Diaz, S. (2013). Standing with our sisters: The life and work of Rehana Hashmi of Pakistan. Retrieved from https://lib.sandiego.edu/peacestudies/documents/ipj/Rehana-Hashmi-Pakistan.pdf 
Domhoff, G. W. (1990). The power elite and the state: How policy is made in America. New York: Aldine De Gruyter.

Donaldson, L. P. (2007). Advocacy by nonprofit human service agencies: Organizational factors as correlates to advocacy behavior. Journal of Community Practice, 15(3), 139-158.

Donaldson, L. (2008). Developing a progressive advocacy program within a human services agency. Administration in Social Work, 32(2), 25-47.

Donmoyer, R. (1990). Generalizability and the single-case study. In: E. W. Eisner \& A. Peshkin (Eds.), Qualitative inquiry in education: The continuing debate (pp. 175200). New York: Teachers College Press.

Donnelly, J. (1981). Recent trends in UN human rights activity: Description and polemic. International Organization, 35(4), 633-655.

Dotlich, D., \& Noel, J. (1998). Action learning. San Francisco: Jossey-Bass.

Duffield, M. (1997). NGO relief in war zones: Towards an analysis of the new aid paradigm. Third World Quarterly 18(3): 527-542.

Earvolino-Ramirez, M. (2007). Resilience: A concept analysis. In Nursing Forum, 42 (2), 73-82.

Edwards, M. (1993). 'Does the doormat influence the boot?': Critical thoughts on UK NGOs and international advocacy. Development in Practice, 3(3), 163-175.

Edwards, M., \& Hulme, D. (Eds.). (1992a). Making a difference: NGOs and development in a changing world. London: Earthscan.

Edwards, M., \& Hulme, D. (1992b). Scaling up NGO impact on development: Learning from experience. Development in practice, 2(2), 77-91.Emden, C. (1998). Conducting a narrative analysis. Collegian 5(3), 34-39.

Ezell, M. (2001). Advocacy in the human services. Belmont, CA: Wadsworth/Thomson Learning.

Fafchamps, M., \& Owens, T. (2009). The Determinants of funding to Ugandan nongovernmental organizations. World Bank Econ Rev, 23(2), 295-321.

Fagen, M. C., Reed, E., Kaye, J. W., \& Jack, L. (2009). Advocacy evaluation: What it is and where to find out more about it. Health Promotion Practice, 10(4), 482-484.

Field, J. (2003). Social capital. London: Routledge. 
Finnemore, M., \& Sikkink, K. (1998). International norm dynamics and political change. International Organization, 52(4), 887-917.

Fisher, J. (1993). The road from Rio: Sustainable development and the nongovernmental movement in the Third World. CT: Praeger Publishers.

Fletcher, D., \& Sarkar, M. (2013). Psychological resilience: A review and critique of definitions, concepts, and theory. European Psychologist, 18(1), 12-23.

Fogel, J. H. (1975). To the IRS, 'Tis better to give than to lobby. ABAJ, 61, 960.

Fowler, A. (1991). The role of NGOs in changing state-society relations: Perspective from Eastern and Southern Africa. Development Studies, 4(15), 759-787.

Fowler, A. (1997). Striking a balance: A guide to enhancing the effectiveness of NGOs in international development. London: Earthscan.

Fox, L., Helweg, P., \& Hansen, G. (1997). Advocacy strategies for civil society: A conceptual framework and practitioner's guide. Unpublished paper for USAID.

Frazer, H. (2005). Setting the scene Europe-wide: The challenge of poverty and social exclusion. Community Development Journal, 40(4), 371-384.

Fruttero, A., \& Gauri, V. (2005). The strategic choices of NGOs: Location decisions in rural Bangladesh. Journal of Development Studies, 41(5), 759-787.

Fukuyama, F. (1999). Social capital and civil society. Retrieved from http://www.eope.ee/_download/euni_repository/file/1256/varukoopia-rit7016-201011041213.zip/course_files/Kirjandus/Fukuyama_1999_Social_Capital_and_Civil_Soci ety.pdf

Gadgil, M., \& Guha, R. (1994). Ecological conflicts and the environmental movement in India. Development and Change, 25(1), 101-136.

Galaskiewicz, J., \& Bielefeld, W. (1998). Organizations in an age of uncertainty: A study of organizational change. New York: Aldine de Gruyter.

Gallagher, D. R., \& Jackson, S. E. (2008). Promoting community involvement at brownfields sites in socio-economically disadvantaged neighbourhoods. Journal of Environmental Planning and Management, 51(5), 615-630.

Gardner, A., \& Geierstanger, S. (2007). Working with logic models to evaluate a policy and advocacy program. The Evaluation Exchange, 13(1), 8-9. 
Garrow, E. E. (2011). Receipt of government revenue among nonprofit human service organizations. Journal of Public Administration Research and Theory, 21(3), 445471.

Garrow, E. E., \& Hasenfeld, Y. (2012). Institutional logics, moral frames, and advocacy: Explaining the purpose of advocacy among nonprofit human-service organizations. Nonprofit and Voluntary Sector Quarterly. Published online. doi: $10.1177 / 0899764012468061$

Gen, S., \& Wright, A. C. (2012) . A framework for policy advocacy. Retrieved from http://wpsa.research.pdx.edu/meet/2012/genandwright.pdf

Ghaus-Pasha, A., Jamal, H., \& Iqbal, M. A. (2002). Dimensions of the nonprofit sector in Pakistan. SPDC, Karachi.

Ghaus-Pasha, A \& Iqbal, M.A. (2003). Defining the nonprofit sector: Pakistan. Working Papers of Johns Hopkins Comparative Nonprofit Sector Project, no. 42. Baltimore: The Johns Hopkins Institute for Policy Studies.

Giugni, M. G. (1998). Was it worth the effort? The outcomes and consequences of social movements. Annual Review of Sociology, 24(1), 371-393.

Glesne, C. (2011). Becoming qualitative researchers: An introduction. Boston: Pearson.

Glesne, C., \& Peshkin. (1992). Becoming qualitative researchers: An introduction. White Plains, NY: Longman.

Goodhand, J., \& Chamberlain, P. (1996). 'Dancing with the prince': NGO's survival strategies in the Afghan conflict. Development in Practice, 6(3), 196-207.

Gramsci, A. (1971). Selections from the Prison Notebooks of Antonio Gramsci. New York, International Publishers.

Gray, R., Bebbington, J., \& Collison, D. (2006). NGOs, civil society and accountability: Making the people accountable to capital. Accounting, Auditing \& Accountability Journal, 19(3), 319-348.

Greenleaf, R. (1998). The power of servant leadership. San Francisco: Berrett-Koehler.

Gunderson, L. H., \& Holling, C.S. (2002). Panarchy: Understanding transformations in human and natural systems. Washington, D.C.: Island Press.

Hailey, J. (1999). Charismatic, autocrats or development leaders: Characteristics of first generation NGO. Oxford: Oxford Brookes University. 
Hailey, J., \& James, R. (2004). "Trees die from the top": International perspective on NGO leadership development. Voluntas: International Journal of Voluntary and Nonprofit Organizations, 15(4), 343-353.

Hansmann, H. (1987). Economic theories of nonprofit organization. In W. W. Powell (Ed.), The nonprofit sector: A research handbook (pp. 27-42). New Haven, CT: Yale University Press.

Hasan, A. (2006). Orangi Pilot Project: The expansion of work beyond Orangi and the mapping of informal settlements and infrastructure. Environment and Urbanization, 18(2), 451- 480.

Heifetz, R. A. (1994). Leadership without easy answers. Cambridge, MA: Harvard University Press.

Henderson, R., \& Pochin, M. (2001). A right result?: Advocacy, justice and empowerment. Bristol: The Policy Press.

Hepworth, D. \& Larsen, J. (1986). Direct social work practice and skills. Chicago: The Dorsey Press.

Hoefer, R. (2012). Advocacy practice for social justice. Chicago, IL: Lyceum Books.

Hoffmann, T. (1999). The meanings of competency. Journal of European Industrial Training, 23 (6): 275-286.

Hofstede, G. (1991). Cultures and organizations: Software of the mind: Intercultural cooperation and its importance for survival. New York: Harper Collins.

Holloway, R. (1998). Establishing and running an advocacy NGO. AKDN Civil Society Programme. Retrieved from http://www.akdn.org/publications/civil_society_advocacy_ngo.pdf

House, R. J., \& Aditya, R. N. (1997). The social scientific study of leadership: Quo vadis? Journal of Management 23(3), 409-473.

House, R. J., Hanges, P. J., Javidan, M., Dorfman, P. W., \& Gupta, V. (Eds.). (2004). Culture, leadership, and organizations: The GLOBE study of 62 societies. Sage publications.

Hsu, S. H. (2005). Advocacy coalitions and policy change on nuclear power utilization in Taiwan. The Social Science Journal, 42(2), 215-229.

Hudson, A. (2000), Making the connection: Legitimacy claims, legitimacy chains and Northern NGOs international advocacy. In D. Lewis, \& T, Wallace. (Eds.), After 
the new policy agenda? Non-governmental organisations and the search for development Alternatives, Bloomfield, CT: Kumarian Press.

Human Rights Commission of Pakistan (HRCP) (2000). State of human rights in 2000, annual report. Lahore: Human Rights Commission of Pakistan.

Human Rights Watch (HRW). (1995). Playing the "communal card": Communal violence and human rights. London: Human Rights Watch.

IFCB. (1998). Southern NGO capacity building: Issues and priorities. New Delhi: PRIA.

IFCB. (2001). Southern NGO capacity building: Issues and priorities. New Delhi: PRIA.

Independent Sector (IS) (2012). Beyond the cause: The science and art of advocacy. Retrieved from http://www.independentsector.org/uploads/advocacystudy/ISBeyondtheCause-Full.pdf

Iqbal, M. A. (2006). The ideological divide of the nonprofit sector in Pakistan. In International Conference of the International Society for Third Sector Research. Accessed from http://c.ymcdn.com/sites/www.istr.org/resource/resmgr/working_papers_bangkok liqbal.muhammadasif.pdf

Iqbal, M. A., Khan, H., \& Javed, S. (2004). Nonprofit sector in Pakistan: Historical background, Karachi: Social Policy and Development Centre.

Jaffar, A. (2007). Engaging fundamentalism: The case of women's NGOs in Pakistan. Social Problems, 54(3), 256-273.

James, R. (2008). Leadership development inside-out in Africa. Nonprofit Management and Leadership, 18(3), 359-375.

James, R., Oladipo, J., Isooba, M., Mboizi, B., \& Kusima, I. (2005). Realities of change: How African NGO leaders develop. Praxis Paper No.6, Oxford: INTRAC.

Jenkins, J. C. (1987). Nonprofit organizations and policy advocacy. In W. Powell (Ed.), The nonprofit sector: A research handbook (pp. 296-320). New Haven, CT: Yale University Press.

Jenkins, J. C. (2006). Nonprofit organizations and political advocacy. In W. W. Powell \&R. S. Steinberg (Eds.), The nonprofit sector: A research handbook (2nd ed., pp. 307-322). New Haven, CT: Yale University Press.

Jivan, J.J, \& Jacob, P. (2012). Life on the Margins. Lahore: NCJP. 
Johansen, M., \& LeRoux, K. (2013). Managerial networking in nonprofit organizations: The impact of networking on organizational and advocacy effectiveness. Public Administration Review, 73(2), 355-363.

Josselson, R., \& Lieblich, A. (1993). The narrative study of lives. Newbury Park, CA: Sage.

Kaplan, A. (2002). Development practitioners and social process: Artists of the invisible. London: Pluto Press.

Karns, M., \& Mingst, K (2010). International organizations: The politics and processes of global governance. Boulder: Reinner.

Kastens, B., \& Newig, J. (2008). Will participation foster the successful implementation of the water framework directive? The case of agricultural groundwater protection in northwest Germany. Local Environment, 13(1), 27-41.

Katzenstein, Peter. (1996) Introduction: Alternative perspectives on national security. In P. Katzenstein (Ed.), The culture of national security: Norms and identity in world politics, New York: Columbia University Press.

Keck, M. E., \& Sikkink, K. (1998). Activists beyond borders: Advocacy networks in international politics. Ithaca, NY: Cornell University Press.

Keefer, P., \& Knack, S. (1997). Why don't poor countries catch up? A cross-national test of an institutional explanation. Economic Inquiry, 35(3), 590-602.

Keller, L. M. (2001). The indivisibility of economic and political rights. Human Rights \& Human Welfare, 1(3), 9-14.

Kellogg, W. K. (2004). Logic model development guide. Michigan: WK Kellogg Foundation.

Khan, A. H. (1996). Orangi Pilot Project: Reminiscences and reflections. Karachi: Oxford University Press.

Khan, A, (2014). Address of His Highness the Aga Khan to both Houses of the Parliament of Canada in the House of Commons Chamber, Ottawa, Retrieved from http://www.akdn.org/Content/1253/Address-of-His-Highness-the-AgaKhan-to-both-Houses-of-the-Parliament-of-Canada-in-the-House-of-CommonsChamber-Ottawa

Khan, A., \& Khan, R. (2004). Drivers of change Pakistan. Retrieved from http://www.researchcollective.org/Documents/Civil_Society_And_Social_Change _In_Pakistan.pdf 
Khawer, M., \& Shaheed, F. (1987). Women in Pakistan: Two steps forward, one step back. Lahore: Vanguard Books.

Kimberlin, S. E. (2010). Advocacy by nonprofits: Roles and practices of core advocacy organizations and direct service agencies. Journal of Policy Practice, 9(3-4), 164182.

Kincheloe, J.L. \& McLaren, P. (2005). Rethinking critical theory and qualitative research. In N. Denzin and Y. Lincoln (Eds.), The Sage handbook of qualitative research (3rd Ed., pp 303-342). Thousand Oaks, CA: Sage Publications.

King, N. K. (2004). Social capital and nonprofit leaders. Nonprofit Management and Leadership, 14(4), 471-486.

Kingdon J. (2002). Agendas, alternatives, and public policies. New York: Longman.

Kitto, S. C., Chesters, J., \& Grbich, C. (2008). Quality in qualitative research. Medical Journal of Australia, 188(4), 243-246.

Klugman, B. (2011). Effective social justice advocacy: A theory-of-change framework for assessing progress. Reproductive health matters, 19(38), 146-162.Knowlton, L. W., \& Phillips, C. C. (2012). The logic model guidebook: Better strategies for great results. Thousand Oaks, CA: Sage.

Koch, D.J. \& Ruben, R. (2008). Spatial clustering of NGOs: An evolutionary economic geography approach. Papers in Evolutionary Economic Geography, (08.14). Retrieved from: http://econ.geo.uu.nl/peeg/peeg0814.pdf.

Koenig, H. O. (2005). Empowerment in local government administration: The case of Elgin, Illinois. The Innovation Journal: The Public Sector Innovation Journal, 10(1). 1-10.

Korten, D. (1990). Getting to the 21st century: Voluntary action and the global agenda. West Hartford, CT: Kumarian.

Korwin, L. (2009). The catalyst fund theory of change. San Francisco: Korwin Consulting for the Tides Foundation.

Kotter, J. (1996). Leading change. Cambridge, MA.: Harvard Business School Press.

Kvale, S., \& Brinkmann, S. (2009). InterViews: Learning the craft of qualitative research interviewing. Los Angeles: Sage Publications.

Kwiatkowska, H. Y. (1978). Family therapy and evaluation through art. Springfield, IL: Thomas. 
Kwon, H. J. (2007). Advocacy coalitions and health politics in Korea. Social Policy \& Administration, 41, 148-161.

Laney, M. L. (2003). Advocacy impact assessment guidelines. Retrieved from http://www.innonet.org/resources/files/Advocacy_Impact_Assessment_Guideline $\underline{\text { s.pdf }}$

Larsen, E. (1978). A flame in barbed wire: The story of Amnesty International. London: Muller.

LeRoux, K., \& Goerdel, H. T. (2009). Political advocacy by nonprofit organizations: A strategic management explanation. Public Performance \& Management Review, 32(4), 514-536.

Lewis, D. (2005). Actors, ideas and networks: trajectories of the nongovernmental in development studies. In U. Kothari (Ed.), A radical history of development studies. London: Zed Books.

Lewis, D., \& Kanji, N. (2009). Non-governmental organisations and development. New York: Routledge.

Lincoln, Y. S., \& Guba, E. G. (1985). Naturalistic inquiry. Beverly Hills, CA: Sage.

Longstaff, P. H. (2009). Managing surprises in complex systems: Multidisciplinary perspectives on resilience. Ecology and Society, 14(1), 49.

Lu, Y. (2009). Non-governmental organizations in China: Paving the way to civil society?, New York: Routledge.

Macbeth, D. (2001). On "reflexivity" in qualitative research: Two readings and a third. Qualitative Inquiry, 7(1), 35-68, doi: 10.1177/107780040100700103

Mahoney, J. L., \& Bergman, L. R. (2002). Conceptual and methodological considerations in a developmental approach to the study of positive adaptation. Journal of Applied Developmental Psychology, 23(2), 195-217.

Martens, K. (2002). Mission impossible? Defining nongovernmental organizations. Voluntas: International Journal of Voluntary and Nonprofit Organizations, 13(3), 271-285.

Martens, K. (2004). An appraisal of Amnesty International's work at the United Nations: Established areas of activities and shifting priorities since the 1990s. Human Rights Quarterly, 26(4), 1050-1070.

Mathison, S. (1988). Why triangulate? Educational Researcher, 17(2), 13-17. 
Maxwell, J. A. (2013). Qualitative research design, an interactive approach (Third ed.). Thousand Oaks, CA: Sage Publications.

McLaverty, P. (2011). Participation. In M. Bevir, (Ed.), The sage handbook of governance, (pp. 402-417). Thousand Oaks, CA: Sage.

McNutt, J. (2011). Is social work advocacy worth the cost? Issues and barriers to an economic analysis of social work political practice. Research on Social Work Practice, 21(4), 397-403.

Mercer, C. (2003). Performing partnership: Civil society and the illusions of good governance in Tanzania. Political Geography, 22(7) 741-763.

Merriam, S. B. (2009). Qualitative research: A guide to design and implementation. San Francisco, CA: Jossey-Bass.

Merriam, S. B., \& Associates (2002). Qualitative research in practice: Examples for discussions and analysis. San Francisco, CA: John Wiley \& Sons.

Milam, W.B. (2009) Bangladesh and Pakistan: Flirting with failure in South Asia. New York: Columbia University Press.

Miles, M. B., \& Huberman, A. M. (1994). Qualitative data analysis (2nd ed.). Thousand Oaks, CA: Sage.

Miller, M. L. (1986). Reliability and validity in qualitative research. Sage.

Miller, V. (1994). NGOs and grassroots policy influence: What is success. IDR Reports, $11(5), 2-24$.

Mills, C. W. (2000). The power elite. New York: Oxford University.

Moghimi S.M. (2007).The relationship between environmental factors and organizational entrepreneurship in non-governmental organizations (NGOs) in Iran. Iranian Journal of Management Studies, (IJMS), 1(1), 39 -55.

Morariu, J., \& Brennan, K. (2009). Effective advocacy evaluation: The role of funders. The Foundation Review, 1(3), 100-108.

Morris-Suzuki, T. (2000). For and against NGOs: The politics of the lived world. Development and Socioeconomic Progress, 2(3), 54-72.

Morse, J. M., Barrett, M., Mayan, M., Olson, K., \& Spiers, J. (2002). Verification strategies for establishing reliability and validity in qualitative research. International Journal of Qualitative Methods, 1(2). Retrieved from: http://www.ualberta.ca/ijqm 
Mosley, J. E. (2010). Organizational resources and environmental incentives:

Understanding the policy advocacy involvement of human service nonprofits. Social Service Review, 84(1), 57-76.

Mosley, J. E. (2011). Institutionalization, privatization, and political opportunity: What tactical choices reveal about the policy advocacy of human service nonprofits. Nonprofit \& Voluntary Sector Quarterly, 40, 435-457.

Mosley, J. E., \& Ros, A. (2011). Nonprofit agencies in public child welfare: Their role and involvement in policy advocacy. Journal of Public Child Welfare, 5(2-3), 297-317.

Mumtaz, K., \& Shaheed, F. (1987). Women in Pakistan: Two steps forward, one step back? London: Zed Books.

Nahapiet, J., \& Ghoshal, S. (1998). Social capital, intellectual capital, and the organizational advantage. Academy of Management Review, 23(2), 242-266.

Naim, M. (2007). What is a gongo? Foreign Policy 160 (6): 95-96.

Naviwala, N. (2010). Harnessing local capacity: U.S. assistance and NGOs in Pakistan. Retrieved from Carr Center for Human Rights Policy: http://www.hks.harvard.edu/cchrp/sbhrap/forum/article_0003/HarnessingLocalCa pacity.pdf

NCJP (2013) Strategic Review. Unpublished manuscript.

Nelson, M. P., \& Vucetich, J. A. (2009). On advocacy by environmental scientists: What, whether, why, and how. Conservation Biology, 23(5), 1090-1101.

Nelson, P. J., \& Dorsey, E. (2008). New rights advocacy: Changing strategies of development and human rights NGOs. Washington: Georgetown University Press.

NGO Resource Center (NGORC). (1999). The state of the citizen sector in Pakistan. Karachi: NGO Resource Centre.

Nicholson-Crotty, J. (2007). Politics, policy, and the motivations for advocacy in nonprofit reproductive health and family planning providers. Nonprofit and Voluntary Sector Quarterly, 36(1), 5-21.

Nizami, F. A. (1983). Madrasahs, scholars, saints: Muslim response to the British presence in Delhi and Upper Doab 1803-1857. Unpublished D.Phil Dissertation, University of Oxford. 
Noman, O. (1990) Pakistan: A political and economic history since 1947. London: Kegan Paul International.

Nyamugasira, W. (1998). NGOs and advocacy: How well are the poor represented?. Development in Practice, 8(3), 297-308.

Nye, J., \& Keohane, R. (1972) Transnational Relations and World Politics: An Introduction. In R. Keohane and J. Nye (Ed.), Transnational relations and world politics. Cambridge: Harvard University Press

Onwuegbuzie, A. J., \& Daniel, L. G. (2003). Typology of analytical and interpretational errors in quantitative and qualitative educational research. Current Issues in Education, 6(2), 1-29.

Onyx, J., Armitage, L., Dalton, B., Melville, R., Casey, J., \& Banks, R. (2010). Advocacy with gloves on: The "manners" of strategy used by some third sector organizations undertaking advocacy in NSW and Queensland. VOLUNTAS: International Journal of Voluntary and Nonprofit Organizations, 21(1), 41-61.

Ostrom, E. (1990). Governing the commons: The evolution of institutions for collective action. Cambridge: Cambridge University Press.

Ostrom, E. (2000). Social capital: A fad or a fundamental concept. In P. Dasgupta, I. Serageldin (Eds.), Social capital: A multifaceted perspective, (172-214). Washington, D.C.: The World Bank.

Parks, T. (2008). The rise and fall of donor funding for advocacy NGOs: Understanding the impact. Development in Practice, 18(2), 213-222.

Pasha, A. G., Iqbal, M. A., \& Mumtaz, S. (2002). Non-profit sector in Pakistan: Government policy and future issues. The Pakistan Development Review, 41(3), 879-908.

Patton, M. Q. (1990). Qualitative evaluation and research methods. Newbury Park, CA: Sage Publications.

Patton, M. Q. (2002). Qualitative research \& evaluation methods (3rd ed.). Thousand Oaks, CA: Sage.

Petro, N. N. (2001). Creating social capital in Russia: The Novgorod model. World Development, 29(2), 229-244.

Pfeffer, J. (1982). Organizations and organization theory. Boston: Pitman.

Polkinghorne, D. E. (1988). Narrative knowing and the human sciences. Suny Press. 
Polkinghorne, D. E. (1995). Narrative configuration in qualitative analysis. International Journal of Qualitative Studies in Education, 8(1), 5-23.

Powell, W.W., \& Steinberg, R. (2006). The non-profit sector: A Research Handbook. Yale:Yale University Press.

Price, R. (1997). The chemical weapons taboo. Ithaca, NY: Cornell University Press.

Putnam, R. (2000). Bowling alone: The collapse and revival of American community. New York: Simon \& Schuster.

Putnam, R. D., Leonardi, R., \& Nanetti, R. Y. (1994). Making democracy work: Civic traditions in modern Italy. Princeton: Princeton university press.

Rais, R. B. (1997). State, society and democratic change in Pakistan. Karachi: Oxford University Press.

Randeria, S. (2003). Glocalization of law: Environmental justice, World Bank, NGOs and the cunning state in India. Current Sociology, 51(3-4), 305-328.

Rappaport, J. (1981). In praise of paradox: A social policy of empowerment over prevention. American Journal of Community Psychology, 9(1): 1-25.

Rees, S. (2001). Effective advocacy on limited resources. In E. Reid \& M. Montilla (Eds.), Exploring organizations and advocacy: Strategies and finances. Nonprofit Advocacy and the Policy Process: A Seminar Series, Volume 2, Issue 1. Retrieved from http://www.urban.org/UploadedPDF/org_advocacy.pdf.

Reid, E. J. (2000). Understanding the word "advocacy": Context and use. In E. J. Reid (Ed.), Structuring the inquiry into advocacy: Nonprofit advocacy and the policy process, a seminar series (pp. 1-8).Washington, DC: Urban Institute.

Reid, E. (2006). Nonprofit advocacy and political participation. In E. T. Boris \& C. E. Steuerle (Eds.), Nonprofits and government: Collaboration and conflict (pp.343371). Washington, DC: Urban Institute Press.

Reid, R., \& Botterill, L. C. (2013). The multiple meanings of 'resilience': An overview of the literature. Australian Journal of Public Administration, 72(1), 31-40.

Reimann, K. D. (2006). A view from the top: International politics, norms and the worldwide growth of NGOs. International Studies Quarterly, 50(1), 45-68.

Reisman, J., Gienapp, A., \& Stachowiak, S. (2007). A guide to measuring advocacy and policy. Retrieved from http://www.ncladvocacy.org/SampleOutcomes_HarvardEvalExchange.pdf 
Richardson, G. E. (2002). The metatheory of resilience and resiliency. Journal of Clinical Psychology, 58(3), 307-321.

Riddell, R. (2007). Does foreign aid really work? Oxford: Oxford University Press.

Rizvi, H. A. (2000). Military, state and society in Pakistan. London: Macmillan Press.

Roche, C. J. (1999). Impact assessment for development agencies: Learning to value change. Oxfam.

Rubio, M. (1997). Pervasive social capital: Some evidence from Colombia. Journal of Economic Issues, 31(3), 805-816.

Rugendyke, B. (Ed.). (2007). NGOs as advocates for development in a globalising world. New York: Routledge.

Rutter, M. (1999). Resilience concepts and findings: Implications for family therapy. Journal of Family Therapy, 21(2), 119-144.

Sabatier, P. A. (Ed.). (1999). Theories of the policy process (pp. 117-166). Boulder, CO: Westview Press.

Sabatier, P. A., \& Jenkins-Smith, H. C. (1999). The advocacy coalition framework: An assessment. In P. A. Sabatier (Ed.), Theories of the policy process (pp. 117-166). Boulder, CO: Westview Press.

Salamon, L. M. (2002). Explaining nonprofit advocacy: An exploratory analysis. Baltimore, MD: Center for Civil Society Studies, Johns Hopkins University.

Salamon, L. M., Sokolowski, S. W., \& List, R. (2003). Global civil society: An overview. Center for Civil Society Studies, Institute for Policy Studies, The Johns Hopkins University.

Saldaña, J. (2009). The coding manual for qualitative researchers. London: Thousand Oaks, CA: Sage.

SAP-PK (2015) Vision. Retrieved from http://sappk.org/

Sato, H. (1999). The advocacy coalition framework and the policy process analysis: The case of smoking control in Japan. Policy Studies Journal, 27(1), 28-44.

Schlager, E. (1995). Policy making and collective action: Defining coalitions within the advocacy coalition framework. Policy Sciences, 28(3), 243-270. 
Schmid, H., Bar, M., \& Nirel, R. (2008). Advocacy activities in nonprofit human service organizations: Implications for policy. Nonprofit \& Voluntary Sector Quarterly, 37(4), 581-602.

Schneider, R., \& Lester, L. (2001). Social work advocacy: A new framework for action. Belmont CA: Brooks Cole.

Schoener, W. (1997). Non-governmental organizations and global activism: Legal and informal approaches. Ind. J. Global Legal Stud., 4(2), 537. Retrieved from http://heinonline.org/HOL/Page?handle=hein.journals/ijgls4\&div=30\&g_sent=1\& collection=journals\#543

Scott, I. (2012). Analyzing advocacy issues in Asia. Administration \& Society, 44 (6), 412.

Seal, A. (1968). The emergence of Indian nationalism: Competition and collaboration in the later nineteenth century. Cambridge: Cambridge University Press.

Shelton, D. (1994). The participation of nongovernmental organizations in international judicial proceedings. American Journal of International Law, 88 (4), 611-642.

Sherani, A.R. (1991). Ulema and Pir in the politics of Pakistan. In H. Donnan and P. Werbner (Eds.), Economy and culture in Pakistan: Migrants and cities in a Muslim society, London: Macmillan.

Siddiqi, M. S. (2001). Who will bear the torch tomorrow? Charismatic leadership and second-line leaders in development NGOs. International Working Paper 9. Centre for Civil Society, London School of Economics and Political Science.

Skjelsbaek, K. (1972). The growth of international nongovernmental organization in the twentieth century. In Transnational relations and world politics, $\mathrm{R}$. Keohane and J. Nye (Ed.). Cambridge: Harvard University Press.

Smillie, I. (1995). The alms bazaar: Altruism under fire-non-profit organizations and international development. International Development Research Centre (IDRC).

Smillie, I. and Hailey, J. (2001). Managing for change: Leadership, strategy and management in Asian NGOs. London: Earthscan.

Stachowiak, S. (2013). Pathways for change: 10 theories to inform advocacy and policy change efforts, Washington DC: Center for Evaluation Innovation.

Stake, R. E. (1988). Case study methods in educational research: Seeking sweet water. In R.M. Jaeger (Ed.), Complementary methods for research in education (pp. 253300). Washington, DC: American Educational Research Association. 
Stirrat, R.L. (2008). Mercenaries, missionaries and misfits: Representations of development personnel, Critique of Anthropology. 28(4), 406-425.

Strauss, A. and Corbin, J. (1998). Basics of qualitative research: Techniques and procedures for developing grounded theory (2nd Edition). Thousand Oaks, CA: Sage Publications.

Tembo, F. (2003). The multi-image development NGO: An agent of the new imperialism? Development in Practice, 13(5): 527-533.

Tilly, Charles. (1978). From mobilization to revolution. New York: McGraw-Hill.

Tomajan, K. (2012). Advocating for nurses and nursing. Online Journal of Issues in Nursing, 17(1), 1-1.

Turner, J. C., Hogg, M.A., Oakes, P.J., Reicher, S.D., \& Wetherell, M.S. (1987). Rediscovering the social group: A self-categorization theory. New York: Basil Blackwell Inc.

Ungar, M. (2008). Resilience across cultures. British Journal of Social Work, 38(2), 218235.

United Nations Development Programme (UNDP). (1993). Human Development Report 1993, Oxford: OUP.

United Nations Rule of Law (UNROL) (2014). Non-governmental organizations. Retrieved from http://www.unrol.org/article.aspx?article_id=23

Uphoff, N. (2000). Understanding social capital: Learning from the analysis and experience of participation. In P. Dasgupta., \& I. Serageldin. (Eds.), Social capital: A multifaceted perspective (pp 215-249). Washington. D.C.: World Bank Publications.

Vanderbilt-Adriance, E., \& Shaw, D. S. (2008). Conceptualizing and re-evaluating resilience across levels of risk, time, and domains of competence. Clinical Child and Family Psychology Review, 11(1-2), 30-58.

Van de Walle, N. (2001). African economies and the politics of permanent crises. New York: Cambridge University Press.

VeneKlasen, L., \& Miller, V. (2002). A new weave of power, people and politics: The action guide for advocacy and citizen participation.

Oklahoma City: World Neighbors. 
Vernick, J. S. (1999). Lobbying and advocacy for the public's health: What are the limits for nonprofit organizations? American Journal of Public Health, 89(9), 14251429.

Wagnild, G. M. (2010). Discovering your resilience core. Retrieved from The Resilience Scale website: $\underline{\text { http://www. }}$ resiliencescale.com/papers/pdfs/Discovering_Your_Resilience_Core.pdf.

Walker, B., Holling, C. S., Carpenter, S. R., \& Kinzig, A. (2004). Resilience, adaptability and transformability in social--ecological systems. Ecology and Society, 9(2), 5.

Walker, B., \& Salt, D. (2006). Resilience thinking: Sustaining ecosystems and people in a changing world. Washington, D.C.: Island Press.

Waller, M. A. (2001). Resilience in ecosystemic context: Evolution of the concept. American Journal of Orthopsychiatry, 71(3), 290-297.

Weible, C. M. (2007). An advocacy coalition framework approach to stakeholder analysis: Understanding the political context of California marine protected area policy. Journal of Public Administration Research and Theory, 17(1), 95-117.

Weible, C. M., Sabatier, P. A., Jenkins-Smith, H. C., Nohrstedt, D., Henry, A. D., \& DeLeon, P. (2011). A quarter century of the Advocacy Coalition Framework: An introduction to the special issue. Policy Studies Journal, 39(3), 349-360.

Weisbrod, B. (1988). The nonprofit economy. Cambridge, MA: Harvard University Press.

Weisbrot, R., \& Cathcart, D. (1990). Freedom bound: A history of America's civil rights movement. New York: Norton.

Widner, J., \& Mundt, A. (1998). Researching social capital in Africa. Africa, 68(1), 1-24.

Wijkström, F., \& Zimmer, A. (Eds.). (2011). Nordic civil society at a cross-roads: Transforming the popular movement tradition. Baden: Nomos.

Wilks, T. (2012). Advocacy and social work practice. England: Open University Press.

Williams, D. (2005). Real leadership: Helping people and organizations face their toughest challenges. Berrett-Koehler Publishers.

Wilson, P.A. (1997). Building social capital: A learning agenda for the twenty-first century. Urban Studies, 34 (5), 745-760.

Willmuth, M., \& Boedy, D. L. (1979). The verbal diagnostic and art therapy combined: An extended evaluation procedure with family groups. Art Psychotherapy, 6, 1118. 
Wolcott, H. F., (1990). On seeking - and rejecting - validity in qualitative research. In E.W. Eisner \& A. Peshkin, (Eds.). Qualitative inquiry in education: The continuing debate (pp. 121-152). New York: Teacher's College Press.

World Bank (2000). What is social capital? Retrieved from http://web.worldbank.org/WBSITE/EXTERNAL/TOPICS/EXTSOCIALDEVEL OPMENT/EXTTSOCIALCAPITAL/0,,contentMDK:20185164 menuPK:418217 حpagePK:148956 piPK:216618 theSitePK:401015,00.html

Zaidi, A.S. (1999). Issues in Pakistan's economy. Karachi: Oxford University Press. 


\section{APPENDICES}

\section{Appendix A: Pakistan Map and Participants' First Location of Advocacy}

The stars on below map mark the locations from where the participants' initiated their advocacy work. The color of stars indicate the area of operation: Purple: Entire country [Four provinces and FATA Region]; Green: Four Provinces; Blue: FATA and Khyber Pakhtunkhwa (previous known as North West Frontier) province. (Source: Economic Survey Pakistan]

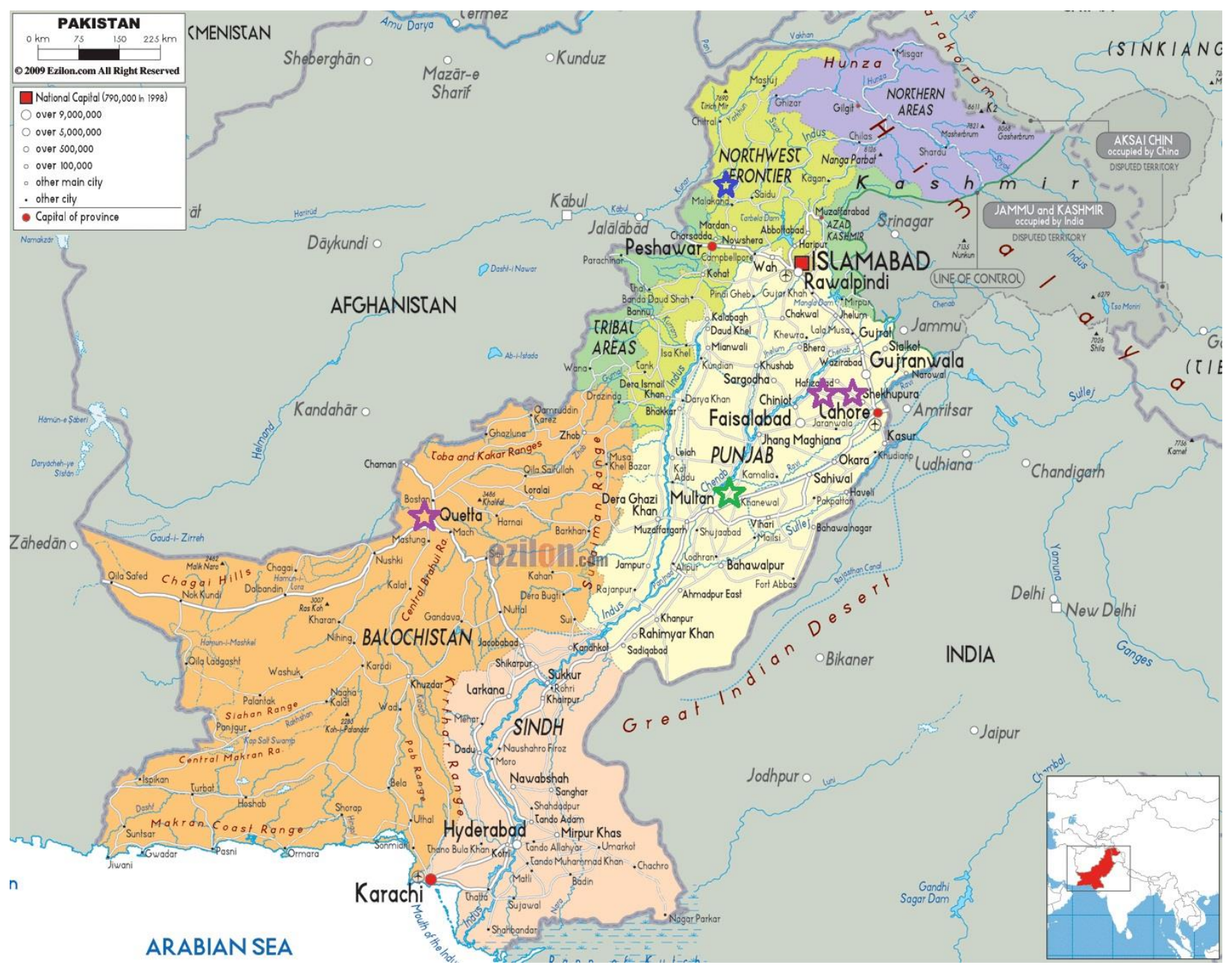




\section{Appendix B: Participant Interview Protocol}

Preliminary Interview Guiding Questions:

\section{What strategies do NGO leaders use for effective advocacy work in a Pakistani context?}

Interview Information

- Date

- Time

- Place

- Interviewer

Participant's Background

- Name

- Age

- Education

- Years of work experience

- Title of position currently held (Duration)

- Organization's name

- Work responsibilities

\section{Opening Questions:}

1. Tell me about your background, including how you came to the leadership position you currently hold?

Probes: What was your motivation for getting into this position? What kind of knowledge and skills do you have that helped you to come to this position? Did you get this position by choice or by chance?

2. Can you briefly tell me about your organization's purpose and activities?

Probes:

How long has your organization been involved in advocacy work? 
Has the organization produced any reports or other documents?

Does your organization network with other NGOs? Do you personally network with other NGO leaders?

\section{Sub-Q 1: How do external factors influence NGO leaders in developing their strategies for effective advocacy? How do the leaders attempt to influence the external environment?}

1. Do you think advocacy work in Pakistan is challenging for NGO leaders? Why or why not?

2. What external factors make advocacy work challenging for you and your organization?

3. Do you have a strategy to meet these challenges for an effective advocacy work?

Probes: Do you attempt to mobilize masses of people? Do you engage or try to influence the media? Do you build coalitions? Do you directly lobby with policy makers? Do you prefer to work in high profile or low profile ways? Please explain your answers.

4. How do the external factors affect your strategy?

\section{Sub-Q-2: How do internal factors influence NGO leaders in developing their} strategies for effective advocacy? What do the leaders do internally to create what is hopefully an effective organization?

1. What are the challenging issues within your NGO that might influence your advocacy work?

2. What strategies you use to meet internal challenges for effective advocacy work?

Probes: Is your organization exclusively involved in advocacy work or is advocacy work a time-to-time activity or one component of your organizational program? Do you have alternative financial resources to encounter pressure from donors? What knowledge and skills are needed for staff involved in advocacy work? What kind of leader are you? 
Conventional, Adaptive? What support system do you have for your volunteers engaged in advocacy work?

3. How do the organizational aspects affect your strategy?

\section{Sub-Q 3: What strategies do NGO leaders use to nurture their personal capacity for effective advocacy?}

1. Why do you persist in the work that is very challenging and what do you do to support your ability to persist?

2. Do you know other advocacy leaders who have burned out and left the work or has this happened to you? If so, what contributed to the burnout? How did the loss of leaders, either temporarily or permanently, impact your effective advocacy?

3. What do you do as a practice to care for yourself physically, mentally, emotionally and spiritually?

4. What is your core purpose and what gives meaning to your work?

5. Where do you find personal support? Do you have close friends? Do you have valued networks in the country? Outside the country?

6. What gives you the courage and confidence to act in the face of opposition?

7. Share ways that you have improvised or adapted your tactics in the face of difficulties? What would have happened to you if you had not adapted? How has adaptation affected you and influenced the effectiveness of your advocacy?

\section{Closing Questions:}

1. How can you evaluate the effectiveness of your advocacy work? Give some concrete examples?

2. What evidence do you point to in order to demonstrate the impact, either positive or negative, of your advocacy work? 


\title{
Appendix C: Consent Form
}

\author{
University of San Diego
}

\section{Research Participant Consent Form}

For the research study entitled:

\section{Exploring Strategies for Effective Advocacy: The Lived Experiences of Leaders of Pakistani Non-Governmental Organizations}

\section{Purpose of the research study}

Rubina Bhatti is a student in the SOLES (School of Leadership and Education Sciences) Leadership PhD program at the University of San Diego. You are invited to participate in a research study she is conducting. The purpose of this research study is to: explore the strategies NGOs leaders employ to sustain their advocacy work in Pakistan.

\section{What you will be asked to do}

If you decide to be in this study, you will be asked to:

- Participate in two in-person one-on-one interviews to discuss your challenges and strategies for responding to these challenges at a societal, organizational and individual level in order to sustain your advocacy work. Each interview will not exceed 90 minutes.

- Review the data collected during the interviews, which will be shared with you after the researcher has analyzed the data, so you could express your concerns and make clarifications for the validity of the data.

In addition, the sessions will be recorded using a digital recorder and notes will be taken during the interview, as per your approval. The digital recorder is also a digital videocamera, and only per your approval will it be used as a video recorder.

\section{Foreseeable risks or discomforts}

This study involves no more risk than the risks you encounter in daily life.

\section{Benefits}

While there may be no direct benefit to you from participating in this study, the indirect benefit of participating will be knowing that you helped researchers better understand the perceived factors that facilitate or impede NGO leaders' engagement in advocacy work.

\section{$\underline{\text { V. Confidentiality }}$}

Any information provided and/or identifying records will remain confidential and kept in a locked file and/or password-protected computer file in the researcher's office for a 
minimum of five years. All data collected from you will be coded with a number or pseudonym (fake name). Your real name will not be used. The results of this research project may be made public and information quoted in professional journals and meetings, but information from this study will only be reported as a group, and not individually.

\section{Compensation}

You will receive no compensation for your participation in the study.

\section{Voluntary Nature of this Research}

Participation in this study is entirely voluntary. You do not have to do this, and you can refuse to answer any question or quit at any time. Deciding not to participate or not answering any of the questions will have no effect on any benefits you're entitled to, like your health care, or your employment, or grades. You can withdraw from this study at any time without penalty.

\section{Contact Information}

If you have any questions about this research, you may contact either:

1) Rubina Bhatti

Email: rubinabhatti@sandiego.edu

Phone: $\quad$ Pakistan: +92-300 6001452

2) Dr. Robert Donmoyer

Email: rdonmoyer@sandiego.edu

Phone: 6192607445

I have read and understand this form, and consent to the research it describes to me. I have received a copy of this consent form for my records.

Signature of Participant

Date

Name of Participant (Printed) 


\section{Appendix D: Sample Posters Depicting Advocacy Messages}
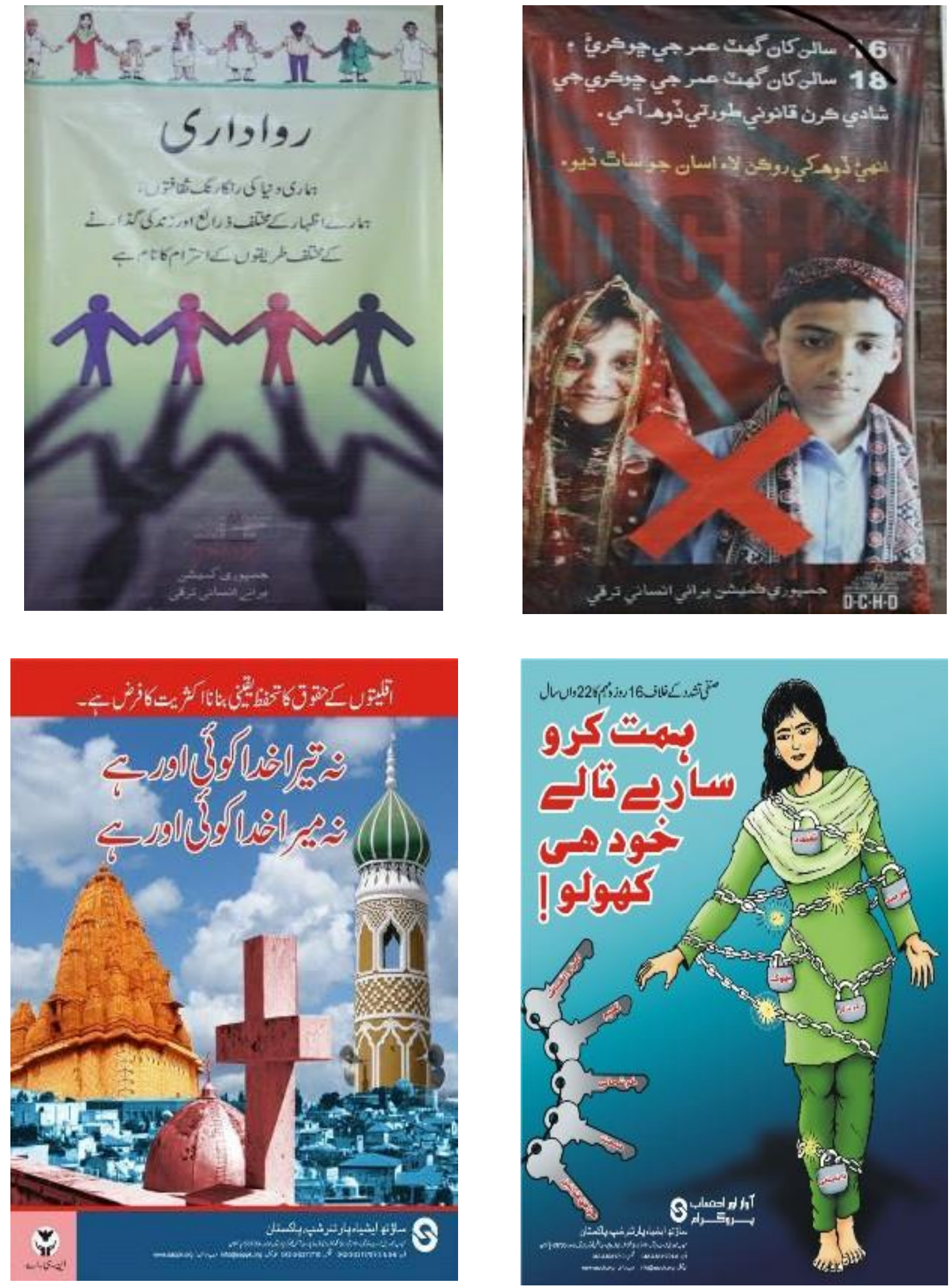

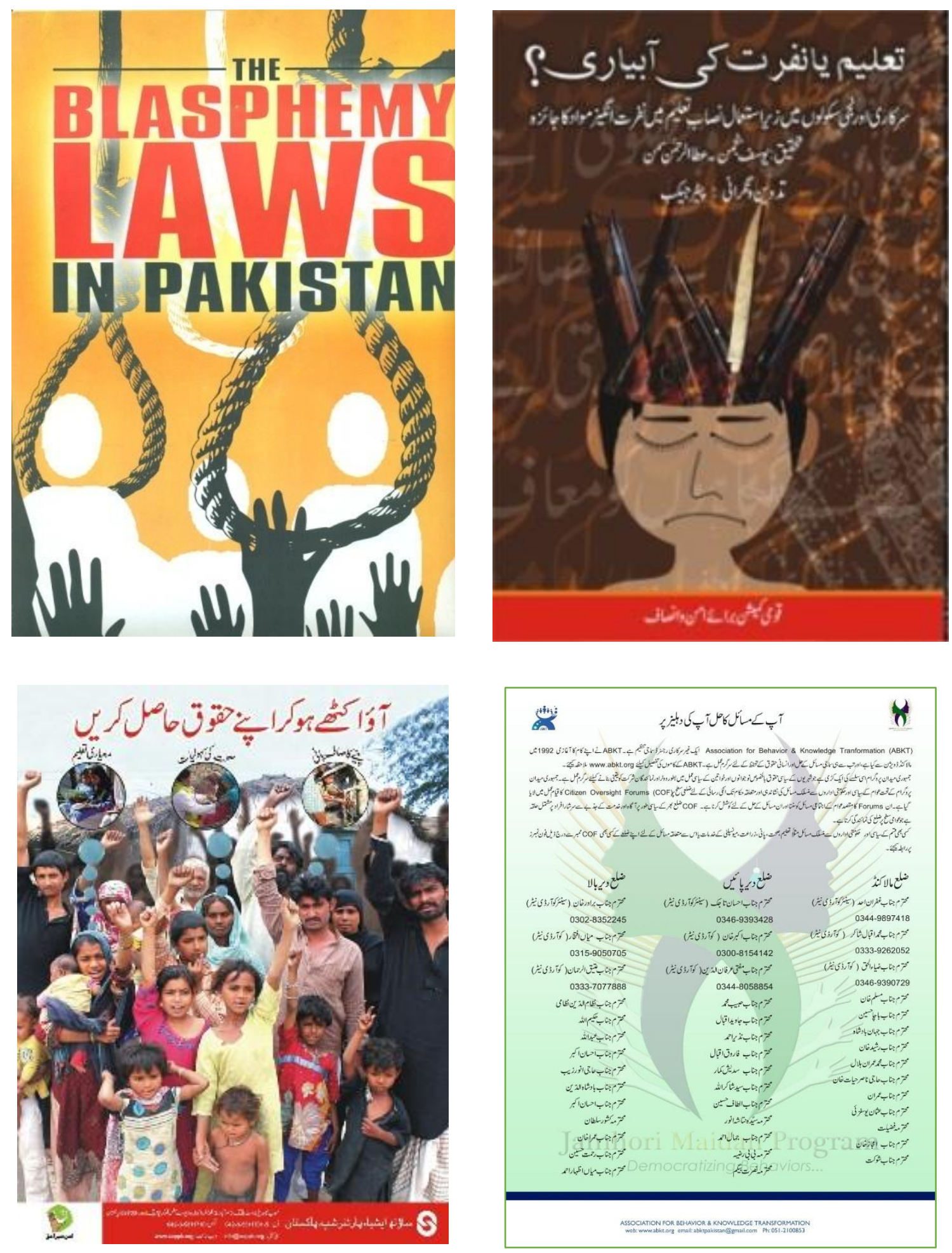


\title{
Appendix E: Assessment Questionnaire for NGO Leaders
}

\author{
Systems-Framework for Effective Advocacy in Restricted Environments Guide
}

Use the following framework and questions as a means of reflection on effective advocacy. Take particular note of any major categories where you as a leader or your organization is particularly strong and particularly weak. Strengths can be built upon and weak areas can become areas of focus for sustained life and work in difficult settings.

\section{External Challenges:}

A. Government:

1. Are there people and units within government with which we can collaborate? How?

2. Are there people and units within government which carry high risks for collaboration and should be avoided?

B. Intelligence Agencies:

1. How can we negotiate with intelligence agencies so that our work can continue?

2. What are the risks and benefits?

C. Culture:

1. What elements of culture can we embrace that enhance our work?

2. What barriers challenge our work in our culture and how do we deal with those?

D. Media:

1. What ways can we harmonize our work with the media so that it mobilizes people, creates awareness, and enhances advocacy?

E. Radical Groups:

2. What risks will media pose to us and how do we limit public risks?

1. How do we protect our staff and organization from threats and dangers?

2. What level of public profile will provide protection and enable advocacy effectiveness?

\section{External Inputs:}

A. Donors:

1. How can we select and sustain donor partner relationships?

2. How can we manage donor pressures and keep true to our advocacy mission?

B. Personnel:

1. How can we recruit, select and empower people resources as staff, volunteers and engaged communities?

2. How do we filter personnel within the organization to maintain high levels of trust and commitment to the organization's mission?

\section{Internal Challenges:}

A. Empowered staff and flexible structures:

1. How do we decentralize power and delegate authority to individuals and small teams?

2. How can we maintain flexible and simple structures that allow continuing adaptation to rapidly changing external challenges? 
B. Motivated and Mobilized Communities:

1. How do we mobilize the communities with which we work?

2. What determines when our communities also need to move into a lower profile of public engagement?

C. Programs and Policies:

1. What security training and policies are needed for protection of our staff, organization and community members?

2. What programs can be resourced, led and implemented that will lead to the greatest advocacy impact in fulfilling our mission?

D. Networks:

1. What networks can be established or strengthened that will enhance effective advocacy?

2. What risks are carried with particular national or international networks? Do the benefits outweigh the risks?

\section{Nurturing Resilience:}

A. Reflective Practices:

1. How do I, as a leader, and we, as a staff team, reflect on our work, our mission and the challenges facing us externally and internally? When did we last do this and what were the outcomes?

2. How do we insure critical thinking and wise decision-making in the midst of high-stress and continuing threats or risks?

B. Self-Care:

1. What patterns do I follow that provide for my own self-care, physically, emotionally, psychologically, and spiritually?

2. How can I pace myself between times of intense work and down times for restoration and renewal?

3. How can we support self-care among our staff and our communities?

C. Social Capital:

1. Bonded Relationships: Who are the people with whom I have deep relationships and mutual support? How can I invest in and nurture such family and friend relationships?

2. Bridging Relationships: Who are the key support relationships I have among my colleagues and communities that sustain me?

3. Linking Relationships: With whom do I network on local, national and international levels that can be critical support as needed for sustained or crisis centered support?

\section{Outputs and Impacts:}

A. People, Programs and Resources:

1. Who are the key people, what are the key programs, and what kind of resources does our organization provide as outputs to our communities that affect their lives?

B. Changes in Laws:

1. Do we see evidence that we have contributed toward changes in laws, regulations and practices that improve the well-being of our communities?

C. Awareness of Masses:

1. How are we instruments of raising awareness and educating the masses regarding rights, attitudes, and engagement in their world?

D. Recognition and Respect:

1. What evidence is there that personal and organizational recognition and respect have been enhanced and has this strengthened advocacy? 
E. Women in Leadership:

1. How have women emerged and flourished in leadership within the communities where you work?

2. How is your organization an instrument of women's empowerment both within the organization and in the communities? 

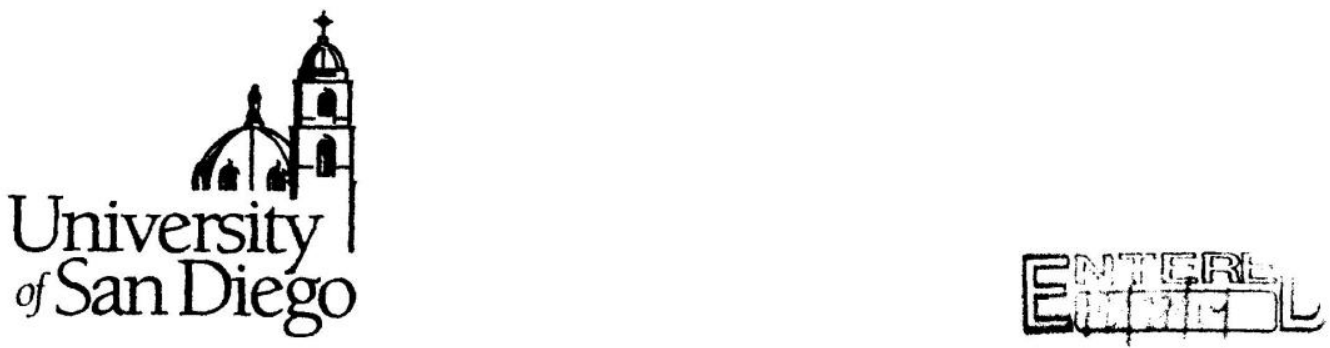

\section{Institutional Review Board Project Action Summary}

Action Date: December 22, 2014 Note: Approval expires one year after this date.

Type: _New Full Review _ X_New Expedited Review ___Continuation Review Modification

Exempt Review

Action:

_._Approved _ Approved Pending Modification

Not Approved

Project Number: 2014-12-135

Researcher(s): Rubina Bhatt Doc SOLES

Dr. Robert Donmoyer Fac SOLES

Project Title: $\quad$ Exploring Strategies of Effective Advocacy: The Lived Experiences of Leaders of Pakistani Non-govemmental Organizations

Note: We send IRB correspondence regarding student research to the faculty advisor, who bears the ultimate responsibility for the conduct of the research. We request that the faculty advisor share this correspondence with the student researcher.

\section{Modifications Required or Reasons for Non-Approval}

None

The next deadline for submitting project proposals to the Provost's Office for full review is N/A. You may submit a project proposal for expedited review at any time.

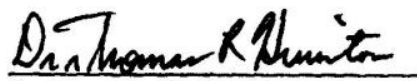

Dr. Thomas R. Herrinton

Administrator, Institutional Review Board

University of San Diego

herrinton@sandiego.edu

5998 Alcalá Park

San Diego, California 92110-2492

Office of the Executive Vice President and Provost

Hughes Administration Center, Room 214

5998 Akalá Park, San Diego, CA $92110-2492$

Phone (619) 260-4553 - Fax (619) 260-2210 • unw.sandiego.edu 